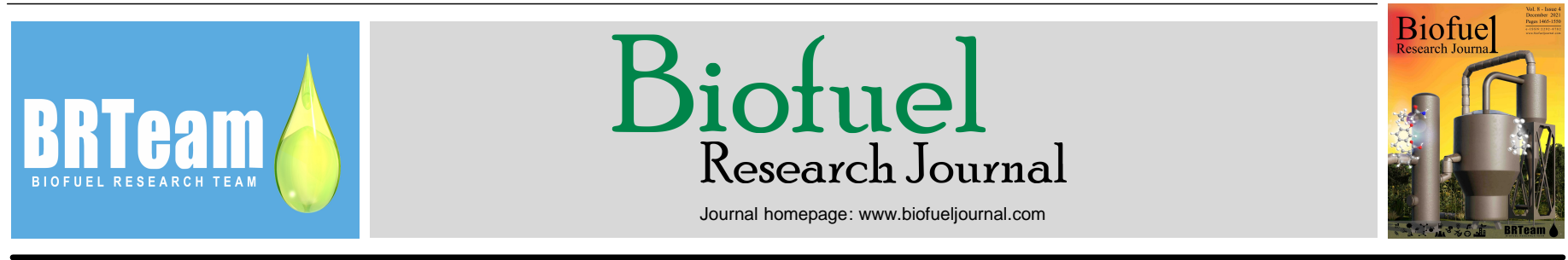

Review Paper

\title{
Modeling of thermochemical conversion of waste biomass - a comprehensive review
}

Sinhara M.H.D. Perera, Chathuranga Wickramasinghe, B.K.T. Samarasiri, Mahinsasa Narayana*

Department of Chemical and Process Engineering, University of Moratuwa, Moratuwa 10400, Sri Lanka.

\section{HIGHLIGHTS}

$>$ Thermochemical processes for waste biomass to energy conversion are presented.

$>$ The effects of process parameters on product yield and distribution are discussed.

$>$ Kinetic and reactor models for waste biomass are

reviewed.

$>$ Accuracy, limitations, and applicability of the

models are presented.

$>$ Drawbacks, potentials, and possible upgrades of the models are discussed.

\section{GRAPHICAL ABSTRACT}

\begin{tabular}{|c|c|c|c|c|c|}
\hline \multicolumn{6}{|c|}{ Thermochemical conversion } \\
\hline $\begin{array}{c}\text { Agriculture } \\
\text { waste }\end{array}$ & $\begin{array}{c}\begin{array}{c}\text { Urban } \\
\text { biowaste }\end{array}\end{array}$ & Pyrolysis & Torrefaction & Bio-oil & Char \\
\hline $\begin{array}{l}\text { Food } \\
\text { waste }\end{array}$ & $\begin{array}{l}\text { Forest } \\
\text { residue }\end{array}$ & Gasification & Combustion & Syngas & $\begin{array}{c}\text { Producer } \\
\text { gas }\end{array}$ \\
\hline $\begin{array}{l}\text { Animal } \\
\text { waste }\end{array}$ & $\begin{array}{c}\text { Agro- } \\
\text { industrial } \\
\text { waste }\end{array}$ & HTC & HTL & Heat & $\begin{array}{c}\text { Value- } \\
\text { added } \\
\text { chemicals }\end{array}$ \\
\hline
\end{tabular}

\section{Reactor modeling}
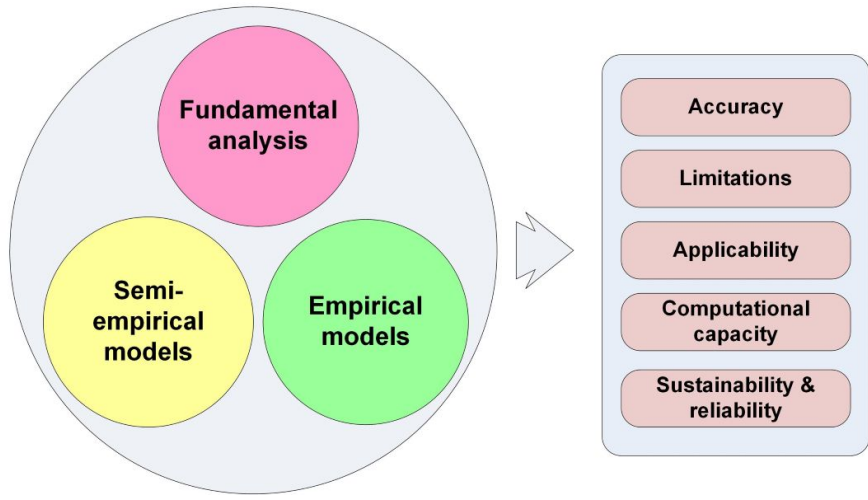

\section{ARTICLE INFO}

\section{Article history:}

Received 6 June 2021

Received in revised form 8 September 2021

Accepted 29 October 2021

Available online 1 December 2021

\section{Keywords:}

Modeling

Waste biomass

Hydrothermal conversion

Pyrolysis

Torrefaction

Gasification

\begin{abstract}
Thermochemical processes, which include pyrolysis, torrefaction, gasification, combustion, and hydrothermal conversions, are perceived to be more efficient in converting waste biomass to energy and value-added products than biochemical processes. From the chemical point of view, thermochemical processes are highly complex and sensitive to numerous physicochemical properties, thus making reactor and process modeling more challenging. Nevertheless, the successful commercialization of these processes is contingent upon optimized reactor and process designs, which can be effectively achieved via modeling and simulation. Models of various scales with numerous simplifying assumptions have been developed for specific applications of thermochemical conversion of waste biomass. However, there is a research gap that needs to be explored to elaborate the scale of applicability, limitations, accuracy, validity, and special features of each model. This review study investigates all above mentioned important aspects and features of the existing models for all established industrial thermochemical conversion processes with emphasis on waste biomass, thus addressing the research gap mentioned above and presenting commercial-scale applicability in terms of reactor designing, process control and optimization, and potential ways to upgrade existing models for higher accuracy.
\end{abstract}

(c) 2021 BRTeam. All rights reserved.

\footnotetext{
* Corresponding author at: Tel.: +94 112614514
}

E-mail address: masinsasa@uom.lk

Please cite this article as: Perera S.M.H.D., Wickramasinghe C., Samarasiri B.K.T., Narayana M. Modeling of thermochemical conversion of waste biomass - a comprehensive review. Biofuel Research Journal 32 (2021) 1481-1528. DOI: 10.18331/BRJ2021.8.4.3 


\section{Contents}

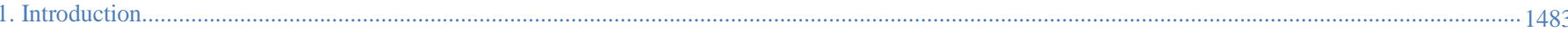

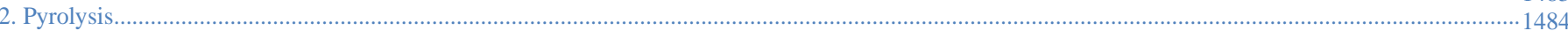

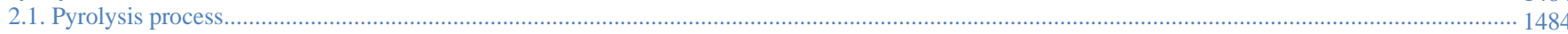

2.2. Pyrolysis principle

2.2.1. Effects of process parameters on pyrolysis

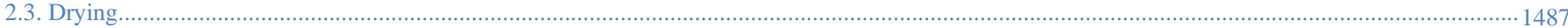

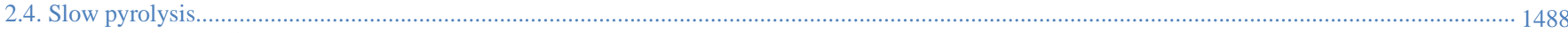

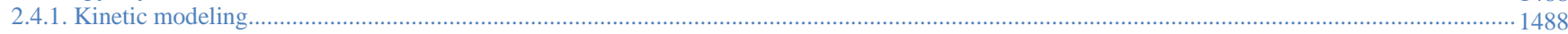

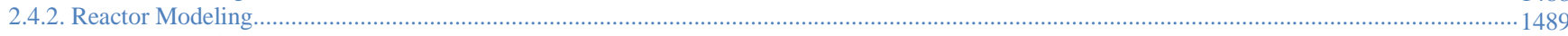

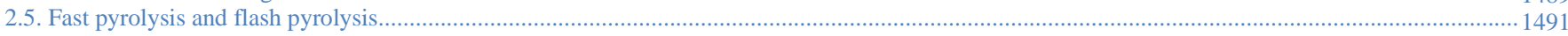

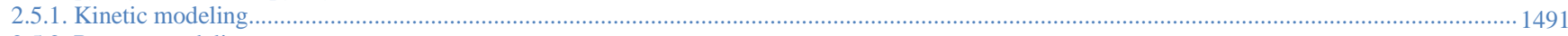

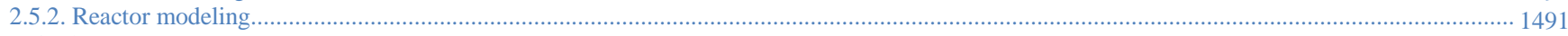

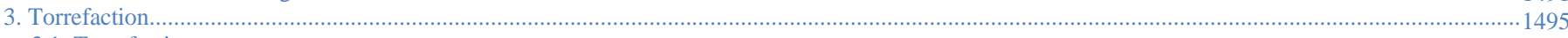

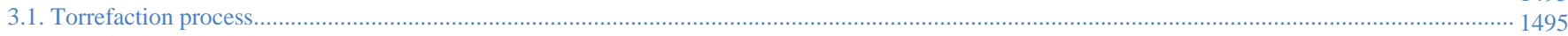

3.2. Torrefaction principle

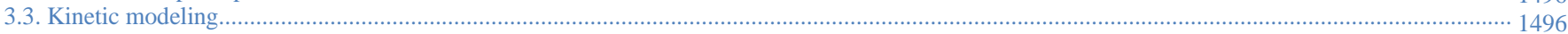

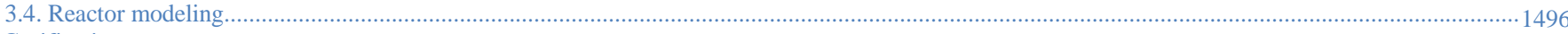

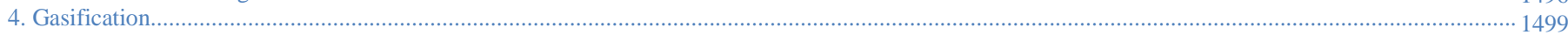

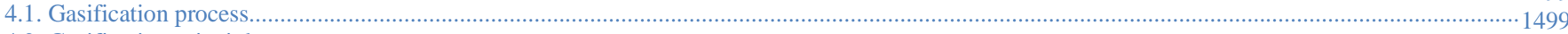

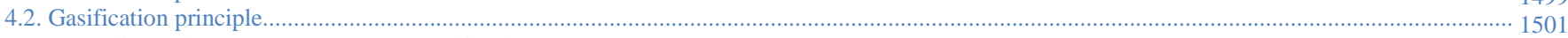

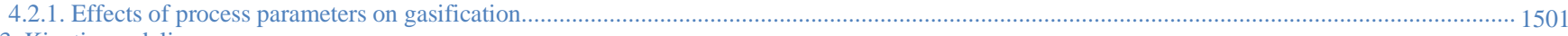

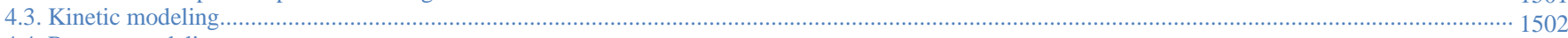

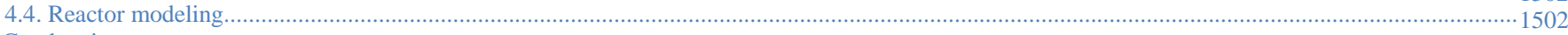

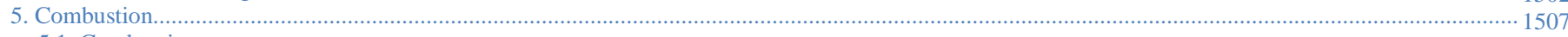

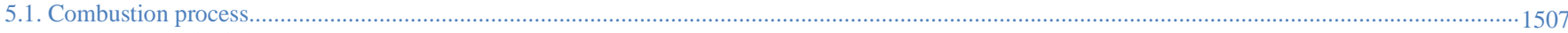

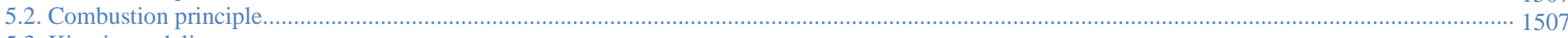

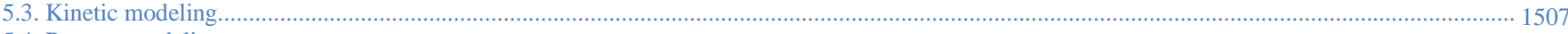

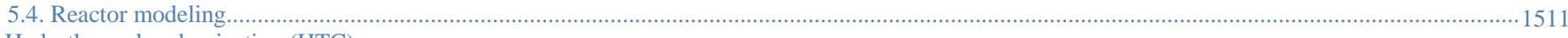

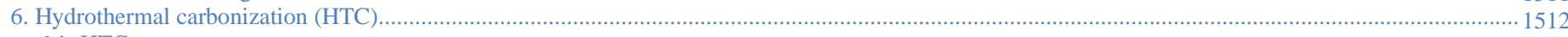

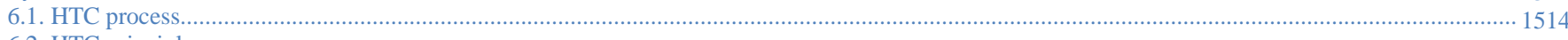

6.2. HTC principle

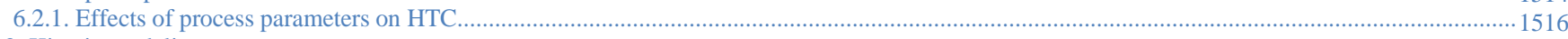

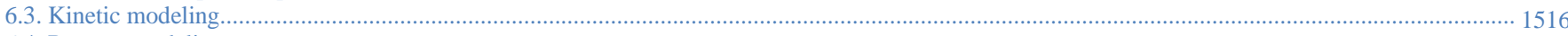

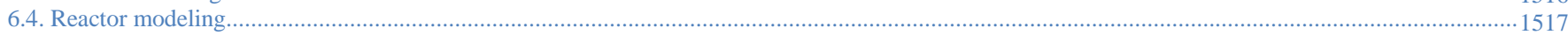

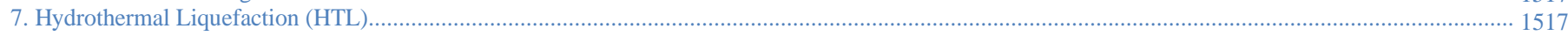

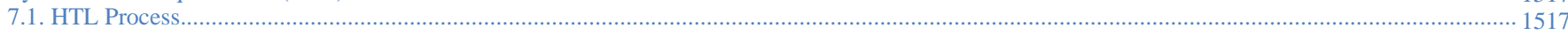

7.2. HTL principle

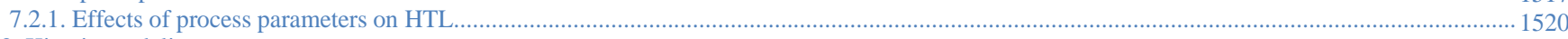

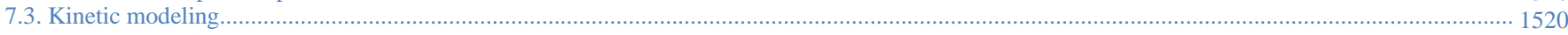

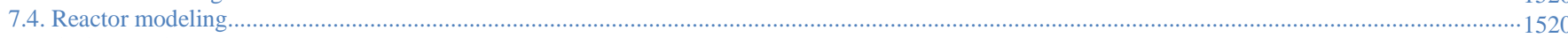

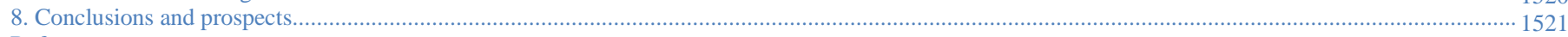

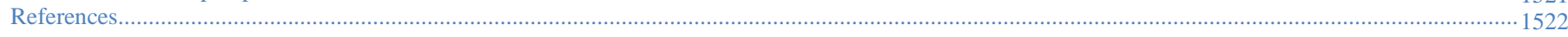

\begin{tabular}{|c|c|c|c|c|c|}
\hline \multicolumn{4}{|c|}{ Abbreviations } & \multicolumn{2}{|l|}{ Nomenclatures } \\
\hline ANN & Artificial neural network & HTL & Hydrothermal liquefaction & $\alpha_{\mathrm{i}}$ & $\begin{array}{l}\text { Stoichiometric coefficient of } \mathrm{i}^{\text {th }} \\
\text { component }\end{array}$ \\
\hline B & Intermediate solid & ILC & Intermediate liquid compound & $\alpha$ & Degree of conversion \\
\hline $\mathrm{CCE}$ & Carbon conversion efficiency & MSW & Municipal solid waste & $\mathrm{m}_{\mathrm{f}}$ & Final mass (kg) \\
\hline CFD & Computational fluid dynamics & OFMSW & Organic fraction of MSW & $\mathrm{m}_{\mathrm{o}}$ & Initial mass (kg) \\
\hline CGE & Cold gas efficiency & PAH & Polycyclic aromatic hydrocarbons & $\mathrm{G}\{\mathrm{x}\}$ & $\begin{array}{l}\text { Lumped pseudo species } \mathrm{x} \\
\text { trapped in the solid matrix }\end{array}$ \\
\hline ER & Equivalence ratio & SBR & Steam to biomass ratio & $\mathrm{T}$ & Temperature $(\mathrm{K})$ \\
\hline HHV & High heating value & WGS & Water-gas shift & $\mathrm{m}_{\mathrm{i}}$ & Mass at given time $\mathrm{t}(\mathrm{kg})$ \\
\hline HTC & Hydrothermal carbonization & & & Lignin* & Active lignin \\
\hline
\end{tabular}

Please cite this article as: Perera S.M.H.D., Wickramasinghe C., Samarasiri B.K.T., Narayana M. Modeling of thermochemical conversion of waste biomass a comprehensive review. Biofuel Research Journal 32 (2021) 1481-1528. DOI: 10.18331/BRJ2021.8.4.3 


\section{Introduction}

The concerns over the ultimate availability of fossil fuels and the progressive environmental deteriorations such as global warming and air pollution caused by mass consumption of these fuels have given rise to the interest in renewable and carbon-neutral energy carriers (Grønli and Melaaen, 2000; Xu et al., 2017). Biomass uniquely stands out as it is the only sustainable carbon carrier among all the other existing renewable sources (solar, wind, hydro, tidal, and geothermal) and has been recognized to play a critical role in the global process of converting to carbon-neutral energy (Van Der Stelt, 2010; Anca-Couce, 2016). Biomass contributes to about $10 \%$ of global energy consumption (Bach et al., 2017). It includes organic matter formed via photosynthesis, consisting of a mixture of hemicellulose, cellulose, lignin, moisture, extractives, and a small amount of various inorganic substances. It also includes biodegradable materials from animals and microorganisms, such as animal waste and sewage sludge (Liu et al., 2020).

Biomass composition varies with many factors, including the biological origin (Di Blasi, 2008). Biomass being abundantly available as waste in many forms such as municipal solid waste (MSW), wood waste, forest residue, agricultural, and industrial waste, has made its acquisition easier, economical, and eco-friendly (Yang et al., 2009). While it is left unprocessed, biomass can create numerous socio-economic and environmental issues. According to Figure 1, about $76 \%$ of biomass used for energy generation is waste (Prasertcharoensuk et al., 2018). Moreover, the use of waste biomass in energy harvesting relieves the criticisms of the first-generation biofuels produced from edible crops, having socio-economic and environmental implications regarding food security, land use, and biodiversity (Gunarathne et al., 2019). It is evidenced from Table 1 that huge amounts of waste biomass are generated worldwide from domestic consumption, agriculture, and industry, thus proving the availability of waste biomass for energy harvesting.

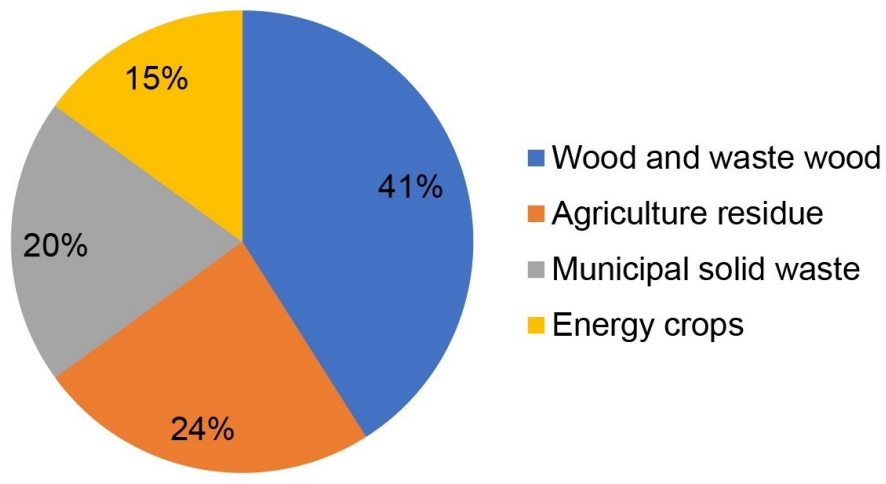

Fig. 1. Biomass usage for the global energy generation.

Table 1.

Global waste biomass generation statistics.

\begin{tabular}{|c|c|c|c|}
\hline \multicolumn{2}{|c|}{ Waste biomass type } & \multirow{2}{*}{$\begin{array}{c}\begin{array}{c}\text { Global generation per } \\
\text { annum }\end{array} \\
\sim 2 \text { billion tons }\end{array}$} & \multirow{2}{*}{$\begin{array}{l}\text { Reference } \\
\text { Magnanelli et al. (2020) }\end{array}$} \\
\hline MSW & & & \\
\hline \multirow{4}{*}{$\begin{array}{l}\text { Agriculture } \\
\text { waste }\end{array}$} & Rice straw & $\sim 731$ million tons & Kapoor et al. (2016) \\
\hline & Rice husk & $\sim 150$ million tons & Goodman (2020) \\
\hline & Wheat straw & $\sim 529$ million tons & Govumoni et al. (2013) \\
\hline & Corn cob & $\sim 144$ million tons & da Silva et al. (2015) \\
\hline \multirow{4}{*}{$\begin{array}{l}\text { Agro- } \\
\text { industrial } \\
\text { waste }\end{array}$} & Oil farm residue & $\sim 140$ million tons & Talero et al. (2019a) \\
\hline & Wheat bran & $\sim 107-143$ million tons & Kapoor et al. (2016) \\
\hline & Apple pomace & $\sim 4.6$ million tons & Kapoor et al. (2016) \\
\hline & Citrus waste & $\sim 44$ million tons & Zhang et al. (2019) \\
\hline
\end{tabular}

Nevertheless, biomass without pretreatment is less effective in direct utilization and has inadequate value due to its inherent chemical and physical properties (Vassilev et al., 2010; Bach and Skreiberg, 2016). Some biomass properties such as high moisture content, hydrophilic nature, high oxygen content, inhomogeneous composition, low calorific value, poorer grindability, and fibrous structure make it unfavorable for direct usage as a fuel (Van Der Stelt, 2010). As a result, conversion of biomass into higher quality biofuel and other value-added products is essential, and numerous research has been conducted on various biomass conversion techniques, which is mainly divided into two categories as thermochemical conversion and biochemical conversion, as depicted in Figure 2 (Porpatham et al., 2012). Biochemical conversion processes employ bacteria and enzymes to biologically degrade biomass to smaller molecules, which is inherently slower and less efficient than thermochemical processes (Fatehi et al. 2021). On the other hand, thermochemical conversion processes use heat to degrade biomass into low molecular products via a series of physicochemical reactions in a controlled environment to yield desired outputs. Even though the thermochemical processes need external heat at least at the beginning of the process, they are comparatively easy to contro (Anca-Couce, 2016). A general comparison of thermochemical and biochemical processes is provided in Table 2 . The major thermochemical conversion processes are combustion, gasification, pyrolysis, torrefaction, hydrothermal carbonization (HTC), and hydrothermal liquefaction (HTL), yielding different distributions of energy outputs such as biochar, bio-oil, syngas, and combustible gases. Moreover, the hydrothermal processes use subcritical or supercritical conditions of water at high pressures, and they are most suitable for biomass with high moisture content, whereas the other thermal processes are suitable for biomass with comparatively less moisture content (Gao et al., 2016; Wijekoon et al., 2021).

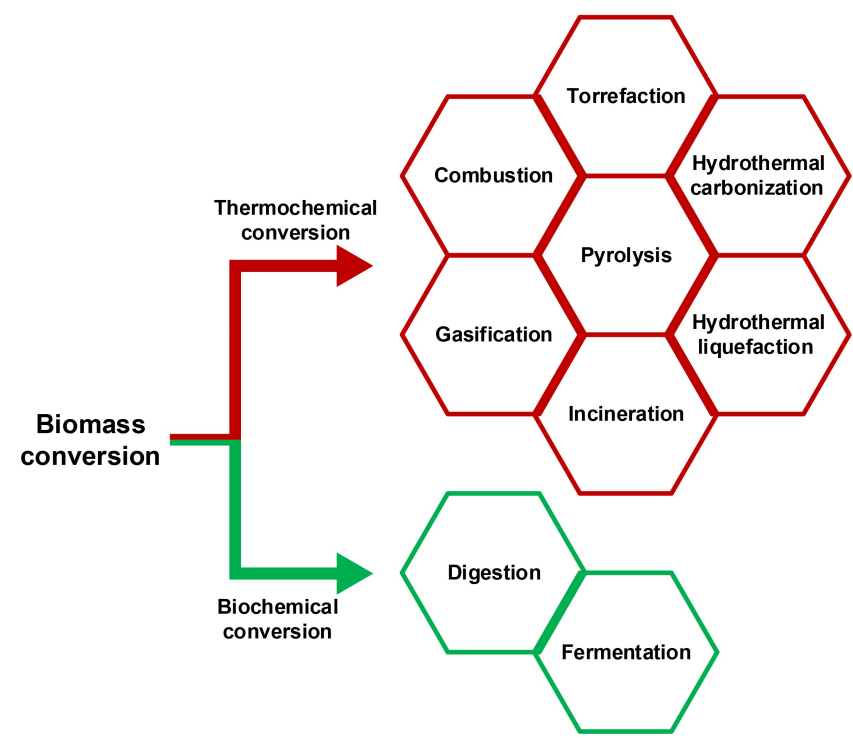

Fig. 2. Biomass thermochemical and biochemical conversion processes.

In the last few decades, numerous studies have been conducted to develop more efficient and reliable tools for the thermochemical conversion of waste biomass. The overall efficiency and the commercial success of these thermochemical processes are contingent upon well-designed and optimized reactors. As a result, the commercial viability of these processes is decided by reactor optimization, which can be carried out either via traditional laboratory-scale trial and error mechanisms or computer-aided modeling and simulation. The former is costly and a highly timeconsuming, tedious task, while the latter is a lot more efficient and significantly less expensive. However, the success of the latter technique solely depends on how accurately the corresponding mathematical model resembles the actual system. Furthermore, the accuracy of the numerical simulation usually needs to be negotiated with the computational burden based on the required degree of accuracy. 
Table 2.

Process conditions, advantages and disadvantages of biochemical and thermochemical processes.

\begin{tabular}{ll}
\hline Biochemical conversion & Thermochemical conversion \\
\hline $\begin{array}{l}\text { Ambient conditions or low } \\
\text { temperatures }\left(<80^{\circ} \mathrm{C}\right)\end{array}$ & Mild $\left(<350^{\circ} \mathrm{C}\right)$ or high temperatures $\left(350-1200^{\circ} \mathrm{C}\right)$ \\
$\begin{array}{l}\text { High reaction time (usually many } \\
\text { days })\end{array}$ & $\begin{array}{l}\text { Moderate to very low reaction times (few seconds to } \\
\text { hours depending on moderate, fast or flash process } \\
\text { conditions employed) }\end{array}$ \\
$\begin{array}{l}\text { Employs microbes and enzymes } \\
\begin{array}{l}\text { Precautions should be taken to avoid } \\
\text { toxic substances which inhibit } \\
\text { bacterial and enzymatic activities. } \\
\text { Pretreatment is usually mandatory. }\end{array}\end{array}$ & $\begin{array}{l}\text { No such precautions are required. } \\
\text { Pretreatment is optional. }\end{array}$ \\
$\begin{array}{l}\text { Limited applicability } \\
\text { Limited productivity }\end{array}$ & $\begin{array}{l}\text { Applicable for any type of biomass } \\
\text { High productivity with higher efficiencies }\end{array}$ \\
Requirement for large reactors & $\begin{array}{l}\text { Relatively smaller reactors are required for the same } \\
\text { capacity }\end{array}$ \\
Limited products (one or few) & Multiple products can be obtained \\
\hline
\end{tabular}

During thermochemical conversion processes, biomass undergoes various sub-processes and chemical reactions, complicating the overall process while further correlations of those sub-processes add to this complication. The chemical kinetics of the reactions involved has a greater impact on the model accuracy, and it is influenced by many factors, making modeling more difficult. Consequently, numerous studies and research have attempted to find the most realistic kinetic models, considering all major influential factors. Moreover, the degree of conversion and product distribution are sensitive and impacted significantly by several process variables such as temperature, heating rate, residence time, pressure, biomass characteristics, and reactor configuration making mathematical modeling with high precision more challenging (AncaCouce, 2016). However, if such process variations are to be studied experimentally, it may need an uncountable number of laboratory experiments to reflect all dependencies, which is not a pragmatic approach. Moreover, the application of information derived through experimental approaches for upscaling the processes to commercial scale has limitations due to various incompatibilities between lab-scale and commercial-scale reactors (Bach et al., 2017). For instance, the ratio of particle dimension to reactor dimension significantly impacts the overall heat and mass transfer and hydrodynamics. Besides, a mathematical model with sufficient accuracy is a powerful tool in analysis to better understand and quantitatively represent an actual system with various associated phenomena, making up-scaling and optimization a lot easier. Also, mathematical modeling is a sophisticated tool for process design, estimation of pollutants evolution, analysis of process dynamics, and effective process control (Di Blasi, 2008; Adeniyi et al., 2019).

Models can basically be categorized as computational models and statistical models. Statistical models are based on empirical statistical formulas built on a large number of experimental data, whereas computational models imply a complex numerical simulation that represents the actual system with a set of mathematical formulas. Models of various scales with numerous assumptions such as particle models, reactor models, and process models have been developed for applications of thermochemical conversion of different waste biomass by using different numerical techniques such as computational fluid dynamics (CFD), statistical techniques such as regression analysis, and artificial neural network (ANN), and also by using commercial software packages. Therefore, selecting a suitable model with sufficient accuracy for the design or optimization purpose of a particular application is never an easy task. To support the industrialization and commercialization of these thermochemical conversion processes of waste biomass, easy access to a wide range of related modeling information is salient.

In light of the above, the present work caters to this demand via a state-ofthe-art review on the modeling of thermochemical conversion processes of waste biomass. Even though there are several previous review studies on the process and technical aspects of thermochemical conversion of biomass with specific focuses as per Table 3, only a few studies have reviewed modeling aspects. Yet again, most such studies on modeling aspects were eccentric on individual thermochemical conversion processes and technical aspects of modeling. As listed in Table 3, a few studies investigated the modeling aspects of popular thermochemical conversion processes, but their scope was narrowed down to specific areas of modeling. All those studies on the modeling of biomass thermochemical conversion were limited in scope to technical aspects without focusing much on the features and potential of models, which are the essential factors in selecting a model for a specific application. Moreover, most of these reviews have not discussed the accuracies of the models, the suitability for other applications, and the potential to upgrade further to improve accuracy and add new simulation features. To the best of the authors' knowledge, no previous review has focused on modeling the thermochemical conversion of waste biomass. We believe this state-of-the-art review is the first of its kind, elaborating all the above-mentioned important aspects and features of the existing models for all established industrial thermochemical conversion processes with an emphasis on waste biomass.

\section{Pyrolysis}

\subsection{Pyrolysis process}

Thermal degradation of feedstock in the absence of an oxidizing agent (usually in an oxygen-depleted environment) at temperatures in the range of $300-600{ }^{\circ} \mathrm{C}$ is commonly known as pyrolysis (Soria-Verdugo et al. 2020). Pyrolysis of biomass yields solid char (biochar), tar (bio-oil), and pyrolysis vapor which are subsequently condensed to obtain tar and producer gas. The distribution and characteristics of the pyrolysis products are influenced by various physical and chemical factors such as type of biomass, particle size, temperature, pressure, heating rate, residence time, etc. (Winterberg and Tsotsas, 2000). As a result, the pyrolysis process needs to be manipulated to yield the desired product more depending on the enduser application. These pyrolysis products can be employed in various energy and other applications. For instance, biochar can be used as a direct fuel in coal-fired boilers with no or few modifications for combined heat and power generation, and it can also be used in co-combustion applications. Moreover, biochar can be upgraded to activated carbon or employed in soil remediation. Also, it can be used in the metallurgical industry as well as for domestic cooking and energy purposes (Anca-Couce, 2016). On the other hand, bio-oil can be upgraded using catalytic cracking or catalytic hydrotreating to be used in combustion engines, or else it can directly be employed in combined heat and power generation (Corma et al., 2007; French and Czernik, 2010). Further, it is a potential source for the production of other chemicals such as biological pesticides. Similarly, pyrolysis gases can also be used in heat and power generation (Balat et al., 2009).

Depending on the heating rates, temperatures, and residence times employed in the process, pyrolysis is mainly categorized into three, i.e., slow pyrolysis, mild pyrolysis, and fast/flash pyrolysis. Mild pyrolysis, which is called torrefaction, is discussed separately in this review. Fast/flash pyrolysis employs high heating rates and shorter residence times to produce more bio-oil yield. Fluidized bed reactors are commonly used for fast pyrolysis due to their high heat transfer rates and better temperature control (Bridgwater, 2012). Fast heating rates accompanied by short residence times hinder the secondary cracking reactions, which favor the formation of permanent gases and thus increase the bio-oil yield. Moreover, the secondary cracking reactions can be limited by using smaller biomass particles to increase bio-oil production (Soria-Verdugo et al., 2020).

The fast pyrolysis process of biomass particles is more complex, and it involves multi-scale, multi-phase hydrodynamics, heat transfer, and chemical reactions. In previous biomass pyrolysis studies, numerous reactor configurations such as fixed bed reactors, fluidized bed reactors, rotary kiln reactors, spouted beds, microwave reactors, rotating cone reactors, vacuum reactors, plasma reactors, ablative reactors, drop tube reactors, auger reactors, and curie-point reactors, have been employed (Soria-Verdugo et al., 2020). A general comparison of widely used reactor configurations for biomass pyrolysis is provided in Table 4 . The pyrolysis process and the reactor configuration are selected primarily based on the biomass feedstock characteristics, desired output, and process economics. 
Table 3.

A comparison of this review paper with the previously published reviews on the thermochemical conversion of biomass.

\begin{tabular}{|c|c|c|c|c|c|c|c|c|c|c|}
\hline \multirow[b]{2}{*}{$\begin{array}{l}\text { Product } \\
\text { characterization \& } \\
\text { evolved gas analysis }\end{array}$} & \multirow[b]{2}{*}{$\begin{array}{l}\text { Principle, } \\
\text { process \& } \\
\text { variables }\end{array}$} & \multirow[b]{2}{*}{$\begin{array}{c}\text { Recent } \\
\text { developments }\end{array}$} & \multirow[b]{2}{*}{ Reactors } & \multirow[b]{2}{*}{$\begin{array}{l}\text { Effect of } \\
\text { catalysis }\end{array}$} & \multirow[b]{2}{*}{$\begin{array}{l}\text { Process } \\
\text { modeling }\end{array}$} & \multirow[b]{2}{*}{$\begin{array}{c}\text { Kinetic } \\
\text { modeling }\end{array}$} & \multicolumn{2}{|c|}{ Reactor modeling } & \multirow[b]{2}{*}{$\begin{array}{l}\text { Waste } \\
\text { biomass }\end{array}$} & \multirow[b]{2}{*}{ Reference } \\
\hline & & & & & & & Models & $\begin{array}{c}\text { Limitation, } \\
\text { accuracy \& } \\
\text { applicability }\end{array}$ & & \\
\hline $\mathrm{P}, \mathrm{T}, \mathrm{G}^{*}$ & $x$ & $x$ & $x$ & $x$ & $x$ & $x$ & $x$ & $x$ & $x$ & Ong et al. (2020) \\
\hline$x$ & $\mathrm{P}, \mathrm{G}$ & $x$ & G & $x$ & $x$ & $x$ & $x$ & $x$ & $x$ & Panwar et al. (2012) \\
\hline$x$ & $\mathrm{P}, \mathrm{G}, \mathrm{C}, \mathrm{HTL}$ & $x$ & $\mathrm{P}, \mathrm{G}, \mathrm{C}$ & $x$ & $x$ & $x$ & $x$ & $x$ & $x$ & Guran (2020) \\
\hline$x$ & $x$ & $x$ & $x$ & $x$ & $x$ & $x$ & $\times$ & $x$ & $\times$ & Goyal et al. (2008) \\
\hline$x$ & $x$ & $x$ & $x$ & $\mathrm{P}, \mathrm{T}, \mathrm{G}, \mathrm{HTL}$ & $x$ & $x$ & $x$ & $x$ & $x$ & Ong et al. (2019) \\
\hline$x$ & $x$ & $\times$ & $x$ & $x$ & G & $x$ & $\times$ & $x$ & $x$ & $\begin{array}{l}\text { Damartzis and Zabaniotou } \\
\text { (2011) }\end{array}$ \\
\hline$x$ & $x$ & $\mathrm{P}, \mathrm{G}, \mathrm{C}, \mathrm{HTL}$ & $x$ & $x$ & $x$ & $x$ & $x$ & $x$ & $x$ & Zhang et al. (2010) \\
\hline$x$ & $x$ & $\mathrm{P}, \mathrm{G}, \mathrm{C}, \mathrm{HTL}$ & $x$ & $x$ & $x$ & $x$ & $x$ & $x$ & $x$ & Othaman et al. (2016) \\
\hline$\times$ & $\mathrm{P}, \mathrm{G}, \mathrm{C}, \mathrm{HTL}$ & $\times$ & $\times$ & $\times$ & $\times$ & $\times$ & $\times$ & $\times$ & $\times$ & Tursi (2019) \\
\hline $\mathrm{P}, \mathrm{G}, \mathrm{C}$ & $\mathrm{P}, \mathrm{G}, \mathrm{C}$ & $x$ & $x$ & $x$ & $x$ & $x$ & $x$ & $x$ & $x$ & Liu et al. (2017a) \\
\hline$x$ & $\mathrm{P}, \mathrm{G}$ & $x$ & G & $x$ & $x$ & $\mathrm{P}, \mathrm{G}$ & $x$ & $x$ & $x$ & Chhiti and Kemiha (2013) \\
\hline $\mathrm{T}$ & $\mathrm{T}$ & $\mathrm{T}$ & $x$ & $x$ & $x$ & $\mathrm{~T}$ & $x$ & $x$ & $\times$ & Chen et al. (2015a) \\
\hline$\times$ & $\times$ & $\times$ & $\times$ & $\times$ & $\times$ & $\mathrm{P}, \mathrm{G}, \mathrm{C}$ & $\mathrm{P}, \mathrm{G}, \mathrm{C}$ & $\times$ & $\times$ & Wang and Yan (2008b) \\
\hline$x$ & $\mathrm{P}$ & $x$ & $\mathrm{P}$ & $\mathrm{P}$ & $x$ & $\mathrm{P}$ & $\mathrm{P}$ & $x$ & $x$ & Sharma et al. (2015) \\
\hline$x$ & $x$ & $x$ & $x$ & $x$ & $\times$ & $\mathrm{P}$ & $\mathrm{P}$ & $x$ & $x$ & Xiong et al. (2017) \\
\hline$\times$ & $x$ & $x$ & $\times$ & $x$ & $\times$ & G & G & $x$ & $x$ & Baruah and Baruah (2014) \\
\hline$x$ & G & $\times$ & $x$ & $x$ & $x$ & G & G & $\times$ & $x$ & Safarian et al. (2019) \\
\hline$x$ & $\mathrm{P}$ & $x$ & $x$ & $x$ & $x$ & $\mathrm{P}$ & $\mathrm{P}$ & $x$ & $x$ & Xia et al. (2021) \\
\hline$x$ & $x$ & $x$ & $x$ & $x$ & $x$ & HTC & HTC & $x$ & $x$ & Ischia and Fiori (2021) \\
\hline$x$ & $x$ & HTC & $x$ & $x$ & $x$ & HTC & HTC & $x$ & $x$ & Román et al. (2018) \\
\hline$\times$ & $\mathrm{P}$ & $x$ & $x$ & $x$ & $x$ & $\mathrm{P}$ & $x$ & $x$ & $x$ & Kaczor et al. (2020) \\
\hline$\times$ & $\begin{array}{l}\text { P,T,G,C, } \\
\text { HTC,HTL }\end{array}$ & $\times$ & $\times$ & $x$ & $\times$ & $\begin{array}{l}\text { P,T,G,C, } \\
\text { HTC,HTL }\end{array}$ & $\begin{array}{l}\text { P,T,G,C, } \\
\text { HTC,HTL }\end{array}$ & $\begin{array}{l}\text { P,T,G,C, } \\
\text { HTC,HTL }\end{array}$ & $\begin{array}{l}\text { P,T,G,C, } \\
\text { HTC,HTL }\end{array}$ & This review \\
\hline
\end{tabular}

* P: Pyrolysis, T: Torrefaction, G: Gasification, C: Combustion, HTC: Hydrothermal carbonization, HTL: Hydrothermal liquefaction, x: Not discussed.

\subsection{Pyrolysis principle}

From a thermal viewpoint, biomass pyrolysis consists of four stages. Drying occurs at the first stage at low temperatures in which unbound moisture evaporates. In the next stage, biomass devolatilization slowly progresses at low temperatures in the range of $100-200{ }^{\circ} \mathrm{C}$, where low-molecular-weight gases (e.g., $\mathrm{CO}$ and $\mathrm{CO}_{2}$ ) and small amounts of acetic acid are released. In the third stage, extensive devolatilization undergoes at high temperatures in the range of 200-600 ${ }^{\circ} \mathrm{C}$, where large biomass molecules decompose into char, condensable gases, and non-condensable gases. The secondary devolatilization of tars into secondary char and non-condensable gases $\left(\mathrm{H}_{2}, \mathrm{CO}, \mathrm{CH}_{4}, \mathrm{CO}_{2}\right.$, etc.) occurs in the final stage, where the temperature is usually $300-900^{\circ} \mathrm{C}$ (Sun et al., 2016). Real-world biomass pyrolysis involves an extremely complex reaction scheme in which various complex reaction pathways that lead to numerous intermediate products are present. Owing to the complexity, the decomposition mechanism of biomass is still not fully discovered. Besides temperature, heating rate, particle size, ambient conditions, and pressure, the kinetics of these enormous reactions are influenced by various factors such as the presence of catalytic material, composition, and degree of crystallinity and polymerization of specific lignocellulose components, which affect intra-particle and interparticle heat and mass transport (Pecha et al., 2019).

\subsubsection{Effects of process parameters on pyrolysis}

The temperature effect on the pyrolysis product distribution, yield, and quality is the most significant among the influential factors mentioned above. The best operating temperature for pyrolysis depends on biomass composition and the desired product (biochar or bio-oil). For bio-oil production, the ideal pyrolysis temperature for most of the lignocellulosic biomass sources was reported to be between $400-600{ }^{\circ} \mathrm{C}$ (Bhoi et al., 2020). The optimum temperature ranges for bio-oil and biochar production from pyrolysis of lignocellulosic biomass, in general, are illustrated in Figure 3. Dhar et al. (2020) reported that the temperature negatively affects the biochar yield of the slow pyrolysis of coconut fiber biomass upon increasing the temperature from $350{ }^{\circ} \mathrm{C}$ to $600{ }^{\circ} \mathrm{C}$. Further, they reported biochar properties such as high heating value (HHV), bulk density, particle sizes, and $\mathrm{H} / \mathrm{C}$ ratio of the produced biochar decreased, while other properties such as fixed carbon, ash content, $\mathrm{pH}$, organic carbon, specific surface area, degree of aromaticity, electrical conductivity, and porosity increased upon increasing the temperature. A similar result was observed for the pyrolysis of coconut shell waste by Sarkar and Wang (2020). They reported that with increasing the temperature from $400{ }^{\circ} \mathrm{C}$ to $600{ }^{\circ} \mathrm{C}$, biochar yield reduced while bio-oil yield enhanced. However, when the temperature was further increased to $800{ }^{\circ} \mathrm{C}$, the bio-oil yield also decreased. The gas production continuously increased with increments in temperature from $400{ }^{\circ} \mathrm{C}$ to 800 ${ }^{\circ} \mathrm{C}$. According to Zadeh et al. (2021), the maximum bio-oil yield from fast pyrolysis of softwood (spruce) and hardwood (populace) was obtained at $600{ }^{\circ} \mathrm{C}$ and $700{ }^{\circ} \mathrm{C}$, respectively. Another study reported an optimum temperature of $550{ }^{\circ} \mathrm{C}$ for bio-oil production from swine manure (Wang et al., 2020a). Moreover, Efeovbokhan et al. (2020) reported that the bio-oil from pyrolysis of yam peel increased with temperature until $450{ }^{\circ} \mathrm{C}$, and then it started to decline. Further, they claimed that the bio-oil yield was increased by more than double when the pyrolysis was carried out between $400-500{ }^{\circ} \mathrm{C}$ with the heterogeneous catalyst zeolite-y.

The heating rate also has a major impact on pyrolysis product yield and quality. Higher heating rates reduce the exposure time and limit the secondary cracking reactions, thus increasing the bio-oil yield. Also, the bio-oil quality is enhanced due to the minimized secondary cracking reactions. On the contrary, slow heating rates lead to higher biochar yields (Bhoi et al., 2020). For instance, Somerville and Deev (2020) reported a 
Table 4.

A comparison of popular reactor configurations for biomass pyrolysis.

\begin{tabular}{|c|c|c|c|c|c|c|}
\hline $\begin{array}{l}\text { Reactor } \\
\text { type }\end{array}$ & $\begin{array}{l}\text { Pyrolysis } \\
\text { conditions }\end{array}$ & $\begin{array}{l}\text { Mode of } \\
\text { operation }\end{array}$ & $\begin{array}{l}\text { Desired } \\
\text { products }\end{array}$ & Yield & Reactor conditions & Merits and limitations \\
\hline Kiln & Slow pyrolysis & Batch & Biochar & Up to $42 \%$ & $\begin{array}{l}\text { Operates at atmospheric pressure. Heating is } \\
\text { provided by the partial combustion of foliage. } \\
\text { Charge ignition is done by small kindle wood or } \\
\text { burning oil or gas-fired torch. Longer residence } \\
\text { time ( } 1-5 \text { weeks). }\end{array}$ & $\begin{array}{l}\text { Simple design. No requirement for a complex control } \\
\text { system. These reactors can be made to accommodate } \\
\text { large capacities. Usually manually operated. }\end{array}$ \\
\hline Retort & Slow pyrolysis & $\begin{array}{l}\text { Continuous or } \\
\text { semi- } \\
\text { continuous }\end{array}$ & Biochar & $30-35 \%$ & $\begin{array}{l}\text { Operates at atmospheric pressure. Residence } \\
\text { times can be up to } 48 \mathrm{~h} \text {. Heating is provided by } \\
\text { contact with hot gases or via external heat or } \\
\text { volatile combustion. Oil burners are used for the } \\
\text { start-up heat. Reactor position is usually vertical, } \\
\text { but horizontal configurations are also there. }\end{array}$ & $\begin{array}{l}\text { Moderate capacities. Higher capital cost. By-products } \\
\text { from vapor can be recovered. Prone to cause attrition } \\
\text { problems. Need external energy. Higher quality biochar } \\
\text { can be produced. Pretreatment may be required (pre- } \\
\text { drying). }\end{array}$ \\
\hline Rotary drum & $\begin{array}{l}\text { Slow pyrolysis, } \\
\text { mild pyrolysis }\end{array}$ & Continuous & Biochar & $19-38 \%$ & $\begin{array}{l}\text { Operates at atmospheric or vacuum pressure } \\
\text { conditions. Heating is provided by contact with } \\
\text { hot gases directly or indirectly heating. Charge } \\
\text { ignition is usually provided by the combustion of } \\
\text { auxiliary fuels. Horizontal reactor position. } \\
\text { Residence time is controlled by the angle of the } \\
\text { drum and the rotation speed. }\end{array}$ & $\begin{array}{l}\text { Relatively large capacities (up to } 288 \text { tons/d). } \\
\text { Pretreatment is required (pre-drying and particle size } \\
\text { reduction). The energy of pyrolysis gas is recycled back } \\
\text { to the reactor. Heat carriers are not mandatory. }\end{array}$ \\
\hline $\begin{array}{l}\text { Auger } \\
\text { reactor }\end{array}$ & $\begin{array}{l}\text { Slow pyrolysis, } \\
\text { mild pyrolysis }\end{array}$ & Continuous & Biochar & $17-30 \%$ & $\begin{array}{l}\text { Operates at atmospheric or vacuum pressure } \\
\text { conditions. Heating is provided by contact hot } \\
\text { gases directly or via a hot heat carrier or indirect } \\
\text { heating. Horizontal reactor position. Charge } \\
\text { ignition is provided by auxiliary fuels combustion } \\
\text { or by contacting combustion gases directly or } \\
\text { indirectly. }\end{array}$ & $\begin{array}{l}\text { Capacities up to } 50 \text { tons/d. Pretreatment is required } \\
\text { (pre-drying and particle size reduction). Biomass is } \\
\text { heated by a mechanically run heat carrier. A carrier gas } \\
\text { is not required. }\end{array}$ \\
\hline Packed bed & $\begin{array}{l}\text { Slow pyrolysis, } \\
\text { mild pyrolysis }\end{array}$ & $\begin{array}{l}\text { Continuous or } \\
\text { Batch }\end{array}$ & Biochar & $19-48 \%$ & $\begin{array}{l}\text { Operates usually at atmospheric pressure. Heating } \\
\text { is provided by contacting hot gases directly or via } \\
\text { a hot heat carrier or indirect heating. Vertical } \\
\text { reactor position. Charge ignition is provided by } \\
\text { auxiliary fuels combustion or by contacting } \\
\text { combustion gases directly or indirectly. }\end{array}$ & $\begin{array}{l}\text { Simple design. Low capital cost. Heat carriers are not } \\
\text { required. }\end{array}$ \\
\hline $\begin{array}{l}\text { Rotating } \\
\text { cone }\end{array}$ & Fast pyrolysis & Continuous & Bio-oil & Up to $70 \%$ & $\begin{array}{l}\text { Operates at atmospheric pressure. Short solid and } \\
\text { gas residence time. Centrifugal force drives } \\
\text { biomass. Heating is provided by the combustion } \\
\text { of char. Vertical reactor position. }\end{array}$ & $\begin{array}{l}\text { A complex reactor configuration. Scaling up is difficult } \\
\text { due to the reactor geometry and design. The energy } \\
\text { integration system is highly complex. Pretreatment is } \\
\text { required (pre-drying). A carrier gas is not required. }\end{array}$ \\
\hline $\begin{array}{l}\text { Ablative } \\
\text { reactor }\end{array}$ & Fast pyrolysis & Continuous & Biochar & Up to $70 \%$ & $\begin{array}{l}\text { Operates at atmospheric pressure. Horizontal } \\
\text { reactor position. Short residence time. }\end{array}$ & $\begin{array}{l}\text { A complex reactor configuration with moving parts at } \\
\text { high temperatures. A compact design. Very high heat } \\
\text { transfer rate. Pretreatment is not required. Relatively } \\
\text { larger biomass particles can be used. A large amount of } \\
\text { biomass is processed in a relatively small volume. A } \\
\text { carrier gas is not required. These reactors are prone to } \\
\text { wear and tear on the moving parts. }\end{array}$ \\
\hline $\begin{array}{l}\text { Conical } \\
\text { spouted bed }\end{array}$ & Fast pyrolysis & Continuous & $\begin{array}{l}\text { Bio-oil } \\
\text { Biochar }\end{array}$ & $40-80 \%$ & $\begin{array}{l}\text { Operates at atmospheric pressure. Very low gas } \\
\text { residence time. Short residence time. Char is } \\
\text { removed continuously. The vigorous cyclic } \\
\text { particle movement leads to high inter-phase heat } \\
\text { and mass transfer rates. }\end{array}$ & $\begin{array}{l}\text { High heat transfer rates. These reactors can handle } \\
\text { irregular particles (fine materials and sticky solids). } \\
\text { Relatively larger biomass particles can be used. For the } \\
\text { same capacity, the required reactor volume is lower } \\
\text { compared to fluidized beds. }\end{array}$ \\
\hline $\begin{array}{l}\text { Bubbling } \\
\text { fluidized bed }\end{array}$ & Fast pyrolysis & Continuous & Biochar & $33-78 \%$ & $\begin{array}{l}\text { Operates at atmospheric pressure. Heating is } \\
\text { usually provided by an inert heat carrier such as } \\
\text { sand. Pyrolysis gas and char may be used to } \\
\text { provide the reactor energy requirement. High heat } \\
\text { transfer. Short residence time. Vertical reactor } \\
\text { position. }\end{array}$ & $\begin{array}{l}\text { Industrial reactors have capacities between } 0.5-200 \\
\text { tons/d. Simple operation. Efficient heat transfer. } \\
\text { Pretreatment is required (drying and particle size } \\
\text { reduction). Moderately complex reactor configuration. } \\
\text { Temperature can be accurately controlled. Susceptible } \\
\text { to scaling. }\end{array}$ \\
\hline $\begin{array}{l}\text { Circulating } \\
\text { bed }\end{array}$ & Fast pyrolysis & Continuous & Bio-oil & $54-71 \%$ & $\begin{array}{l}\text { Operates at atmospheric pressure. Heating is } \\
\text { provided by recirculating the sand reheated by } \\
\text { char combustion. Char is separated and recycled } \\
\text { back to the reactor. Rapid heat transfer. Short } \\
\text { residence time. Vertical reactor position. }\end{array}$ & $\begin{array}{l}\text { Suitability for very large throughputs. Pretreatment is } \\
\text { required (drying and particle size reduction). } \\
\text { Moderately complex reactor configuration. Precise } \\
\text { temperature control. Complex hydrodynamics. Higher } \\
\text { char and sand attrition. These reactors can be enhanced } \\
\text { to a catalytic cracking reactor by using a catalyst } \\
\text { instead of inert sand. }\end{array}$ \\
\hline Vacuum bed & $\begin{array}{l}\text { Combined fast } \\
\text { and slow } \\
\text { pyrolysis }\end{array}$ & - & Bio-oil & $35-50 \%$ & $\begin{array}{l}\text { Operates at vacuum conditions. Slow heating rate. } \\
\text { Short residence time. Short volatile residence } \\
\text { time. }\end{array}$ & $\begin{array}{l}\text { A complex design. Produces comparatively low bio-oil } \\
\text { yield. A carrier gas is not required. Heat transfer is } \\
\text { comparatively low. }\end{array}$ \\
\hline
\end{tabular}




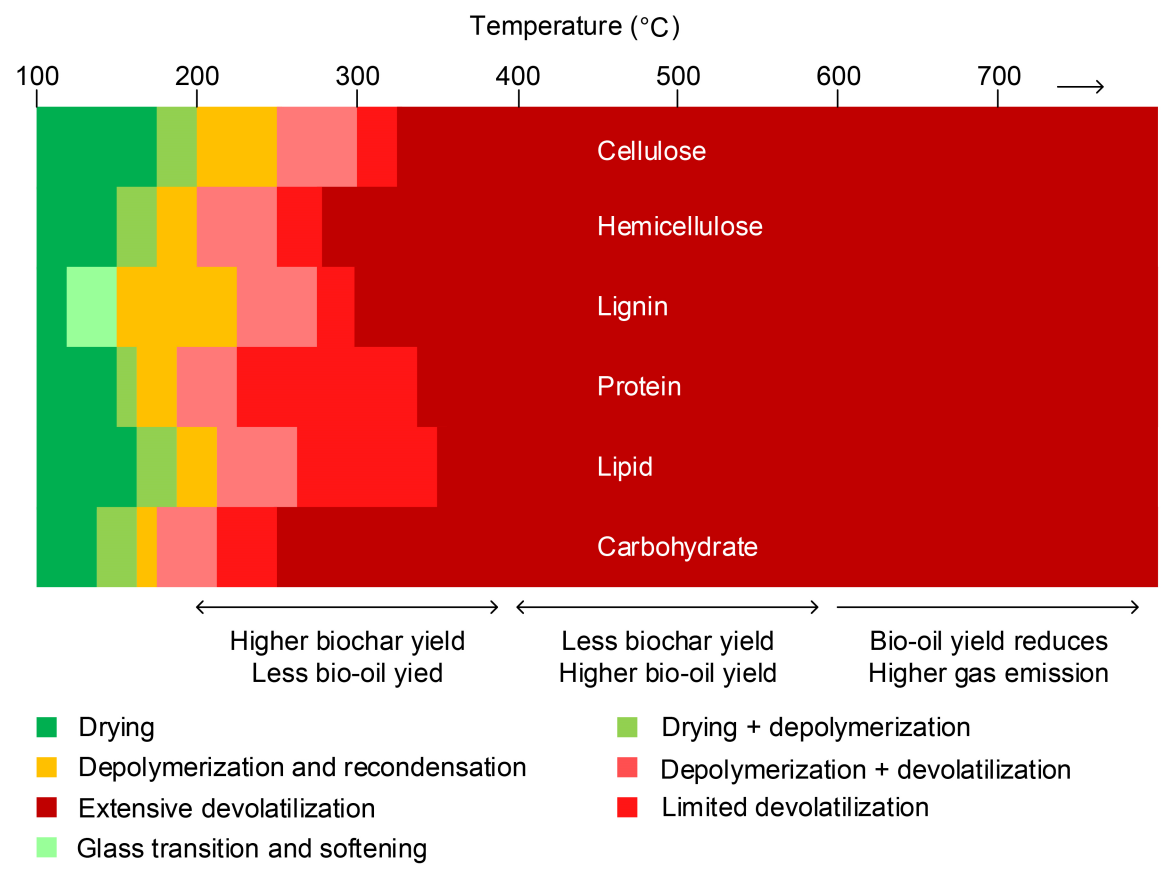

Fig. 3. Reaction stages and product yield variations of biomass pyrolysis.

decrease in biochar yield for pyrolysis of pinewood upon increasing the heating rate from 0.11 to $10{ }^{\circ} \mathrm{C} \mathrm{min}-1$. Furthermore, it was reported that the primary decomposition was catalyzed by the initial char. Lower heating rates accompanied by longer residence times also increased the retention time of pyrolysis of vapor, thus leading to an increased formation of secondary char. At a certain heating rate, increasing the residence time encourages the secondary decomposition reactions due to longer exposure to heat and consequently favors the gas formation. Particle size is also a key factor that influences the pyrolysis process. This is mainly because the particle size affects reactions kinetics, heat and mass transfers, and phase transition (Wang et al., 2020b; Xiao et al., 2020). Interparticle and intraparticle heat transfers improve by decreasing the particle size. As a result, biomass decomposition is faster when the feed contains smaller particle sizes. Consequently, small particle sizes favor bio-oil production, whereas larger particles tend to promote char formation. Nevertheless, very small particles reduce the bio-oil yield, increasing the gas formation due to the rapid decomposition accompanied by secondary reactions. The optimum particle size range for bio-oil production has been reported by several previous studies to be between 0.6-1.2 $\mathrm{mm}$ (Bhoi et al., 2020).

Pressure also has a significant impact on the pyrolysis product yield and quality. When the operating pressure is set to be higher than the atmospheric pressure, biochar and syngas yield is reported to increase since higher pressures increase the vapor residence time, favoring the secondary cracking reactions, which in turn reduce the bio-oil yield (Qin et al., 2020). However, high pressures also promote decarboxylation and hence, reduce the oxygen content, enhancing the calorific value of bio-oil. Matamba et al. (2020) studied the pressure effect on flash pyrolysis of palm kernel shells between $0.1-4.00 \mathrm{MPa}$ and reported that higher pressures favor the formation of polycyclic aromatic hydrocarbons (PAH) and $\mathrm{H}_{2}$. They suggest biomass pyrolysis at elevated temperatures as a potential method for polygeneration. The pressure effect on fast pyrolysis of walnut shells in different atmospheric conditions $\left(\mathrm{CO}_{2}\right.$ and $\mathrm{N}_{2}$ environments) up to $0.8 \mathrm{MPa}$ was investigated by Cerciello et al. (2021). They identified that the combustion pattern and reactivity of char are sensitive to the operating pressure. Indeed, char combustion reactivity progressively diminished with increasing the pressure, and this effect was limited in $\mathrm{CO}_{2}$ environments compared to $\mathrm{N}_{2}$ ones. Purging gas flow also has a significant impact on the output of pyrolysis. Somerville and Deev (2020) reported that with increasing inert carrier gas flow rate through biomass (pine wood), biochar yield decreased while the decomposition rate increased.
As with the development of advanced and low-cost catalysts, catalytic pyrolysis is recently gaining popularity. For instance, catalytic pyrolysis can increase the bio-oil yield and enhance the quality by reducing oxygenated components and carboxylic acids while enriching hydrocarbons. Currently, four major types of catalysts are employed in biooil production from biomass pyrolysis; i.e., zeolite-based catalysts, metal oxide catalysts, noble metal catalysts, and supported transition.

\subsection{Drying}

Raw biomass usually contains a high amount of moisture, and the drying process significantly impacts the overall process efficiency since evaporation consumes a large amount of energy. In previous studies, the drying process for high-temperature biomass thermochemical conversion processes has been modeled in three ways, i.e., first-order global evaporation model (Kersten et al., 2005; Xiong et al., 2013), equilibrium model (Di Blasi, 2008; Kabir et al., 2015), and heat sink model (Neves et al., 2011; Matta et al., 2017). The first approach is comparatively simple, and it considers that evaporation is a thermally activated process meaning drying begins only after reaching a specific boiling temperature. It can be described by a first-order Arrhenius equation, and hence, in such models, evaporation is integrated as an additional chemical reaction to the kinetic model. This approach results in smooth intra-particle gradients, thus leading to higher numerical stability. However, this global reaction approach is with a disadvantage that in a real case, drying undergoes before reaching the boiling temperature (Peters and Bruch, 2001).

The second approach (equilibrium model) assumes an equilibrium between the local gas phase and the moisture absorbed in the solid phase (bound and capillary). This approach is comparatively complex since it is required to consider the pressure drops, which occur at locations ahead of the drying front, demanding more numerical power (Bates and Ghoniem, 2014). The third approach (heat sink model) is primarily based on the assumption that upon a moist particle layer reaching the boiling temperature, evaporation entirely consumes all energy flowing to the moist layer until drying ceases. This approach is implemented using two techniques, i.e., assuming an infinitely thin drying front or dividing particles into two regions (moist and dry regions). However, the former technique is prone to result in inaccuracies when the drying front has a significant thickness compared to the particle size, while the latter 
technique requires including conditional statements in governing equations, leading to discontinuities in numerical solution, making it less computationally efficient (Bryden et al., 2002). To model the drying process, Bates and Ghoniem (2014) employed a first-order global reaction that activates upon exceeding the vaporization temperature. Drying is included as an extra chemical reaction described by a first-order Arrhenius equation in the model. Since this approach does not need to modify governing equations, it provides better numerical efficiency and stability.

\subsection{Slow pyrolysis}

\subsubsection{Kinetic modeling}

This high sensitivity of kinetics to various factors makes its interpretation and determination even more difficult (Özsin and Pütün, 2017). As a result, kinetic modeling of pyrolysis requires drastic simplifications and is generally based on the apparent kinetics and lump components (Ravi et al., 2004). Several types of reaction schemes are employed in literature for biomass pyrolysis studies, as depicted in Figure 4. Though pyrolysis is considered a standalone process, it is also a critical and major step in gasification. Therefore, pyrolysis kinetics are also important in gasification reactor modeling (Gupta and Mahajani, 2020). A kinetic model with a single-step parallel reaction scheme for pseudo components (hemicellulose, cellulose, and lignin) was used by Amutio et al. (2013). Liu et al. (2020) employed a similar model for basswood waste pyrolysis, and the kinetic parameters were optimized by the shuffled complex evolution (SCE) algorithm coupled with the three-component parallel reaction scheme. Di Blasi (1993) developed a lumped kinetic model for wood pyrolysis, which is based on a two-stage parallel reaction scheme in which biomass is first decomposed into gas, vapor, and char, and then the vapor is converted to secondary gas and char.

Soria-verdugo et al. (2020) constructed a lumped kinetic model for olive stone pyrolysis in which biomass is decomposed into char and volatiles. It is combined with a secondary tar cracking reaction which yields $\mathrm{CO}, \mathrm{H}_{2}$, $\mathrm{CO}_{2}, \mathrm{CH}_{4}$, and inert tar. Similarly, Grønli and Melaaen (2000) employed a two-stage lumped kinetic model for wood pyrolysis, which considers three parallel competitive reactions for primary production of gas, tar, and char and a consecutive reaction to account for the secondary cracking of tar into secondary gases. Another two-stage lumped kinetic model for wood pyrolysis was used by Ghabi et al. (2008). In the first stage of their model, biomass decomposes into char, tar, and gas, and then consecutive tar cracking reaction occurs in the second stage to yield secondary tar and gas. A similar kinetic model was constructed by Sarkar et al. (2014) for sesame oil cake pyrolysis in which biomass decomposes into char and volatiles, and then the volatiles are converted into main gases $\left(\mathrm{CO}, \mathrm{CO}_{2}, \mathrm{H}_{2}\right.$, and $\left.\mathrm{CH}_{4}\right)$ and inert tar. Table 5 lists the above kinetic models. It should be noted that the general kinetic equation expressed in Equations 1 and 2 (Naqvi et al., 2019) and the reaction rate constant (Eq. 3) in the form of amplified Arrhenius equations (Álvarez-Murillo et al., 2016) is applied for the kinetic parameters presented in Table $\mathbf{5}$ (as well as those shown later in Tables 8 , $10,12,14,16$, and 18).

$\frac{d \alpha}{d x}=k(T) f(\alpha)$

where,

$\alpha=\frac{m_{o}-m_{i}}{m_{o}-m_{f}}$

$\mathrm{k}(\mathrm{T})=A \mathrm{~T}^{\mathrm{m}} \mathrm{e}^{\frac{-\mathrm{E}_{\mathrm{a}}}{\mathrm{RT}}}$

where $\alpha$ represents the decomposition rate of biomass at given time $\mathrm{t}$, $\mathrm{f}(\alpha)$ is the kinetic model function, $\mathrm{m}_{\mathrm{o}}, \mathrm{m}_{\mathrm{i}}$, and $\mathrm{m}_{\mathrm{f}}$ are respectively initial

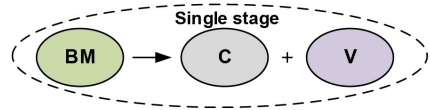

One-step global reaction

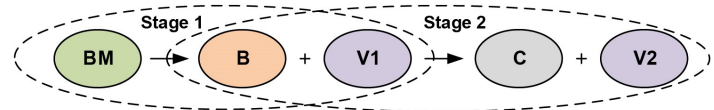

Two consecutive reactions

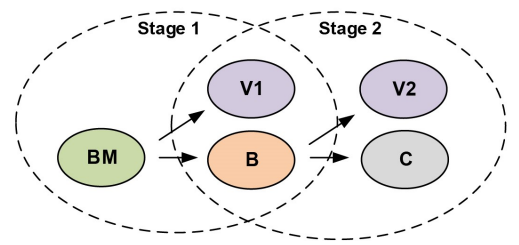

Two consecutive parallel reactions

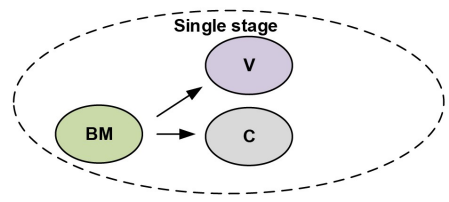

Parallel reactions

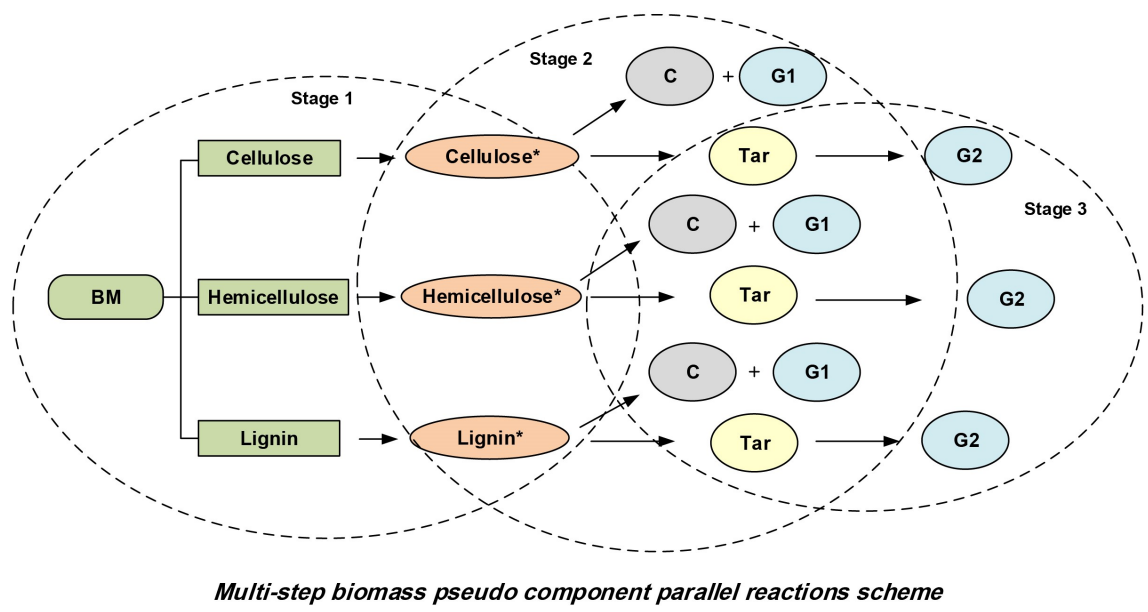

BM: Biomass, C: Char, V: Volatiles, B: Intermediate solid, G: Gas, *: Active, 1: Primary, 2: Secondary 
Table 5.

Slow pyrolysis kinetic models which were already employed or having potential in reactor modeling for waste biomass.

\begin{tabular}{|c|c|c|c|c|c|c|c|c|c|}
\hline \multirow[b]{2}{*}{ No } & \multirow[b]{2}{*}{ Biomass source } & \multirow{2}{*}{$\begin{array}{l}\text { Temperature } \\
\text { range }\left({ }^{\circ} \mathrm{C}\right)\end{array}$} & \multirow{2}{*}{\multicolumn{2}{|c|}{ Reaction mechanism/model }} & \multicolumn{4}{|c|}{ Kinetic parameters } & \multirow[b]{2}{*}{ Reference } \\
\hline & & & & & $A\left(s^{-1}\right)$ & $\begin{array}{c}\mathbf{E a} \\
\left(\mathrm{kJ} \mathrm{mol}^{-1}\right)\end{array}$ & $\mathbf{n}$ & $\mathbf{m}$ & \\
\hline \multirow{2}{*}{1} & \multirow{2}{*}{$\begin{array}{l}\text { Wood waste } \\
\text { (Basewood) }\end{array}$} & \multirow{2}{*}{$175-525$} & \multicolumn{2}{|c|}{ Hemicellulose $\rightarrow \alpha_{H}$ Char $+\left(1-\alpha_{H}\right)$ Volatiles } & $2.94 \times 10^{8}$ & 115.65 & 1 & 0 & \\
\hline & & & \multicolumn{2}{|l|}{ Lignin $\rightarrow \alpha_{L}$ Char $+\left(1-\alpha_{L}\right)$ Volatiles } & $2.01 \times 10^{4}$ & 83.56 & 1 & 0 & \\
\hline 2 & Olive stone & $225-375$ & \multicolumn{2}{|c|}{$\begin{array}{l}\text { A simplified distributed activation energy model (DAEM), } \\
\text { which assumes a large number of independent irreversible first- } \\
\text { order reactions, was proposed in this study. The activation } \\
\text { energy and the pre-exponential factor were determined with } \\
\text { respect to the degree of conversion. }\end{array}$} & $\begin{aligned}(\alpha & \leq 80 \%) \\
& \approx 10^{12}\end{aligned}$ & $\begin{aligned}(\alpha & \leq 80 \%) \\
& \approx 175\end{aligned}$ & 1 & 0 & $\begin{array}{l}\text { Soria-Verdugo et } \\
\text { al. (2020) }\end{array}$ \\
\hline \multirow{4}{*}{3} & \multirow{4}{*}{$\begin{array}{l}\text { Wood } \\
\text { (Norwegian birch, } \\
\text { pine, and spruce) }\end{array}$} & \multirow{4}{*}{$100-900$} & \multicolumn{2}{|l|}{ Biomass $\rightarrow$ Char } & $1.10 \times 10^{7}$ & 121.3 & 1 & 0 & \multirow{4}{*}{$\begin{array}{l}\text { Grønli and } \\
\text { Melaaen (2000) }\end{array}$} \\
\hline & & & \multirow{2}{*}{\multicolumn{2}{|c|}{$\begin{aligned} \text { Biomass } & \rightarrow \text { Gas } \\
\text { Biomass } & \rightarrow \text { Tar }\end{aligned}$}} & $1.30 \times 10^{8}$ & 140.3 & 1 & 0 & \\
\hline & & & & & $2.00 \times 10^{8}$ & 133.1 & 1 & 0 & \\
\hline & & & \multicolumn{2}{|l|}{ Tar $\rightarrow$ Gas } & $2.30 \times 10^{4}$ & 80.0 & 1 & 0 & \\
\hline \multirow{2}{*}{4} & \multirow{2}{*}{ Wood } & \multirow{2}{*}{$100-800$} & \multicolumn{2}{|l|}{ Biomass $\rightarrow$ Char } & $2.66 \times 10^{10}$ & 106.5 & 1 & 0 & \multirow{2}{*}{ Di Blasi (1993) } \\
\hline & & & \multicolumn{2}{|l|}{ Tar $\rightarrow$ Gas } & $4.28 \times 10^{6}$ & 108.0 & 1 & 0 & \\
\hline \multirow{3}{*}{5} & \multirow{3}{*}{ Forest residue } & \multirow{3}{*}{$150-600$} & \multirow{3}{*}{$\begin{array}{l}\text { The proposed reaction mechanism is } \\
\text { composed of three independent and parallel } \\
\text { decomposition reactions for main pseudo } \\
\text { components. }\end{array}$} & Hemicellulose & $2.64 \times 10^{7}$ & 98.0 & 1 & 0 & \multirow{3}{*}{$\begin{array}{l}\text { Amutio et al. } \\
\text { (2013) }\end{array}$} \\
\hline & & & & Cellulose & $8.35 \times 10^{11}$ & 161.0 & 1 & 0 & \\
\hline & & & & Lignin & 1.05 & 32.0 & 1 & 0 & \\
\hline 6 & Wood & $225-375$ & Biomass $\rightarrow \alpha_{B, C}$ Char $+\alpha_{B, T} \operatorname{Tar}_{1}+\alpha_{B, G} G$ & & $1.95 \times 10^{6}$ & 92.41 & 1 & 0 & (2000) \\
\hline 0 & Wood & $225-3 / 5$ & $\operatorname{Tar}_{1} \rightarrow \alpha_{T, T} \operatorname{Tar}+\alpha_{T, G}$ Gas & & $1.30 \times 10^{5}$ & 107.10 & 1 & 0 & Ghabl et al. (2008) \\
\hline & & & Biomass $\rightarrow$ Volatiles & & $6.57 \times 10^{-3}$ & 14.51 & 1 & 0 & \\
\hline 7 & Sesame oil cake & $400-900$ & Biomass $\rightarrow$ Char & & $7.07 \times 10^{-4}$ & 4.38 & 1 & 0 & Sarkar et al. \\
\hline & & & Volatiles $\rightarrow \alpha_{1} \mathrm{CO}+\alpha_{2} \mathrm{CO}_{2}+\alpha_{3} \mathrm{CH}_{4}+\alpha$ & $H_{2}+\alpha_{5}$ Tar $_{\text {inert }}$ & $9.55 \times 10^{4}$ & 93.37 & 1 & 0 & \\
\hline
\end{tabular}

mass, mass at given time $\mathrm{t}$ and final mass, $\mathrm{A}$ is the pre-exponential factor $\left(\mathrm{s}^{-1}\right)$, $\mathrm{E}_{\mathrm{a}}$ is the activation energy $\left(\mathrm{kJ} \mathrm{mol}^{-1}\right), \mathrm{T}$ and $\mathrm{m}$ are respectively the temperature $(\mathrm{K})$ and its power, and $\mathrm{R}$ is the universal gas constant $\left(8.314 \times 10^{-3} \mathrm{~kJ} \mathrm{~mol}^{-1} \mathrm{~K}^{-}\right.$ $1)$

\subsubsection{Reactor Modeling}

Modeling of thermochemical conversion of biomass is mainly categorized into three approaches; i.e., empirical models, semi-empirical models, and fundamental analysis. A basic comparison of these three modeling approaches is given in Table 6. In the empirical modeling approach, data obtained from rigorous experiments are converted to mathematical equations using different statistical techniques, whereas the semi-empirical modeling approach uses experimental data together with theoretical principles and simplifying assumptions to generalize the system. The accuracy of empirical models is contingent upon the amount of experimental data, and their prediction capacity is usually limited to the vicinity of the experimental data span. In comparison with empirical models, semi-empirical models are computationally more efficient with a higher prediction capacity and require less experimental data. On the other hand, in fundamental analysis, a physical system is converted to a full-scale mathematical model by using theoretical principles with simplifying assumptions, thus developing more realistic models which closely resemble the actual systems. For instance, computational fluid dynamic (CFD) is a sophisticated tool in fundamental analysis and is extensively used for reactor modeling as the best choice for implementing full-scale theoretical models. There are several commercial and open-source CFD software packages. ANSYS Fluent, COMSOL Multiphysics, PowerFLOW, SimScale, Autodesk CFD, FLOW-3D, IVRESS, SimulationX, and Altair HyperWorks Suite are some commercial CFD software packages, whereas OpenFOAM, SU2, Palabos, Fire Dynamics Simulator, NEK5000, and MFIX are some popular open-source CFD software packages. ANSYS Fluent, Open FOAM, and
COMSOL Multiphysics are the most popular tools for reactor modeling of biomass thermochemical conversion routes. A stepwise CFD model development procedure is illustrated in Figure 5 .

Ravi et al. (2004) constructed a semi-empirical model for sawdust pyrolysis in an annular packed bed. The model can predict the mass-loss and mass-loss rate, and the study performed a sensitivity analysis to investigate the effects of thermal conductivity of char, thermal conductivity of void, and reaction rate constant on the mass loss. Though the model predictions were reasonably compatible with the experimental data, they underpredicted the mass loss and mass-loss rates. The accuracy can be enhanced by including the volatile flow through the porous bed, secondary pyrolysis reactions, and heat transfer through convection and radiation Soria-Verdugo et al. (2020) developed a model which combines the lumped capacitance method and the simplified distributed activation energy mode to simulate pyrolysis of crushed olive stone particles in a bubbling fluidized bed reactor. The model can predict the conversion degree, and the model results were in good agreement with the experimental data. Further, the study investigated the effects of gas velocity, bed temperature, and particle size on the conversion. Also, a direct relationship between the characteristic heating time and the pyrolysis time was obtained for constant bed temperatures. A three-layer ANN model was developed by Sun et al. (2016) for pine sawdust pyrolysis. The model can predict the effects of temperature, particle size, and space velocity on the product yield and distribution. The model predictions were fairly agreed with the experimental data. The study revealed benzene was favored at lower temperatures such as $400{ }^{\circ} \mathrm{C}$ while polyaromatic hydrocarbons were generated at a higher temperature over $600{ }^{\circ} \mathrm{C}$. The composition of main gas products $\left(\mathrm{CO}, \mathrm{CO}_{2}, \mathrm{H}_{2}\right.$, and $\left.\mathrm{CH}_{4}\right)$ increased from $29.12 \%$ to $34.03 \%$ upon increasing the space velocity from $45 \mathrm{~min}^{-1}$ to $85 \mathrm{~min}^{-1}$, whereas the composition of main gas products increased from $2.91 \%$ to $34.31 \%$ upon increasing the temperature from $300^{\circ} \mathrm{C}$ to $900{ }^{\circ} \mathrm{C}$. Further, the sample 
Table 6.

A comparison of merits and limitations of empirical modeling, semi-empirical modeling, and fundamental analysis.

\begin{tabular}{|c|c|c|}
\hline Empirical modeling & Semi-empirical models & Fundamental analysis \\
\hline $\begin{array}{l}\text { A Primary modeling } \\
\text { technique which is purely } \\
\text { based on experimental data }\end{array}$ & $\begin{array}{l}\text { Experimental data are used } \\
\text { together with simplifying } \\
\text { assumptions and relevant } \\
\text { theoretical principles }\end{array}$ & $\begin{array}{l}\text { Purely theoretical. } \\
\text { Models should be } \\
\text { validated }\end{array}$ \\
\hline $\begin{array}{l}\text { Need a large amount of } \\
\text { experimental data for higher } \\
\text { accuracy }\end{array}$ & $\begin{array}{l}\text { A lesser amount of data is } \\
\text { comparatively required }\end{array}$ & $\begin{array}{l}\text { Experimental data is not } \\
\text { required }\end{array}$ \\
\hline $\begin{array}{l}\text { Requirement for time- } \\
\text { consuming and expensive } \\
\text { rigorous trial-and-error } \\
\text { experiments }\end{array}$ & $\begin{array}{l}\text { A fewer number of experiments } \\
\text { are comparatively performed. }\end{array}$ & $\begin{array}{l}\text { Experiments are } \\
\text { performed only for } \\
\text { validation }\end{array}$ \\
\hline $\begin{array}{l}\text { Experimental data is } \\
\text { converted to mathematical } \\
\text { relationships (black-box } \\
\text { models) }\end{array}$ & $\begin{array}{l}\text { Black-box models with a higher } \\
\text { flexibility }\end{array}$ & $\begin{array}{l}\text { Full-scale theoretical } \\
\text { mathematical models } \\
\text { with very high } \\
\text { flexibility }\end{array}$ \\
\hline $\begin{array}{l}\text { Highly accurate in the } \\
\text { vicinity of the experimental } \\
\text { data range }\end{array}$ & $\begin{array}{l}\text { Accuracy depends on the } \\
\text { assumptions, theories, and data } \\
\text { manipulation techniques } \\
\text { employed }\end{array}$ & $\begin{array}{l}\text { Accuracy needs to be } \\
\text { verified via a thorough } \\
\text { validation process }\end{array}$ \\
\hline Limited prediction capacity & Better prediction capacity & $\begin{array}{l}\text { Sophisticated with a } \\
\text { higher prediction } \\
\text { capacity }\end{array}$ \\
\hline $\begin{array}{l}\text { Uses statistical techniques } \\
\text { such as polynomial regression }\end{array}$ & $\begin{array}{l}\text { Uses statistical techniques such } \\
\text { as Artificial Neural Network } \\
\text { (ANN), regression analysis, and } \\
\text { machine learning techniques }\end{array}$ & $\begin{array}{l}\text { Uses techniques such as } \\
\text { computational Fluid } \\
\text { Dynamics (CFD), Finite } \\
\text { Elemental Analysis } \\
\text { (FEA), etc. }\end{array}$ \\
\hline $\begin{array}{l}\text { Required computational } \\
\text { capacity is very low }\end{array}$ & $\begin{array}{l}\text { A lesser computation capacity } \\
\text { is required }\end{array}$ & $\begin{array}{l}\text { A higher computational } \\
\text { capacity is required }\end{array}$ \\
\hline
\end{tabular}

particle size in the range of $0.1-1.7 \mathrm{~mm}$ had no significant impact on the number of main gas products.

Aspen Plus $®$, a popular commercial chemical process simulator, is an equation-oriented simulation program that can simulate chemica processes, including solid, liquid, and gaseous phases, under well-defined conditions based on energy and mass balances and phase equilibrium. It is user-friendly and does not require rigorous programming. Most importantly, it allows conducting sensitivity analysis, and hence the process optimization is easier. Moreover, it has a large extensive property databank, including numerous models and stream properties. It also permits the addition of custom blocks through FORTRAN subroutines when advanced, or application-specific modeling is required (Tungalag et al., 2020). A fourstage steady-state equilibrium model by Aspen Plus ${ }^{\circledR}$ was developed by Kabir et al. (2015) to simulate pyrolysis of municipal green waste in a rotary kiln. The model can predict the product yield and distribution, and it was used to optimize operating variables such as temperature, heat air to fuel ratio, moisture content, and particle size. It was identified that the optimum reactor temperature is a function of the process heat air flow rate. The pyrolysis time and temperature were strongly affected by the biomass moisture content. When the moisture content was increased, the oil yield decreased while gas yield increased. The model predictions reasonably agreed with the experimental data, and the maximum deviation for elemental compositions was less than $16 \%$. The maximum bio-oil yield was obtained for the temperatures in the range $500-550{ }^{\circ} \mathrm{C}$. In a similar approach, Adeniyi et al. (2019) developed a steady-state process model by Aspen Plus ${ }^{\circledR}$ to simulate banana waste pyrolysis. The model revealed that the highest char yield was obtained for the pseudo-stem and the respective bio-oil yields for the pseudo-stem, peel, and leaves were $26.7 \%, 39.9 \%$, and $35 \%$, respectively. This model was validated by the existing literature. However, an experimental analysis is required to assure the model's accuracy.

Safin et al. (2016) built a simple mathematical model to simulate wood pyrolysis in a fluidized bed reaction. The model can predict the temperature

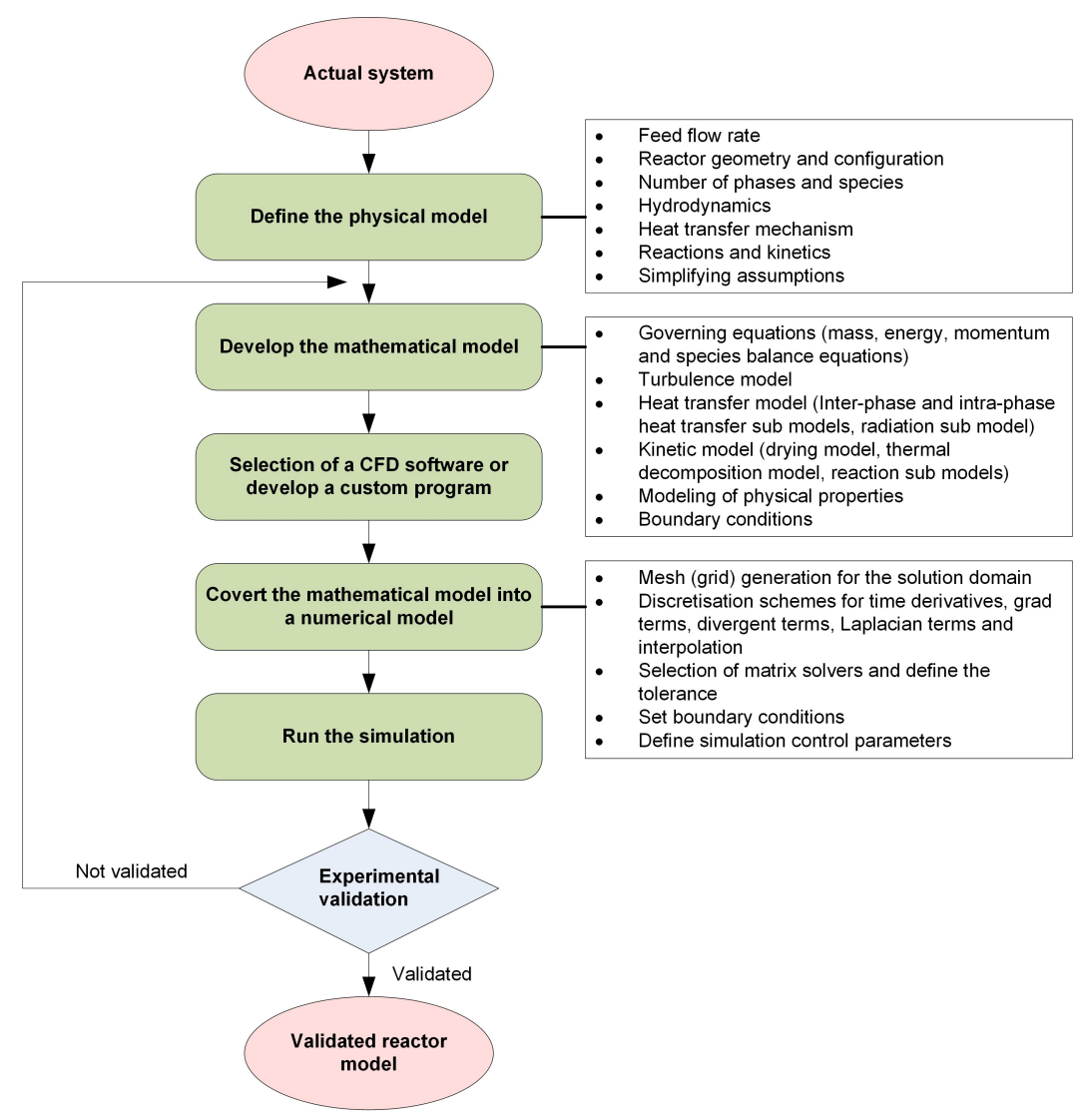

Fig. 5. A flow chart of the stepwise computation fluid dynamics (CFD) reactor model development procedure.

Please cite this article as: Perera S.M.H.D., Wickramasinghe C., Samarasiri B.K.T., Narayana M. Modeling of thermochemical conversion of waste biomass a comprehensive review. Biofuel Research Journal 32 (2021) 1481-1528. DOI: 10.18331/BRJ2021.8.4.3 
distribution along the particle radius, the effect of reactor temperature on kinetics, and the effect of reactor temperature and reactor length on the product yield. The model results confirmed that the increase of reaction temperature tends to increase the gas yield. The model predictions were adequately compatible with the experimental data with a maximum deviation of $18 \%$. Sarkar et al. (2014) developed a 1D mathematical model to simulate pyrolysis of sesame oil cake under isothermal conditions in a semi-batch pyrolyzer (fixed bed reactor) in the temperature range of $673-1173 \mathrm{~K}$. The model can predict unreacted solid, char, bio-oil, $\mathrm{CO}, \mathrm{H}_{2}, \mathrm{CO}_{2}$, and $\mathrm{CH}_{4}$ profiles. The model predictions satisfactorily agreed with the experimental data, and it can be used for other reactor configurations and biomass types by adopting suitable kinetic schemes. The model can also be further upgraded by including bed shrinkage and density variations of gas and solid.

Grønli and Melaaen (2000) developed a 1D mathematical model to simulate the pyrolysis of wood in a bell-shaped Pyrex reactor. This model included a comprehensive heat transfer sub-model that considers the thermal conductivity of solids as a function of density, temperature, and grain orientation. The model can predict the product yield and distribution and the effect of heat flux variations on the product yield distribution. The model sensitivity was analyzed for the most crucial parameters such as thermal conductivity, permeability, and kinetic rate coefficient. It revealed that mass transfer was more important in modeling secondary reactions. Though the strong interaction between the heat and mass transfer processes and chemical reactions was not rigorously resembled, the model predictions agreed well with the experimental data. Peters (2011) proposed a 1D transient model to simulate pyrolysis of wood. The model can predict the product yield and distribution profiles in time and space, and the model predictions were in good agreement without exceptions. Further, the model was claimed to be applicable to many biomass types under various boundary conditions and hence suited to several reactor configurations such as fixed bed, fluidized bed, rotary kiln, or grate systems. On the other hand, Ghabi et al. (2008) developed a 2D model to simulate the pyrolysis of wood in a fixed bed reactor. The model considered two-dimensional heat and mass transfer effects and can predict the temperature and product yield profiles over time. The model was validated by the existing literature, and the predictions were well agreed with the experimental data. The model can be used to optimize the operating parameters, such as gas temperature and mass fractions of char and light gas. Basic assumptions and modeling techniques of the above slow pyrolysis reactor models are listed in Table 7.

\subsection{Fast pyrolysis and flash pyrolysis}

\subsubsection{Kinetic modeling}

The two-competing-rates model uses two distinct decomposition reactions that individually dominate at low and high-temperature regimes. These models, which require fewer input parameters, can usually be employed over a wide range of temperatures. Li et al. (2015) used such a kinetic model, which was based on a two-competing first-order reaction scheme for fast pyrolysis of forest residue. This modified kinetic model with the optimal kinetic parameters predicted the mass loss and compositional data with high accuracy. Sun et al. (2010) employed a single-stage lumped kinetic model for flash pyrolysis of rice husk and sawdust. Here biomass was considered to be decomposed into char and volatiles. For fast pyrolysis of straw and wood, Bech et al. (2009) employed a three-stage lumped kinetic model in which biomass decomposes into intermediate liquid, which subsequently undergoes two parallel reactions to form gas and char, and organics. Then again, organics are degraded into gas. The kinetic parameters were further modified for the straw to include the catalytic effect of its alkali-containing ash content. It was identified that the ash constituents had a high impact on the kinetics. The generalized lumped kinetic model for pyrolysis of lignocellulose biomass developed by Miller and Bellan (1997) was used by a few fast pyrolysis reactor modeling studies (Luz et al., 2018a and b). It is based on a three-step pseudo-component parallel reaction scheme in which cellulose, hemicellulose, and lignin are converted to their active counterparts and then decomposed via two competitive reactions into char and gas, and tar. Next, the tar undergoes cracking reactions to form secondary gas.

Eri et al. (2017) constructed a detailed kinetic model for cellulose flash pyrolysis considering major individual chemicals. Most importantly, this model took the effect of potassium into account, and it revealed that when potassium concentration is increased, char and gas yields increase while bio- oil yield decreases. This is mainly because potassium inhibits the fragmentation and the depolymerization of activated cellulose, whereas it catalyzes the cellulose depolymerization reaction. An advanced complex kinetic model considering major intermediate products was developed by Ranzi et al. (2008) for pyrolysis of softwood and hardwood. The model is based on a pseudo component lumped kinetic scheme. The model elaborates degradation steps and the corresponding characteristic times, thus allowing to predict product distributions accurately. The study attempted to develop a model that closely resembles real biomass pyrolysis by considering the most impactful reactions and intermediate products from the complex reaction pathways and the large number of intermediate products occurring during the pyrolysis. The above-described fast pyrolysis kinetic models with the reaction mechanisms and the kinetic data are listed in Table 8.

\subsubsection{Reactor modeling}

Tuntsev et al. (2015) developed a simple mathematical model to simulate the fast pyrolysis of wood waste in a fluidized bed reactor. The model can predict the temperature distribution along the particle radius, the effect of reactor temperature on the kinetics, and the effects of temperature and reactor length on the product yield. The model predictions were in reasonable agreement with the experimental data, with the maximum deviation being less than $18 \%$. Dupont et al. (2009) constructed a detailed mathematical model for wood pyrolysis in an entrained flow reactor under high temperature $\left(800-1000^{\circ} \mathrm{C}\right)$ and flash heating rate conditions $(10-100$ $\mathrm{kWm}^{-2}$ ). The model consists of three sub-models, i.e., a semi-global kinetic model proposed by Ranzi et al. (2008), a particle, and a reactor model. This kinetic model considers successive gas-phase reactions of the released species, and hence the gas composition can be predicted. The study investigated the effect of particle size and the role of secondary gas-phase reactions. The biomass devolatilization for small particles lesser than 0.4 $\mathrm{mm}$, was completed approximately at a reactor length of $0.3 \mathrm{~m}$, producing a total gas yield higher than $75 \mathrm{wt} \%$ and a char yield between 10-15 wt $\%$. On the other hand, the biomass decomposition for large particles in the range $0.4-1.1 \mathrm{~mm}$ progressed up to a length of $0.9 \mathrm{~mm}$, owing to internal heat transfer limitations. The model predictions were promising and compatible with the experimental data. However, more complete validation, including product analysis of heavier hydrocarbons, is required.

A 1D steady-state mathematical model (solved by MATLAB) was developed by Luz et al. (2018b) to simulate fast pyrolysis of spent coffee grounds in a shaftless screw reactor. The model can predict the temperature profile and the product distribution. The gas and solid temperatures predicted by the model were in good agreement with the experimental values. The highest bio-oil yield was obtained around a temperature of 500 ${ }^{\circ} \mathrm{C}$. Further, the model had a higher sensitivity to the wall temperature and the gas-solid heating rate. The extended work of this model was presented by Luz et al. (2018a) for fast pyrolysis of spruce wood in a shaftless screw reactor. This model showed that model predictions are highly sensitive to screw geometry also. Trendewicz et al. (2014) built a 1D model to simulate the steady-state operation of fast pyrolysis of four different biomass types (pine, wheat straw, olive husks, and organic fraction of municipal solid waste; OFMSW) in a circulating fluidized-bed reactor. This model can simply be integrated with a plant system model. It was observed that $99 \%$ of biomass conversion was achieved within $0.9 \mathrm{~s}$ upon increasing the pyrolysis temperature to $513{ }^{\circ} \mathrm{C}$ in $0.3 \mathrm{~s}$. The model-predicted pyrolysis product yield was compared with the literature data, and the model predictions were in good agreement despite water yield being underpredicted. Further, fluid dynamics and heat transfer results predicted by this 1D model were compared with a more precise 2D transient reactor model, and a reasonable agreement was found between the flow patterns of the two models with an average relative error of $10 \%$ for the gas velocities. However, the model-predicted solid velocities had a larger error due to the neglect of particle clustering.

Vortex reactors are perceived to be an efficient reactor configuration for commercial-scale production of condensable tars from biomass pyrolysis. In vortex pyrolysis, a cylindrical reactor undergoes a centrifugal acceleration caused by a strongly swirling flow of superheated steam, making the injected biomass particles come into contact with the hightemperature outer wall. The produced tars and gases are subsequently 
Table 7.

Slow pyrolysis reactor models developed for waste biomass.

\begin{tabular}{|c|c|c|c|c|}
\hline \multirow{2}{*}{ Biomass source } & \multirow{2}{*}{ Kinetic Model } & \multicolumn{2}{|c|}{ Reactor/particle model } & \multirow{2}{*}{ - Reference } \\
\hline & & Reactor type and model description & Main simplifying assumptions & \\
\hline
\end{tabular}

Olive stone

Table 5; No 1

The proposed model integrates the Lump Capacitance Method (LCM) with the simplified distributed activation energy model (DAEM). A bubbling fluidized bed reactor was simulated by this combined LCM-DAEM model.

A 1D mathematical model was developed for a bellshaped Pyrex reactor. The first-order up-winding

Wood waste

(Norwegian birch, pine, Table 5; No 3 and spruce) scheme was used to discretize the convective terms, while a central differencing scheme was employed to discretize the diffusive terms. The numerical code DASSL was employed to achieve the numerical solution.
Wood waste

(Spruce and pine wood)
A 1D model with transient differential conservation equations was proposed.

\section{Wood waste (Softwood) Table 5: No 5}

Agriculture waste (Banana waste)

A steady-state simulation model by Aspen Plus ${ }^{\circledR}$ v8.8 was proposed for banana waste pyrolysis. In this model, RYIELD and RGIBBS reactors were integrated. The former was used to convert the feedstock to conventional simulation components such as hemicellulose, cellulose, lignin, water, and ash, while the latter was employed to calculate chemical and phase of heat transfer (conduction, convection, and radiation) was proposed for wood pyrolysis in a fixed bed reactor
Table 5: No 7 equilibrium based on the Gibbs free energy minimization method. Further, the stream class, enthalpy, and density property methods used respectively are MIXCINC, HCOALGEN, and DGOALIGT.

A steady-state model for pyrolysis of municipal green waste in a rotary furnace was modeled by Aspen Plus. The model consists of four stages for drying, decomposition into elemental constituents, separation of volatile components, and pyrolysis, which were respectively modeled by RSTOIC, RYIELD, SEP2, and RGIBBS blocks. Further, enthalpy and density calculations were done by HCOALGEN and DCOALIGT models.

A semi-empirical model was developed for pyrolysis of sawdust in an annular packed bed. The numerical model was coded in a FORTRAN program.

A 1D model was developed for slow pyrolysis of sesame oil cake under isothermal conditions in a semibatch pyrolyzer (fixed bed reactor). A lumped paramete model is used to predict isothermal kinetics. The numerical solution was achieved by using MATLAB

A three-layer ANN model was developed for the pyrolysis of sawdust. The model combined the pyrolysis of sawdust. The model combined the
Levenberg-Marquardt training algorithm with a target sigmoid transfer function.
The developed combined LCM-DAEM model assumes a thermally small particle which means the Biot number is very small.

Bed shrinkage is neglected. All the phases are assumed to be at the same temperature, and the partial pressure of vapor is at its equilibrium pressure. Wood shrinkage and crack formation are not omitted. Diffusion in the gas phase is negligible. Solid properties are linearly varied based on the wood and char composition.

Particles consist of solid, inert, gaseous, and liquid phases, and thermal equilibrium is assumed between the phases. The gas phase is assumed to obey the equation of state. Both the convective and diffusive transport in the gas phase is considered. Transport properties are spatially resolved for diffusion and conduction inside a particlebased on local composition.

The intraparticle processes such as diffusion and filter of the vapor-gas mixture are assumed to have negligible impact on the pyrolysis product yield owing to the small particle sizes. Ideal mixing is assumed in the solid phase. The gas-phase obeys the equation of state. Thermochemical properties are assumed to vary with

This model is a steady-state and isothermal model by using a sequential-modular calculation technique. The influence of feedstock particle size distribution on biomass energy recovery is negligible. All feedstock moisture in the assumed that all feedstock Sulphur is organic Sulphur. Char is assumed to be composed of solids alone. All elements excluding ash are assumed to take part in chemical reactions.

The Rosseland approximation presented in Incropera and Dewitt (1990) is used to model the radiation heat transfer Specific heat of the species is determined by using the model suggested by Grønli and Melaaen (2000). The bed porosity variation is determined by the correlation presented in Winterberg and Tsotsas (2000).

Steady-state operation under isobaric conditions and kinetic free equilibrium models are assumed. All sulfur converts to $\mathrm{H}_{2} \mathrm{~S}$. The formation of oxides of nitrogen is negligible.

Other types of heat transfer except for the conduction are neglected. The flow of volatiles is neglected. Chemical reactions are assumed to be pseudo-first-order reactions. The residence time of volatiles is not considered, and hence secondary reactions are neglected. The bed volume remains constants. The heat of pyrolysis and the latent heat of vaporization of moisture are neglected.

All reactions are assumed to be first-order irreversible. The reactor is operated at isothermal conditions. The packed bed is considered as two subsystems, i.e., gas phase an solid matrix. The volatiles cracking only takes place in the gas-phase, and gaseous products of tar cracking do not interact with each other. The diffusivity of tar is assumed to be similar to that of Guaiacol. respect to the proportion of reacted wood. biomass transfers to either bio-oil or gasses produced. It is
Soria-Verdugo et al. (2020)

\section{Grønli and Melaaen}

(2000) 
Table 8.

Fast/flash pyrolysis kinetic models which were already employed or have potential in reactor modeling for waste biomass.

\begin{tabular}{|c|c|c|c|c|c|c|c|c|}
\hline \multirow{2}{*}{ No } & \multirow{2}{*}{ Biomass source } & \multirow{2}{*}{$\begin{array}{l}\text { Temperature } \\
\text { range }\left({ }^{\circ} \mathrm{C}\right)\end{array}$} & \multirow{2}{*}{ Proposed reaction mechanism/model } & \multicolumn{4}{|c|}{ Kinetic parameters } & \multirow[b]{2}{*}{ Reference } \\
\hline & & & & $A\left(s^{-1}\right)$ & $\begin{array}{c}\mathbf{E}_{\mathrm{a}} \\
\left(\mathbf{k J} \mathrm{mol}^{-1}\right)\end{array}$ & $\mathbf{n}$ & $\mathbf{m}$ & \\
\hline \multirow{4}{*}{1} & \multirow{4}{*}{ Cellulose } & \multirow{4}{*}{$430-515$} & Cellulose $\rightarrow$ Cellulose $e^{* 1}$ & $4.00 \times 10^{13}$ & 188.4 & 1 & 0 & \multirow{4}{*}{$\begin{array}{l}\text { Eri et al. } \\
(2017)\end{array}$} \\
\hline & & & $\begin{aligned} \text { Cellulose }^{*} \rightarrow 0.8 \mathrm{HAA}+ & 0.2 \mathrm{GLYOX}+0.1 \mathrm{CH}_{3} \mathrm{CHO} \\
& +0.25 \mathrm{HMFU}+0.3 \mathrm{C}_{3} \mathrm{H}_{6} \mathrm{O} \\
& +0.21 \mathrm{CO}_{2}+0.1 \mathrm{H}_{2}+0.4 \mathrm{CH}_{2} \mathrm{O} \\
& +0.16 \mathrm{CO}+0.83 \mathrm{H}_{2} \mathrm{O}+0.02 \mathrm{HCOOH} \\
& +0.61 \mathrm{Char}\end{aligned}$ & $3.78 \times 10^{9}$ & $100.16[\mathrm{~K}]^{0.0168}$ & 1 & 0 & \\
\hline & & & Cellulose $^{*} \rightarrow L V G$ & $2.61 \times 10^{9}$ & $118.99[\mathrm{~K}]^{0.056}$ & 1 & 0 & \\
\hline & & & $\mathrm{CELL} \rightarrow 6 \mathrm{Char}+\mathrm{H}_{2} \mathrm{O}+2 \mathrm{CO}+\mathrm{CO}_{2}+4 \mathrm{H}_{2}$ & $2.00 \times 10^{9}$ & $124.52[\mathrm{~K}]^{0.03}$ & 1 & 0 & \\
\hline \multirow{2}{*}{2} & Rice husk & $700-1000$ & Biomass $\rightarrow$ Char + Volatiles & $9.28 \times 10^{1}$ & 35.67 & 1 & 0 & \multirow{2}{*}{$\begin{array}{l}\text { Sun et al. } \\
(2010)\end{array}$} \\
\hline & Saw dust & $700-1000$ & Biomass $\rightarrow$ Char + Volatiles & $8.06 \times 10^{1}$ & 32.59 & 1 & 0 & \\
\hline \multirow{10}{*}{3} & \multirow{10}{*}{ Waste biomass } & \multirow{10}{*}{$550-1200$} & Cellulose $\rightarrow$ Cellulose ${ }^{*}$ & $2.80 \times 10^{19}$ & 242.40 & 1 & 0 & \multirow{10}{*}{$\begin{array}{l}\text { Miller and } \\
\text { Bellan } \\
(1997)\end{array}$} \\
\hline & & & Cellulose $^{*} \rightarrow$ Char + Gas $_{1}$ & $1.30 \times 10^{10}$ & 150.50 & 1 & 0 & \\
\hline & & & Cellulose ${ }^{*} \rightarrow$ Tar & $3.28 \times 10^{14}$ & 196.50 & 1 & 0 & \\
\hline & & & Hemicellulose $\rightarrow$ Hemicellulose ${ }^{*}$ & $2.10 \times 10^{16}$ & 186.70 & 1 & 0 & \\
\hline & & & Hemiellulose $^{*} \rightarrow$ Char + Gas $_{1}$ & $2.60 \times 10^{11}$ & 145.70 & 1 & 0 & \\
\hline & & & Hemicellulose $e^{*} \rightarrow$ Tar & $8.75 \times 10^{15}$ & 202.40 & 1 & 0 & \\
\hline & & & Lignin $\rightarrow$ Lignin $*$ & $9.60 \times 10^{8}$ & 107.60 & 1 & 0 & \\
\hline & & & Lignin $^{*} \rightarrow$ Char + Gas $_{1}$ & $7.70 \times 10^{6}$ & 111.40 & 1 & 0 & \\
\hline & & & Lignin $^{*} \rightarrow$ Tar & $1.50 \times 10^{9}$ & 143.80 & 1 & 0 & \\
\hline & & & Tar $\rightarrow \mathrm{Gas}_{2}$ & $4.28 \times 10^{6}$ & 108.00 & 1 & 0 & \\
\hline \multirow{4}{*}{4} & \multirow{4}{*}{ Pine, Wheat straw } & \multirow{4}{*}{$475-600$} & Biomass $\rightarrow I L C$ & $2.80 \times 10^{19}$ & 206.00 & 1 & 0 & \multirow{4}{*}{$\begin{array}{l}\text { Bech et al. } \\
(2009)\end{array}$} \\
\hline & & & $I L C \rightarrow$ Organics & $6.79 \times 10^{9}$ & 140.00 & 1 & 0 & \\
\hline & & & $I L C \rightarrow \alpha_{\text {Gas }}$ Gas $+\left(1-\alpha_{\text {Gas }}\right)$ Char & $1.30 \times 10^{10}$ & 150.00 & 1 & 0 & \\
\hline & & & Organics $\rightarrow$ Gas & $4.30 \times 10^{6}$ & 108.00 & 1 & 0 & \\
\hline \multirow{8}{*}{5} & \multirow{8}{*}{$\begin{array}{l}\text { Softwood (pine \& } \\
\text { spruce), Hardwood }\end{array}$} & \multirow{8}{*}{$100-700$} & Cellulose $\rightarrow$ Cellulose $e^{*}$ & $8.00 \times 10^{13}$ & 46.00 & 1 & 0 & \multirow{8}{*}{$\begin{array}{l}\text { Ranzi et al. } \\
(2008)\end{array}$} \\
\hline & & & $\begin{aligned} \text { Cellulose }^{*} \rightarrow 0.95 \mathrm{HAA} & +0.25 \text { Glyoxal }+0.20 \mathrm{CH}_{3} \mathrm{CHO} \\
& +0.25 \mathrm{HMFU}+0.20 \mathrm{C}_{3} \mathrm{H}_{6} \mathrm{O} \\
& +0.20 \mathrm{CO}_{2}+0.1 \mathrm{H}_{2}+0.1 \mathrm{CH}_{4} \\
& +0.15 \mathrm{CO}+0.9 \mathrm{H}_{2} \mathrm{O}+0.65 \mathrm{Char}\end{aligned}$ & $1.00 \times 10^{9}$ & 30.00 & 1 & 0 & \\
\hline & & & Cellulose $^{*} \rightarrow L V G$ & 4.00 & 10.00 & 1 & 1 & \\
\hline & & & $\mathrm{CELL} \rightarrow 6 \mathrm{Char}+5 \mathrm{H}_{2} \mathrm{O}$ & $8.00 \times 10^{7}$ & 32.00 & 1 & 0 & \\
\hline & & & Hemicellulose $\rightarrow 0.4$ Hemicellulose ${ }^{* 1}+0.6$ Hemicellulose $e^{* 2}$ & $1.00 \times 10^{10}$ & 31.00 & 1 & 0 & \\
\hline & & & $\begin{aligned} \text { Hemicellulose }^{* 1} \rightarrow 2.5 & \mathrm{H}_{2}+0.125 \mathrm{H}_{2} \mathrm{O}+\mathrm{CO}+0.5 \mathrm{CH}_{2} \mathrm{O} \\
& +0.25 \mathrm{CH}_{3} \mathrm{OH}+0.125 \mathrm{C}_{2} \mathrm{H}_{5} \mathrm{OH} \\
& +2 \mathrm{Char}\end{aligned}$ & $3.00 \times 10^{9}$ & 27.00 & 1 & 0 & \\
\hline & & & Hemicellulose $e^{* 1} \rightarrow$ Xylose & 3.00 & 11.00 & 1 & 1 & \\
\hline & & & $\begin{aligned} \text { Hemicellulose }^{* 2} \rightarrow 1.5 & \mathrm{H}_{2}+0.125 \mathrm{H}_{2} \mathrm{O}+0.2 \mathrm{CO}_{2} \\
& +0.7 \mathrm{CH}_{2} \mathrm{O}+0.25 \mathrm{CH}_{3} \mathrm{OH} \\
& +0.125 \mathrm{C}_{2} \mathrm{H}_{5} \mathrm{OH}+0.8 \mathrm{G}\left\{\mathrm{CO}_{2}\right\} \\
& \left.+0.8 \mathrm{G} \mathrm{COH}_{2}\right\}+2 \mathrm{Char}\end{aligned}$ & $1.00 \times 10^{10}$ & 33.00 & 1 & 0 & \\
\hline
\end{tabular}

Please cite this article as: Perera S.M.H.D., Wickramasinghe C., Samarasiri B.K.T., Narayana M. Modeling of thermochemical conversion of waste biomass a comprehensive review. Biofuel Research Journal 32 (2021) 1481-1528. DOI: 10.18331/BRJ2021.8.4.3 
Table 8.

Continued.

\begin{tabular}{|c|c|c|c|c|c|c|c|c|}
\hline \multirow[b]{2}{*}{ No } & \multirow[b]{2}{*}{ Biomass source } & \multirow{2}{*}{$\begin{array}{l}\text { Temperature } \\
\text { range }\left({ }^{\circ} \mathrm{C}\right)\end{array}$} & \multirow[b]{2}{*}{ Proposed reaction mechanism/model } & \multicolumn{4}{|c|}{ Kinetic parameters } & \multirow[b]{2}{*}{ Reference } \\
\hline & & & & $A\left(s^{-1}\right)$ & 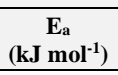 & $\mathbf{n}$ & $\mathbf{m}$ & \\
\hline & & & $\begin{aligned} \text { Lignin }_{C} \rightarrow 0.35 \text { Lignin }_{C C} & +0.1 \text { pCoumaryl }+0.08 \text { Phenol } \\
& +1.49 \mathrm{H}_{2}+\mathrm{H}_{2} \mathrm{O}+1.32 \mathrm{G}\left\{\mathrm{COH}_{2}\right\} \\
& +7.05 \text { Char }\end{aligned}$ & $4.00 \times 10^{15}$ & 48.50 & 1 & 0 & \\
\hline & & & Lignin $_{H} \rightarrow$ Lignin $_{O H}+\mathrm{C}_{3} \mathrm{H}_{6} \mathrm{O}$ & $2.00 \times 10^{13}$ & 37.50 & 1 & 0 & \\
\hline & & & Lignin $_{O} \rightarrow$ Lignini $_{\mathrm{OH}}+\mathrm{CO}_{2}$ & $1.00 \times 10^{9}$ & 25.50 & 1 & 0 & \\
\hline & & & $\begin{array}{l}\text { Lignin }_{\mathrm{CC}} \rightarrow 0.3 \text { pCoumaryl }+0.2 \mathrm{Phenol}+0.35 \mathrm{C}_{3} \mathrm{H}_{4} \mathrm{O}_{2}+ \\
\left.1.2 \mathrm{H}_{2}+0.7 \mathrm{H}_{2} \mathrm{O}+0.25 \mathrm{CH}_{4}+0.25 \mathrm{C}_{2} \mathrm{H}_{4}+1.3 \mathrm{G}_{2} \mathrm{COH}_{2}\right\}+ \\
0.5 \mathrm{G}\{\mathrm{CO}\}+7.5 \text { Char }\end{array}$ & $5.00 \times 10^{6}$ & 31.50 & 1 & 0 & \\
\hline & & & $\begin{array}{l}\text { Lignin }_{\mathrm{OH}} \rightarrow \text { Lignin }^{*}+0.5 \mathrm{H}_{2}+\mathrm{H}_{2} \mathrm{O}+\mathrm{CH}_{3} \mathrm{OH}+\mathrm{G}\{\mathrm{CO}\}+ \\
\left.1.5 \mathrm{G} \mathrm{COH}_{2}\right\}+5 \text { Char }\end{array}$ & $1.00 \times 10^{13}$ & 49.50 & 1 & 0 & \\
\hline & & & Lignin $^{*} \rightarrow \mathrm{C}_{11} \mathrm{H}_{12} \mathrm{O}_{4}$ & $8.00 \times 10^{1}$ & 12.00 & 1 & 1 & \\
\hline & & & $\begin{aligned} \text { Lignin }^{*} \rightarrow 0.7 \mathrm{H}_{2}+\mathrm{H}_{2} \mathrm{O} & +0.2 \mathrm{CH}_{2} \mathrm{O}+0.5 \mathrm{CO}+0.2 \mathrm{CH}_{2} \mathrm{O} \\
& +0.4 \mathrm{CH}_{3} \mathrm{OH}+0.2 \mathrm{CH}_{3} \mathrm{CHO} \\
& +0.2 \mathrm{C}_{3} \mathrm{H}_{6} \mathrm{O}_{2}+0.4 \mathrm{CH}_{4}+0.5 \mathrm{C}_{2} \mathrm{H}_{4} \\
& \left.+\mathrm{G}\{\mathrm{CO}\}+0.5 \mathrm{G} \mathrm{COH}_{2}\right\}+6 \mathrm{Char}^{2}\end{aligned}$ & $1.20 \times 10^{9}$ & 30.00 & 1 & 0 & \\
\hline & & & $G\left\{\mathrm{CO}_{2}\right\} \rightarrow \mathrm{CO}_{2}$ & $1.00 \times 10^{5}$ & 24.00 & 1 & 0 & \\
\hline & & & $G\{C O\} \rightarrow C O$ & $1.00 \times 10^{13}$ & 50.00 & 1 & 0 & \\
\hline & & & $G\left\{\mathrm{COH}_{2}\right\} \rightarrow \mathrm{CO}+\mathrm{H}_{2}$ & $5.00 \times 10^{11}$ & 65.00 & 1 & 0 & \\
\hline \multirow{8}{*}{6} & Forest residue & $800-1200$ & At Low T, Biomass $\rightarrow \alpha_{1}$ Volatiles $_{1}+\left(1-\alpha_{1}\right)$ Residue $_{1}$ & $3.63 \times 10^{4}$ & 22.20 & 1 & 0 & \multirow{8}{*}{$\begin{array}{l}\text { Li et al. } \\
(2015)\end{array}$} \\
\hline & & & At High T, Biomass $\rightarrow \alpha_{2}$ Volatiles $_{2}+\left(1-\alpha_{2}\right)$ Residue $_{2}$ & $3.68 \times 10^{9}$ & 62.90 & 1 & 0 & \\
\hline & Torrefied forest & $800-1200$ & At Low T, Biomass $\rightarrow \alpha_{1}$ Volatiles $_{1}+\left(1-\alpha_{1}\right)$ Residue $_{1}$ & $6.01 \times 10^{5}$ & 48.10 & 1 & 0 & \\
\hline & residue & & At High T, Biomass $\rightarrow \alpha_{2}$ Volatiles $_{2}+\left(1-\alpha_{2}\right)$ Residue $_{2}$ & $1.53 \times 10^{9}$ & 91.00 & 1 & 0 & \\
\hline & \multirow{2}{*}{$\begin{array}{l}\text { Norwegian } \\
\text { spruce }\end{array}$} & \multirow{2}{*}{$800-1200$} & At Low T, Biomass $\rightarrow \alpha_{1}$ Volatiles $_{1}+\left(1-\alpha_{1}\right)$ Residue $_{1}$ & $5.80 \times 10^{3}$ & 18.00 & 1 & 0 & \\
\hline & & & At High T, Biomass $\rightarrow \alpha_{2}$ Volatiles $_{2}+\left(1-\alpha_{2}\right)$ Residue $_{2}$ & $2.55 \times 10^{8}$ & 55.70 & 1 & 0 & \\
\hline & \multirow{2}{*}{$\begin{array}{l}\text { Torrefied Norwegian } \\
\text { spruce }\end{array}$} & \multirow{2}{*}{$800-1200$} & At Low T, Biomass $\rightarrow \alpha_{1}$ Volatiles $_{1}+\left(1-\alpha_{1}\right)$ Residue $_{1}$ & $2.33 \times 10^{5}$ & 43.30 & 1 & 0 & \\
\hline & & & At High T, Biomass $\rightarrow \alpha_{2}$ Volatiles $_{2}+\left(1-\alpha_{2}\right)$ Residue $_{2}$ & $1.75 \times 10^{8}$ & 81.70 & 1 & 0 & \\
\hline
\end{tabular}

1: Cellulose*: active cellulose, Hemicellulose*: active hemicellulose, Lignin*: active lignin.

removed through a central exit pipe of the reactor while partially pyrolyzed products are re-circulated back to the reactor. Miller and Bellan (1998) developed a detailed mathematical model to simulate the steady-state wood pyrolysis in a vortex reactor. The model results revealed that the optimal reactor wall temperature corresponding to the maximum tar yield (about 80\%) is around $627{ }^{\circ} \mathrm{C}$. Further, higher tar yield was observed for feedstock with high lignin content. The fragmentation sub-model employed in the study used an estimated critical porosity and hence experimentally found that actual values would further increase the model accuracy. Bech et al. (2009) developed a transient state model to simulate solid-convective flash pyrolysis of straw and wood in a centrifuge reactor. The model is based on the concept for ablative pyrolysis in which biomass decomposes into an intermediate liquid compound that is then degraded to form tar, char, and gas. It considers the limiting case that a reacting particle continuously peels the formed char layer. Even though the ablative degradation is not satisfied in a real case, the model prediction adequately agreed with the experimental results, thus making it suitable to model flash pyrolysis processes. The model can predict the product yield, and it further considered the catalytic effect of alkali-containing ash for straw. The study revealed that the ash constituents have a greater impact on the kinetics, and hence the model accuracy can further be improved by determining more realistic kinetics.

A CFD model by Fluent software to simulate flash pyrolysis of rice husk and sawdust in an entrained flow reactor in the temperature range of 700$1000{ }^{\circ} \mathrm{C}$ was developed by Sun et al. (2010). The study confirmed that the temperature had a large impact on the pyrolysis reactions, and an increase in temperature increased the gas yield while reducing the char and bio-oil yields. The model can predict the product yield and distribution as well as the mass loss. The model predictions for gas yield were reasonably agreed with the experimental data. The optimal gas yield was identified to be between $800-900{ }^{\circ} \mathrm{C}$, and the energy conversion efficiency was at the maximum at $900{ }^{\circ} \mathrm{C}$. Li et al. (2015) developed a simplified 3D CFD model based on the Eulerian-Lagrangian approach by Ansys Fluent 14.0 to simulate the biomass devolatilization in a drop-tube reactor under high heating rate conditions. The model results showed that the particle temperature is strongly dependent on the particle diameter, and the torrefied biomass particles gain higher initial temperatures than the non-torrefied biomass particles since torrefied biomass particles need lesser drying time. It was identified that the overall conversion process for torrefied biomass is longer than for non-torrefied biomass, and consequently, a reactor with a larger dimension is required. Further, the study revealed that rapid devolatilization causes an extensive fragmentation of biomass. This model can be upgraded by considering nonspherical particles, particle shrinkage, and fragmentation. The above reactor models for fast/flash pyrolysis with their basic assumptions and modeling techniques are listed in Table 9. 
Table 9.

Fast/flash pyrolysis reactor models developed for waste biomass.

\begin{tabular}{|c|c|c|}
\hline Biomass source & Kinetic Model & Reactor/particle model \\
\hline
\end{tabular}

$\begin{array}{lll} & \\ & \begin{array}{l}\text { A CFD model by Fluent was developed for biomass flash } \\ \text { pyrolysis in an entrained flow reactor. This model includes a k } \\ \epsilon \text { model (as per Shih et al., 1995) and a P-1 radiation model (a } \\ \text { simplified form of the P-N model suggested by Siegel and } \\ \text { dust }\end{array} \quad \text { Table 8; No 2 saw } \\ & \begin{array}{l}\text { Howell (1992) to simulate the turbulent effect and the radiative } \\ \text { heat transfer. }\end{array}\end{array}$

$\begin{array}{lll} & \begin{array}{l}\text { A 1D steady-state numerical model was developed and solved } \\ \text { by MATLAB for fast pyrolysis in a shaftless screw reactor. A } \\ \text { reaction framework, including all modes of heat transfer } \\ \text { (conductive, convective, and radiative) based on four parallel } \\ \text { DAEMs, was employed in the model. Further, an axial } \\ \text { dispersion model is incorporated to simulate variable residence } \\ \text { times caused to stratification and undesired back mixing. }\end{array} \\ & \text { Table 8; No } 3 \quad\end{array}$

Spruce wood

Table 8; No 3

This research work is an extension of Luz et al. (2018a). The granular flow modeling basics in a CFD-DEM approach discussed by Cordiner et al. (2017) were used to evaluate the cold residence time distribution (RTD)

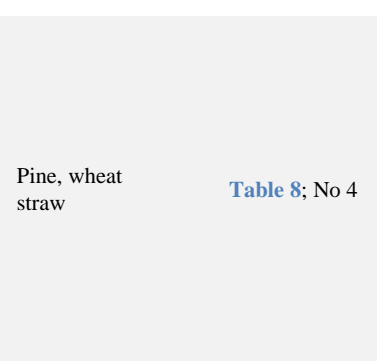

Softwoods (Scot

pine and spruce) Table 8; No 5 and beech

A mathematical model was developed for wood pyrolysi under flash heating rates in an entrained flow reactor. The model consists of three submodels, i.e., a kinetic model, a particle model, and a reactor model. The numerical solution was achieved by using the $\mathrm{C}++$ BzzDAE solver.

A 3D CFD model based on the Eulerian-Lagrangian approach was developed by Ansys Fluent 14.0 for rapid devolatilization of biomass in a drop-tube reactor. The turbulence and the radiation effects were modeled by using the discrete ordinates model and the standard $\mathrm{k}-\epsilon$ model.

A steady-state mathematical model is developed for biomass
Biomass is assumed to be composed of elements $\mathrm{C}, \mathrm{H}$, and $\mathrm{O}$ only. Only the gas-phase species such as $\mathrm{CO}, \mathrm{CO}_{2}, \mathrm{H}_{2}, \mathrm{CH}_{4}$, $\mathrm{C}_{2} \mathrm{H}_{4}$, tar (given as $\mathrm{CH}_{\mathrm{m}} \mathrm{O}_{\mathrm{n}}$ ), and $\mathrm{N}_{2}$ are considered in the model. Biomass particles are assumed spherical, and any fragmentation, attrition, or agglomeration of solids is neglected. No-slip between the particle and carrier gas. The gas is assumed to follow ideal gas laws. The distribution of particle size can be represented by the Rosin-Rammler equation. The scattering in the gas phase is neglected.

Ideal mixing is assumed between solid and gas phases in the radial direction, and hence gas and solid phase temperatures vary only in the z-direction. Solid particles are in variable sizes. The gas-phase consists of pyrolysis gas, tar, and inert and is assumed to follow ideal gas laws. Wall temperature is constant. Water vapor reactions with other species are insignificant for relatively small residence times and limited reactor operating temperatures.

The same assumptions as in Luz et al. (2018a) are applied here. $\quad \begin{aligned} & \text { Luz et al. } \\ & \text { (2018b) }\end{aligned}$

Wall temperature and particle density are constant. Intermediate liquid compound (ILC) formation is only considered to influence the particle degradation, while the split between products is determined by the particle surface temperature. The initial spatial temperature profile is considered uniform. Particles are symmetric. Convective heat transfer to the external surface is considered to be transported into the material by conduction. Variable heat transfer coefficient with respect to the particle characteristic length is considered. Particles are assumed to be indefinite. Compared to the latent heat, the heat of the reaction is insignificant. ILC is considered to be consumed immediately as it forms.

The solid residue is pure carbon. Biomass particles are considered to be spherical in shape and homogenous in composition. Perfect mixing inside the reactor is assumed. The gas velocity is assumed to be uniform inside the reactor.

Biomass particles are spherical and with constant diameter. The intra-particle heat and mass transfer are neglected. Pellet density instead of particle density is used in the simulation.

Particles are in the shape of parallelepipeds. Boundary conditions of the particles on the wall side are independent of the momentum equation. The convection coefficient is constant (20 W K-1). The pressure is constant. The vortex reactor flow thermally insulting. The particles are in sliding contact with the pyrolysis in a vortex reactor. The model consists of three submodels, i.e., the individual particle pyrolysis, the turbulent swirling flow, and the particle trajectories.

Pine, wheat straw, olive husks, and OFMSW

Table 8; No 5

A 1D steady-state model was developed for biomass fast pyrolysis in a circulating fluidized-bed reactor.

A mathematical model was developed for wood fast pyrolysis Wood waste in a fluidized bed reactor. is assumed axisymmetric. End walls are considered to be wall. The relative dimension of the particles in the transverse direction is constant. The coefficient of sliding friction is constant $(0.1)$.

Secondary reactions are neglected. Particles are assumed to be identical spheres. Physical properties are isotropic. Particle attrition and shrinkage are negligible. Intra-particle mass transport is considered to be no rate limiting.

Diffusion and filtration of the vapor-gas mixture in wood particles have an insignificant impact on the product yield. Ideal mixing is assumed. The gas-phase behaves like an ideal gas mixture.

Miller and Bellan (1998)

\section{Torrefaction}

\subsection{Torrefaction process}

Torrefaction, also known as mild pyrolysis or roasting, is typically carried out at temperatures between $200{ }^{\circ} \mathrm{C}$ and $300{ }^{\circ} \mathrm{C}$ using slow heating rates to either enhance the fuel properties of raw biomass or produce biochar for other applications (Chiou et al., 2018; Świechowski et al., 2019). Torrefied biomass, which is composed of a modified polymeric structure compared to the raw biomass, has better fuel properties such as low moisture content, higher heating value, lower volatile content, and better grindability (Chiou et al., 2018), making it suitable for direct usage as a fuel (Talero et al., 
2019a). Moreover, enhanced energy density and resistance to biological degradation make it more logistically economical. A significant mass loss occurs during torrefaction due to the volatilization of both condensable and non-condensable gases while maintaining a minimum loss of its energy content (Świechowski et al., 2019). Despite torrefaction being first introduced long ago, it has only gained popularity at the commercial level recently. In 2015, the estimated global production capacity of torrefied biomass was 450,000 tons per annum (Talero et al., 2019a).

As similar to pyrolysis, the torrefaction process is influenced by many process variables, which can be categorized into biomass characteristics (source, particle size, and composition, etc.), heating conditions (temperature, heating rate), and reaction atmosphere (pressure, reactor type, and geometry, etc.) (Shankar Tumuluru et al., 2011). According to the published literature (Eseltine et al., 2013; Peng et al., 2013), the solid mass yield achieved by torrefaction ranges from $50 \%$ to $90 \%$, usually accompanied by HHV between $16 \mathrm{MJ} \mathrm{kg}^{-1}$ to $29 \mathrm{MJ} \mathrm{kg}^{-1}$. However, the optimum conditions achieved are contingent upon the desired application of torrefied biomass (Chen et al., 2015b). Apart from the energy applications, biochar yielded from torrefaction is used in other important applications such as soil remediation, fertilizer production, activated carbon production, etc. It is also used as a sorbent material in water purification, methane fermentation, etc. (Turner et al., 2010; Kadem et al., 2011).

\subsection{Torrefaction principle}

Torrefaction can be explained as the removal of volatile compounds from the solid driven by heat application with comparatively slow rates in moderate temperatures $200-300{ }^{\circ} \mathrm{C}$. Owing to the removal of volatiles $\left(\mathrm{CO}_{2}, \mathrm{H}_{2}, \mathrm{CH}_{4}\right.$, $\mathrm{H}_{2} \mathrm{O}, \mathrm{CO}$, etc.), oxygen and hydrogen are removed from biomass, thus reducing oxygen-carbon $(\mathrm{O} / \mathrm{C})$ and hydrogen-carbon $(\mathrm{H} / \mathrm{C})$ ratios, leading to biochar (Van Der Stelt, 2010). From a chemical point of view, torrefaction is a fourstage process, as depicted in Figure 6. In the first stage, drying occurs evaporating unbound moisture present in biomass, and then macromolecules undergo depolymerization and recondensation reactions. As the temperature reaches around $180{ }^{\circ} \mathrm{C}$, devolatilization begins in the $3^{\text {rd }}$ stage, and then it gradually progresses into an extensive devolatilization and carbonization in the $4^{\text {th }}$ stage at temperatures over $250^{\circ} \mathrm{C}$ (Bates and Ghoniem, 2014).

\subsection{Kinetic modeling}

Prins et al. (2006) constructed a kinetic model based on the two-consecutive parallel reaction scheme for torrefaction of willow. In this model, biomass is first decomposed into active solid and primary volatiles, and then the active solid is converted to char and secondary volatiles in the second step. The study revealed that the fast reaction step contributes to a high solid yield, primarily representing the hemicellulose decomposition, whereas the slower second reaction step corresponds to cellulose decomposition and secondary charring. Bates and Ghoniem (2014) constructed a similar kinetic model for torrefaction of willow, incorporating drying into the model via a separate reaction, which activates upon reaching the boiling temperature. Nguyen et al. (2020) also developed a kinetic model based on the two-consecutive parallel reaction scheme to determine the isothermal kinetics for sewage sludge pyrolysis. The model revealed that the reaction rate constant for the sewage sludge in the first stage is higher than that of lignocellulosic biomass since it is less thermally resistant. The solid yield was comparatively higher for sewage sludge at torrefaction temperatures higher than $280{ }^{\circ} \mathrm{C}$ since woody biomass contained lower ash content. Yet again, Shang et al. (2013 and 2014) constructed kinetic models based on the two-consecutive parallel reaction scheme for pinewood and wheat straw, respectively. Both the models were well-agreed with the experimental data for a range of heating rates. Similar kinetic models were developed by Nikolopoulos et al. (2013) and Patuzzi et al. (2014) for wheat straw and common reed, respectively.

For the torrefaction of olive tree punning waste, Martín-Lara et al. (2017) developed a kinetic model based on the pseudo component independent parallel reaction scheme, including the moisture evaporation kinetics. The predictions of this pseudo-mechanistic model were in good agreement with the experimental data. A similar kinetic model was also developed by Perera et al. (2020) for torrefaction of urban biowaste. Talero et al. (2019b) developed a kinetic model based on a formal pseudo-component independent parallel $\mathrm{n}$ order reaction scheme for oil palm waste (empty fruit bunches and mesocarp fiber). The pseudo components include extractives as well as hemicellulose,

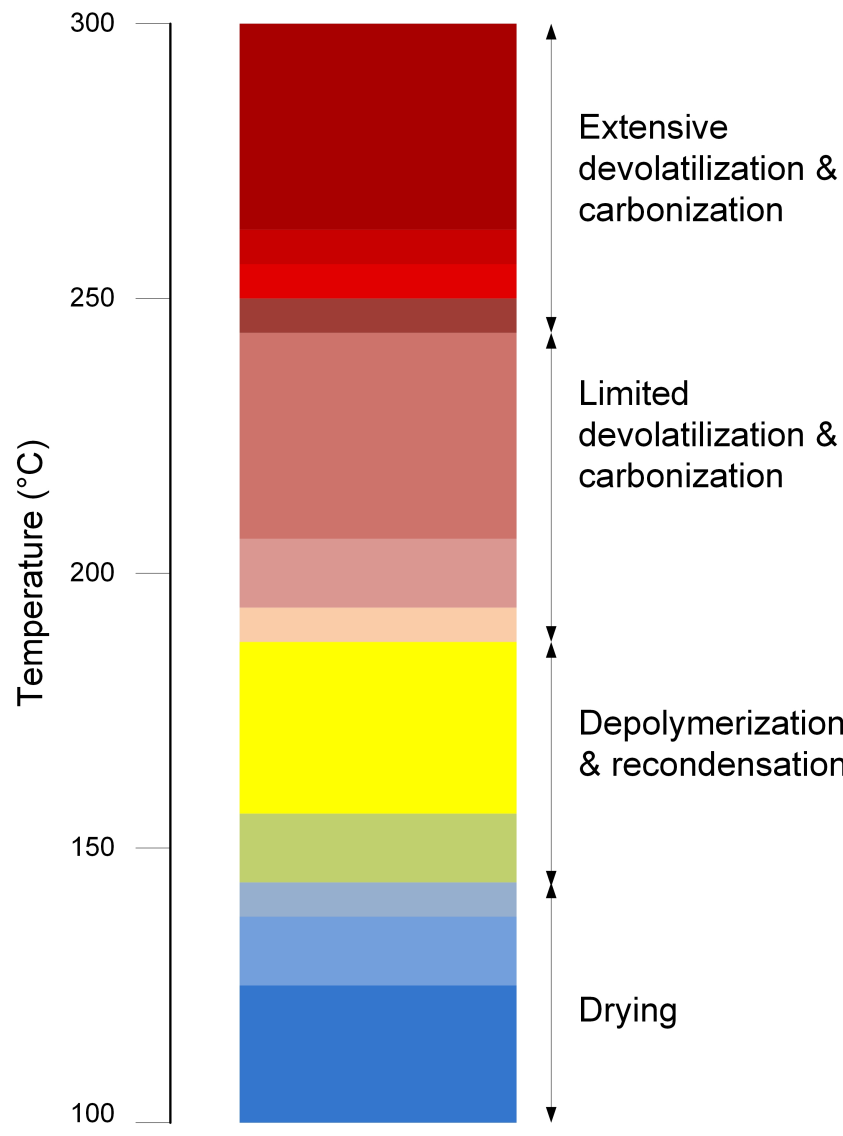

Fig. 6. Reaction stages of biomass torrefaction

cellulose, and lignin. The model-estimated kinetic parameters for empty fruit bunches and mesocarp were well-agreed with the experimental data with an error below 3\%. Further, the study confirmed that solid yield depends mainly on torrefaction temperature, and the residence time and heating rate have comparatively lesser influence. Harun et al. (2017) built two different kinetic models based on a two-consecutive parallel reaction scheme and a pseudo components independent parallel reaction scheme for torrefaction of oil palm empty fruit bunches in the temperature range of $240-270{ }^{\circ} \mathrm{C}$. In the latter approach, lignin is considered to be decomposed into char and volatiles in a single step, whereas hemicellulose decomposes as per the two-consecutive parallel reaction scheme. Cellulose is taken to be degraded via two parallel reactions to form tar and char, and volatiles, respectively.

Chiou et al. (2018) constructed four different kinetic models (based on single-step first-order reaction, single-step $\mathrm{n}^{\text {th }}$ order reaction, two consecutive reactions, single-step parallel reactions, and two consecutive parallel reactions schemes) for torrefaction of almond and walnut shells in the temperature range of $240-300{ }^{\circ} \mathrm{C}$. The study revealed that the decomposition rate was higher for almond shells due to the higher concentration of potassium which catalyzes degradation reactions. Overall, it was identified that the kinetic model based on the two consecutive paralle reactions was best fitted with the experimental data. The reaction mechanism and kinetic data of the above torrefaction kinetic models are listed in Table $\mathbf{1 0 .}$

\subsection{Reactor modeling}

In CFD modeling applications, models are primarily based on two methods, i.e., the Eulerian-Eulerian approach and the Eulerian-Lagrangian approach. The former approach considers the solid phase as a continuum which is comparatively simple, demanding significantly less computational 
Table 10.

Torrefaction kinetic models which were already employed or have potential in reactor modeling for waste biomass.

\begin{tabular}{|c|c|c|c|c|c|c|c|c|}
\hline \multirow[b]{2}{*}{ No. } & \multirow{2}{*}{ Biomass source } & \multirow{2}{*}{$\begin{array}{l}\text { Temperature } \\
\text { range }\left({ }^{\circ} \mathrm{C}\right)\end{array}$} & \multirow[b]{2}{*}{ Proposed reaction mechanism/model } & \multicolumn{4}{|c|}{ Kinetic parameters } & \multirow[b]{2}{*}{ Reference } \\
\hline & & & & $A\left(s^{-1}\right)$ & $\begin{array}{c}\mathbf{E}_{\mathrm{a}} \\
\left(\mathrm{kJ} \mathrm{mol}^{-1}\right) \\
\end{array}$ & $\mathbf{n}$ & $\mathbf{m}$ & \\
\hline \multirow{7}{*}{1} & \multirow{4}{*}{$\begin{array}{l}\text { Oil farm empty } \\
\text { fruit bunches }\end{array}$} & \multirow{4}{*}{$220-270$} & $\begin{array}{c}\text { Hemicellulos } \rightarrow \alpha_{\text {char }} \text { Char }+\alpha_{\mathrm{CO}} \mathrm{CO}+\alpha_{\mathrm{CO}_{2}} \mathrm{CO}_{2}+\alpha_{\mathrm{FV}} \mathrm{FV} \\
+\alpha_{\mathrm{H}_{2} \mathrm{O}} \mathrm{H}_{2} \mathrm{O}\end{array}$ & $4.55 \times 10^{10}$ & 133.3 & 1 & 0 & \multirow{7}{*}{$\begin{array}{l}\text { Talero et al. } \\
(2019 b)\end{array}$} \\
\hline & & & $\begin{aligned} \text { Cellulose } \rightarrow \alpha_{\text {char }} \text { Char }+ & \alpha_{\mathrm{CO}} \mathrm{CO}+\alpha_{\mathrm{CO}_{2}} \mathrm{CO}_{2}+\alpha_{F V} F V \\
& +\alpha_{\mathrm{H}_{2} \mathrm{O}} \mathrm{H}_{2} \mathrm{O}\end{aligned}$ & $6.51 \times 10^{14}$ & 189.4 & 1 & 0 & \\
\hline & & & Lignin $\rightarrow \alpha_{\text {char }}$ Char $+\alpha_{\mathrm{CO}} \mathrm{CO}+\alpha_{\mathrm{CO}_{2}} \mathrm{CO}_{2}+\alpha_{\mathrm{FV}} \mathrm{FV}+\alpha_{\mathrm{H}_{2} \mathrm{O}} \mathrm{H}_{2} \mathrm{O}$ & $3.79 \times 10^{7}$ & 109.5 & 3.1 & 0 & \\
\hline & & & $\begin{array}{c}\text { Extractives } \rightarrow \alpha_{\text {char }} \text { Char } \\
+\alpha_{C O} \mathrm{CO}+\alpha_{\mathrm{CO}_{2}} \mathrm{CO}_{2}+\alpha_{\mathrm{FV}} \mathrm{FV} \\
+\alpha_{\mathrm{H}_{2} \mathrm{O}} \mathrm{H}_{2} \mathrm{O}\end{array}$ & $1.40 \times 10^{9}$ & 108.8 & 1 & 0 & \\
\hline & \multirow{3}{*}{$\begin{array}{l}\text { Oil farm } \\
\text { mesocarp fibers }\end{array}$} & \multirow{3}{*}{$220-270$} & $\begin{array}{c}\text { Hemicellulos } \rightarrow \alpha_{\text {char }} \text { Char }+\alpha_{\mathrm{CO}} \mathrm{CO}+\alpha_{\mathrm{CO}_{2} \mathrm{CO}_{2}+\alpha_{F V} F V} \\
+\alpha_{\mathrm{H}_{2} \mathrm{O}} \mathrm{H}_{2} \mathrm{O}\end{array}$ & $4.59 \times 10^{10}$ & 133.5 & 1 & 0 & \\
\hline & & & $\begin{aligned} \text { Cellulose } \rightarrow \alpha_{\text {char }} \text { Char }+ & \alpha_{\mathrm{CO}} \mathrm{CO}+\alpha_{\mathrm{CO}_{2}} \mathrm{CO}_{2}+\alpha_{\mathrm{FV}} \mathrm{FV} \\
& +\alpha_{\mathrm{H}_{2} \mathrm{O}} \mathrm{H}_{2} \mathrm{O}\end{aligned}$ & $8.30 \times 10^{13}$ & 187.7 & 1 & 0 & \\
\hline & & & Lignin $\rightarrow \alpha_{\text {char }}$ Char $+\alpha_{\mathrm{CO}} \mathrm{CO}+\alpha_{\mathrm{CO}_{2}} \mathrm{CO}_{2}+\alpha_{F V} \mathrm{FV}$ & $3.94 \times 10^{7}$ & 109.5 & 3.1 & 0 & \\
\hline \multirow{4}{*}{2} & \multirow{4}{*}{$\begin{array}{l}\text { Olive tree } \\
\text { pruning }\end{array}$} & \multirow{4}{*}{$200-300$} & Moisture $\rightarrow$ Vapour & $4.64 \times 10^{9}$ & 74.55 & 6.99 & 0 & \multirow{4}{*}{$\begin{array}{l}\text { Martín- } \\
\text { Lara et al. } \\
\text { (2017) }\end{array}$} \\
\hline & & & Hemicellulose $\rightarrow \alpha_{\text {vol }}$ Volatiles $+\alpha_{\text {char }}$ Char & $3.53 \times 10^{12}$ & 151.65 & 3.90 & 0 & \\
\hline & & & Cellulose $\rightarrow \alpha_{v o l}$ Volatiles $+\alpha_{\text {char }}$ Char & $8.98 \times 10^{15}$ & 209.25 & 4.83 & 0 & \\
\hline & & & Lignin $\rightarrow \alpha_{v o l}$ Volatiles $+\alpha_{\text {char }}$ Char & $3.78 \times 10^{14}$ & 76.56 & 4.51 & 0 & \\
\hline \multirow{4}{*}{3} & \multirow{4}{*}{$\begin{array}{l}\text { Forest residue } \\
\text { (Willow) }\end{array}$} & \multirow{4}{*}{$225-300$} & Biomass $\rightarrow B^{*}$ & $2.48 \times 10^{4}$ & 75.98 & 1 & 0 & \multirow{4}{*}{$\begin{array}{l}\text { Prins et al. } \\
(2006)\end{array}$} \\
\hline & & & 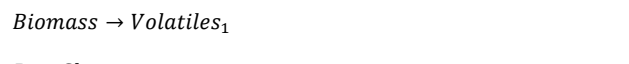 & $3.23 \times 10^{7}$ & 114.21 & 1 & 0 & \\
\hline & & & $B \rightarrow$ Char & $1.10 \times 10^{10}$ & 151.71 & 1 & 0 & \\
\hline & & & $B \rightarrow$ Volatiles $_{2}$ & $1.60 \times 10^{10}$ & 151.71 & 1 & 0 & \\
\hline \multirow{5}{*}{4} & \multirow{5}{*}{ Wood (Willow) } & \multirow{5}{*}{$250-300$} & Biomass $\rightarrow B$ & $2.48 \times 10^{4}$ & 75.98 & 1 & 0 & \multirow{5}{*}{$\begin{array}{l}\text { Bates and } \\
\text { Ghoniem } \\
(2014)\end{array}$} \\
\hline & & & 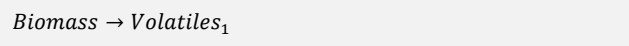 & $3.23 \times 10^{7}$ & 114.21 & 1 & 0 & \\
\hline & & & $B \rightarrow$ Char & $1.10 \times 10^{10}$ & 151.71 & 1 & 0 & \\
\hline & & & $B \rightarrow$ Volatiles $_{2}$ & $1.59 \times 10^{10}$ & 151.71 & 1 & 0 & \\
\hline & & & For T $>\mathrm{TB}$, Moisture $_{L} \rightarrow$ Moisture $_{V}$ & $4.50 \times 10^{3}$ & 45.00 & 1 & 0 & \\
\hline \multirow{4}{*}{5} & & & Biomass $\rightarrow B$ & $7.71 \times 10^{1}$ & 46.85 & 1 & 0 & \\
\hline & & & 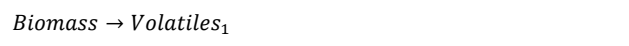 & $2.68 \times 10^{8}$ & 122.11 & 1 & 0 & \\
\hline & Wood (Pine) & $200-300$ & $B \rightarrow C$ & $1.00 \times 10^{-5}$ & 0.0061 & 1 & 0 & $\begin{array}{l}\text { Shang et al. } \\
\text { (2014) }\end{array}$ \\
\hline & & & $B \rightarrow$ Volatiles $_{2}$ & $5.75 \times 10^{4}$ & 94.40 & 1 & 0 & \\
\hline & & & Biomass $\rightarrow B$ & $3.48 \times 10^{4}$ & 70.99 & 1 & 0 & \\
\hline & & & 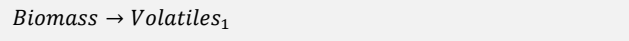 & $3.91 \times 10^{10}$ & 139.46 & 1 & 0 & \\
\hline 6 & Wheat straw & $250-300$ & $B \rightarrow C$ & $4.34 \times 10^{3}$ & 76.57 & 1 & 0 & $\begin{array}{l}\text { Shang et al. } \\
(2013)\end{array}$ \\
\hline & & & $B \rightarrow$ Volatiles $_{2}$ & $3.48 \times 10^{7}$ & 118.62 & 1 & 0 & \\
\hline & & & Biomass $\rightarrow \alpha_{B} B+\left(1-\alpha_{B}\right)$ Volatiles & $1.04 \times 10^{9}$ & 127.48 & 1 & 0 & \\
\hline & & & Biomass $\rightarrow \alpha_{B} B+\left(1-\alpha_{B}\right)$ Volatiles & $3.27 \times 10^{11}$ & 151.36 & 3 & 0 & \\
\hline & & & Biomass $\rightarrow \alpha_{B} B+\left(1-\alpha_{B}\right)$ Volatiles & $2.27 \times 10^{10}$ & 134.06 & 1 & 0 & \\
\hline & & & $B \rightarrow \alpha_{c} C+\left(1-\alpha_{c}\right)$ Volatiles & $4.18 \times 10^{19}$ & 246.29 & 1 & 0 & \\
\hline 7 & Almond shell & $240-300$ & Biomass $\rightarrow B$ & $2.52 \times 10^{-2}$ & 14.38 & 1 & 0 & Chiou et al. \\
\hline 1 & Amond stent & $240=500$ & Biomass $\rightarrow$ Volatiles & $3.32 \times 10^{4}$ & 80.98 & 1 & 0 & $(2018)$ \\
\hline & & & Biomass $\rightarrow B$ & $2.32 \times 10^{2}$ & 50.50 & 1 & 0 & \\
\hline & & & 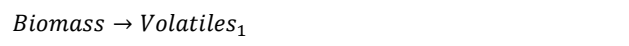 & $9.32 \times 10^{4}$ & 83.22 & 1 & 0 & \\
\hline & & & $B \rightarrow C$ & $2.43 \times 10^{4}$ & 82.18 & 1 & 0 & \\
\hline & & & $B \rightarrow$ Volatiles $_{2}$ & $4.43 \times 10^{10}$ & 153.59 & 1 & 0 & \\
\hline
\end{tabular}

Please cite this article as: Perera S.M.H.D., Wickramasinghe C., Samarasiri B.K.T., Narayana M. Modeling of thermochemical conversion of waste biomass a comprehensive review. Biofuel Research Journal 32 (2021) 1481-1528. DOI: 10.18331/BRJ2021.8.4.3 
Table 10.

Continued.

\begin{tabular}{|c|c|c|c|c|c|c|c|c|}
\hline \multirow[b]{2}{*}{ No } & \multirow[b]{2}{*}{ Biomass source } & \multirow{2}{*}{$\begin{array}{l}\text { Temperature } \\
\text { range }\left({ }^{\circ} \mathrm{C}\right)\end{array}$} & \multirow[b]{2}{*}{ Proposed reaction mechanism/model } & \multicolumn{4}{|c|}{ Kinetic parameters } & \multirow[b]{2}{*}{ Reference } \\
\hline & & & & $\mathbf{A}\left(\mathbf{s}^{-1}\right)$ & $\begin{array}{c}\mathbf{E}_{\mathrm{a}} \\
\left(\mathrm{kJ} \mathrm{mol}^{-1}\right) \\
\end{array}$ & $\mathbf{n}$ & $\mathbf{m}$ & \\
\hline \multirow{10}{*}{8} & \multirow{10}{*}{ Walnut shell } & \multirow{10}{*}{$240-300$} & Biomass $\rightarrow \alpha_{B} B+\left(1-\alpha_{B}\right)$ Volatiles & $5.03 \times 10^{6}$ & 105.94 & 1 & 0 & \multirow{10}{*}{$\begin{array}{l}\text { Chiou et al. } \\
(2018)\end{array}$} \\
\hline & & & Biomass $\rightarrow \alpha_{B} B+\left(1-\alpha_{B}\right)$ Volatiles & $2.57 \times 10^{8}$ & 123.20 & 3 & 0 & \\
\hline & & & Biomass $\rightarrow \alpha_{B} B+\left(1-\alpha_{B}\right)$ Volatiles & $2.15 \times 10^{7}$ & 104.60 & 1 & 0 & \\
\hline & & & $B \rightarrow \alpha_{c} C+\left(1-\alpha_{c}\right)$ Volatiles & $8.60 \times 10^{14}$ & 198.30 & 1 & 0 & \\
\hline & & & Biomass $\rightarrow B$ & $6.75 \times 10^{-4}$ & 0.23 & 1 & 0 & \\
\hline & & & Biomass $\rightarrow$ Volatiles & $7.22 \times 10^{2}$ & 67.67 & 1 & 0 & \\
\hline & & & Biomass $\rightarrow B$ & $1.13 \times 10^{3}$ & 61.14 & 1 & 0 & \\
\hline & & & 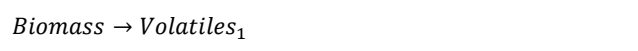 & $6.38 \times 10^{4}$ & 86.39 & 1 & 0 & \\
\hline & & & $B \rightarrow C$ & $1.75 \times 10^{6}$ & 106.46 & 1 & 0 & \\
\hline & & & $B \rightarrow$ Volatiles $_{2}$ & $4.63 \times 10^{10}$ & 158.25 & 1 & 0 & \\
\hline \multirow{11}{*}{9} & \multirow{11}{*}{$\begin{array}{l}\text { Oil palm empty } \\
\text { fruit bunches }\end{array}$} & \multirow{4}{*}{$240-270$} & Biomass $\rightarrow B$ & $4.26 \times 10^{1}$ & 34.00 & 1 & 0 & \multirow{11}{*}{$\begin{array}{l}\text { Harun et al. } \\
(2017)\end{array}$} \\
\hline & & & 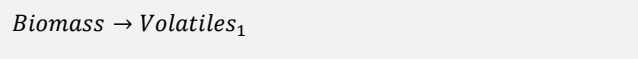 & $5.97 \times 10^{6}$ & 87.50 & 1 & 0 & \\
\hline & & & $B \rightarrow C$ & $5.18 \times 10^{10}$ & 39.40 & 1 & 0 & \\
\hline & & & $B \rightarrow$ Volatiles $_{2}$ & $1.26 \times 10^{3}$ & 25.60 & 1 & 0 & \\
\hline & & \multirow{7}{*}{$240-270$} & Lignin $\rightarrow$ Char $_{1}+$ Volatiles $_{1}$ & $6.70 \times 10^{6}$ & 102.43 & 1 & 0 & \\
\hline & & & Cellulose $\rightarrow$ Tar & $2.51 \times 10^{9}$ & 117.90 & 1 & 0 & \\
\hline & & & Cellulose $\rightarrow$ Char $_{2}+$ Volatiles $_{2}$ & $6.66 \times 10^{9}$ & 201.75 & 1 & 0 & \\
\hline & & & Hemicellulose $\rightarrow$ Intermediate & $4.26 \times 10^{1}$ & 0.066 & 1 & 0 & \\
\hline & & & Hemicellulose $\rightarrow$ Volatiles $_{3}$ & $1.10 \times 10^{7}$ & 91.40 & 1 & 0 & \\
\hline & & & Intermediate $\rightarrow \mathrm{Char}_{3}$ & $1.01 \times 10^{3}$ & 58.30 & 1 & 0 & \\
\hline & & & ${\text { Intermediate } \rightarrow \text { Volatiles }_{4}}$ & $1.09 \times 10^{4}$ & 52.60 & 1 & 0 & \\
\hline \multirow{4}{*}{10} & \multirow{4}{*}{ Sewage sludge } & \multirow{4}{*}{$220-300$} & Biomass $\rightarrow B$ & $9.81 \times 10^{7}$ & 81.83 & 1 & 0 & \multirow{4}{*}{$\begin{array}{l}\text { Nguyen et al. } \\
(2020)\end{array}$} \\
\hline & & & 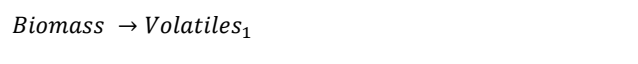 & $1.31 \times 10^{8}$ & 89.02 & 1 & 0 & \\
\hline & & & $B \rightarrow$ Char & $1.88 \times 10^{2}$ & 36.86 & 1 & 0 & \\
\hline & & & $B \rightarrow$ Volatiles $_{2}$ & $3.64 \times 10^{5}$ & 75.95 & 1 & 0 & \\
\hline \multirow{4}{*}{11} & \multirow{4}{*}{ Wheat straw } & \multirow{4}{*}{$240-300$} & Biomass $\rightarrow B$ & $3.27 \times 10^{-7}$ & 3.49 & 1 & 0 & \multirow{4}{*}{$\begin{array}{l}\text { Nikolopoulos } \\
\text { et al. (2013) }\end{array}$} \\
\hline & & & 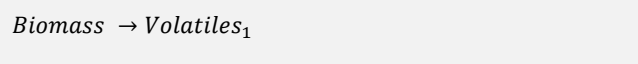 & $5.00 \times 10^{19}$ & 240.66 & 1 & 0 & \\
\hline & & & $B \rightarrow$ Char & $1.92 \times 10^{-2}$ & 15.89 & 1 & 0 & \\
\hline & & & $B \rightarrow$ Volatiles $_{2}$ & 84.79 & 56.29 & 1 & 0 & \\
\hline \multirow{4}{*}{12} & \multirow{4}{*}{ Common reed } & & Biomass $\rightarrow B$ & $2.6 \times 10^{4}$ & 69.70 & 1 & 0 & \\
\hline & & $175-300$ & 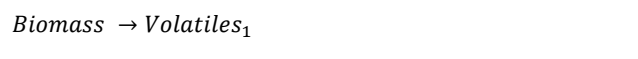 & $3.2 \times 10^{7}$ & 107.00 & 1 & 0 & Patuzzi et al. \\
\hline & & & $B \rightarrow$ Char & $1.1 \times 10^{10}$ & 150.00 & 1 & 0 & (2014) \\
\hline & & & $B \rightarrow$ Volatiles $_{2}$ & $1.60 \times 10^{10}$ & 150.00 & 1 & 0 & \\
\hline & & & Wet biomass $\rightarrow$ Dry biomass $+\mathrm{H}_{2} \mathrm{O}_{(g)}$ & $5.56 \times 10^{6}$ & 87.90 & 1 & 0 & \\
\hline 13 & OFMSW & $200-350$ & $\begin{array}{c}\text { Cellulose } \rightarrow \alpha_{1} \mathrm{C}+\alpha_{2} \mathrm{CO}+\alpha_{3} \mathrm{CO}_{2}+\alpha_{4} \mathrm{H}_{2}+\alpha_{5} \mathrm{CH}_{4} \\
+\alpha_{6} \mathrm{Ash}\end{array}$ & $1.38 \times 10^{14}$ & 193.00 & 1 & 0 & Perera et al. \\
\hline & & & $\begin{array}{c}\text { Polyose } \rightarrow \beta_{1} \mathrm{C}+\beta_{2} \mathrm{CO}+\beta_{3} \mathrm{CO}_{2}+\beta_{4} \mathrm{H}_{2}+\beta_{5} \mathrm{CH}_{4} \\
+\beta_{6} \text { Ash }\end{array}$ & $2.53 \times 10^{11}$ & 147.00 & 1 & 0 & $(2020)$ \\
\hline & & & Lignin $\rightarrow \gamma_{1} \mathrm{C}+\gamma_{2} \mathrm{CO}+\gamma_{3} \mathrm{CO}_{2}+\gamma_{4} \mathrm{H}_{2}+\gamma_{5} \mathrm{CH}_{4}+\gamma_{6}$ Ash & $2.20 \times 10^{12}$ & 181.00 & 1 & 0 & \\
\hline
\end{tabular}

* B: Intermediate solid, C: Solid residue. 
burden, while the latter approach treats the solid phase as a discrete phase, and hence each particle is tracked, making the model highly accurate. The latter approach is more suitable for modeling fluidized bed gasifier reactors. However, much higher accuracy achieved by the Eulerian-Lagrange approach might not be feasible considering its enormous computational burden. A 2D CFD model was developed by Talero et al. (2019a) to simulate torrefaction of oil palm solid residues in a standard retort under temperatures between $220-270{ }^{\circ} \mathrm{C}$ at residence time up to $60 \mathrm{~min}$. The model could predict product yields and fuel properties (moisture content and LHV) and found the optimal conditions for the best trade-off between the solid yield and the LHV to be respectively $272{ }^{\circ} \mathrm{C}$ and $282{ }^{\circ} \mathrm{C}$ for empty fruit bunches and fibers at a heating rate of $10{ }^{\circ} \mathrm{C} \mathrm{min}{ }^{-1}$ and a residence time of $30 \mathrm{~min}$. Further, the model revealed that the temperature distribution has more impact on the solid yield and suggested that the secondary pyrolysis reactions have lesser influence at temperatures below $270{ }^{\circ} \mathrm{C}$. The model predictions were compatible with the experimental data with a relative error below $3.1 \%$. The model accuracy can further be improved by considering inhomogeneity in solid yield caused due to the temperature distribution and the characteristic temperature gradients inside the fixed bed.

Patuzzi et al. (2014) developed a CFD model by Ansys Fluent to simulate torrefaction of common reed in a bench-scale reactor. The model can predict product yield and velocity, and temperature profiles inside the reactor. The model predictions were satisfactorily agreed with the experimental data, with the highest temperature deviation of approximately $10 \%$ in the ramp and the mass yield deviation less than $1 \%$. The model assumed that the biomass volume remained unchanged since the biomass bed was subjected to mild temperatures and hardly applied movements and friction. However, the model can further be improved by including the volume effect. Perera et al. (2020) built a 3D CFD model based on the Eulerian-Eulerian method by OpenFOAM software to simulate continuous torrefaction of urban biowaste in a packed bed reactor. The model can predict solid and gas phase temperature profiles over time, product yield, component mass fraction profiles over time, and gas velocity profiles over time. Further, the study investigated the optimum reactor geometry by performing a sensitivity analysis on reactor L/D ratio. The optimum biochar yield of $55.7 \%$ with an ash content of $19.1 \%$ was obtained when the gas inlet temperature, residence time, and reactor aspect ratio were respectively $573 \mathrm{~K}$, $13000 \mathrm{~s}$, and 24/6. The model predictions agreed with the experimental data for temperature profile and mass loss with deviation, which were $3.75 \%$ and under $1 \%$, respectively. This model can further be upgraded by including the particle size variations, bed shrinkage, and secondary reactions.

A simple polynomial model (based on the Akaike criterion) using raw data for torrefaction of Oxytree pruned biomass was constructed by Świechowski et al. (2019). The model can describe the effects of torrefaction temperature and residence time on the solid yield and its properties such as low heating value (LHV), HHV, ash content, and elemental composition $(\mathrm{C}, \mathrm{H}, \mathrm{O}, \mathrm{N}$ and $\mathrm{S}$ content). The model predictions were well agreed with the experimental data with the determination coefficient $\left(\mathrm{R}^{2}\right)$ exceeding 0.78 . The highest HHV of 21 $\mathrm{MJ} \mathrm{kg}{ }^{-1}$ was observed at a temperature around $300{ }^{\circ} \mathrm{C}$ under a residence time of $20 \mathrm{~min}$. Sukiran et al. (2020) constructed an empirical model by power model fitting based on the least-squares method to predict product yield, composition, HHV, and energy yield from torrefaction of oil palm empty fruit bunches in a fixed bed reactor at variable moisture contents and residence times at a temperature of $270{ }^{\circ} \mathrm{C}$. The study confirmed that torrefied mass yield, HHV, and energy yield increased with decreasing the moisture content. The empirical equations developed in the model accurately fitted the experimental data.

Nikolopoulos et al. (2013) developed a process model by Aspen Plus® software to simulate the torrefaction of wheat straw in both single batch and two-batch reactors. The model can predict gas and solid product compositions and mass-loss rate, and the model predictions were well-agreed with the experimental data. The study investigated the effects of torrefaction temperature and residence time to select the most optimal design parameters. In addition, the model provides useful information such as HHV and flow rates of the heating oil, nitrogen, and cooling water. However, this model does not include a complete heat transfer mechanism within the particle, and it is only valid in the temperature range of $240-300{ }^{\circ} \mathrm{C}$. Therefore, a more rigorous reactor model would be needed to resemble the actual process better. In a similar approach, Bach et al. (2017) developed a steady-state model by Aspen Plus ${ }^{\circledR}$ v8.8 to simulate the torrefaction of forest residue (birch branches). The model can predict a detailed distribution of products and ultimate analysis and heating value of the torrefied solid. The model predictions were in good agreement with experimental data. As with increasing the torrefaction temperature, the solid yield decreased while the heating value increased. Further, the model estimated the process energy efficiency, and it revealed that about $76-80 \%$ of the total heat demand was accounted for drying. The process energy efficiency was in a decline when the torrefaction temperature was increased. The optimal torrefaction conditions were identified to be around $275-278^{\circ} \mathrm{C}$ at a residence time of $30 \mathrm{~min}$. The above reactor models with the basic assumptions and modeling techniques are presented in Table 11.

\section{Gasification}

\subsection{Gasification process}

Gasification, in which biomass is combusted with insufficient oxygen to produce combustible gases or synthesis gas (syngas), also known as producer gas, is an attractive and flexible method of efficient energy extraction. Syngas, mainly composed of $\mathrm{CO}$ and $\mathrm{H}_{2}$ with relatively small amounts of $\mathrm{CO}_{2}, \mathrm{CH}_{4}, \mathrm{~N}_{2}$, light hydrocarbons, tar, char, ash, and trace amounts of oxygen and sulfur compounds, can be directly consumed as a gaseous fuel. It can also be utilized to produce electricity, heat, $\mathrm{H}_{2}$, liquid fuel and other value-added chemicals such as methanol, dimethyl ether, ethanol, methyl tert-butyl ether, etc. (Kuo et al., 2014; Dhanavath et al., 2018). Gasification is a promising technique in waste-to-energy applications considering the conversion efficiencies and hazardous emissions of other processes. For instance, gasification can achieve significantly higher conversion efficiencies up to $50 \%$ compared to combustion, which is usually in the range of $20-40 \%$ (Liu et al., 2013a). Any form of biomass, including loose forms such as sticks and large pieces, chips, pellets, briquettes, or powder, can be used as feedstock in the gasification (Keche et al., 2015). As per the perceived understanding, gasification is one of the most viable pathways for biomass to energy conversion. However, the requirement for feedstock preparation, which costs time, labor, and energy, is one drawback in the gasification process. Gasification can produce clean gas free from particulate matter and tar (Saravanakumar et al., 2010). The amount of tar present in the product gas affects the syngas quality and causes issues such as corrosion, clogging, and fouling in the downstream processes.

The overall performance of the gasification process, including the gas quality and the yield, is influenced by many factors such as gasification temperature, gasification agent, equivalence ratio (ER), gasifying agent to biomass ratio, biomass moisture content, feedstock characteristics, reactor design and configuration, incorporation of catalysts, etc. Gasifiers are usually conical in shape and have compact designs. They are integrated with gas cooling water jackets and filter units to remove ash and tar. There are several types of gasification technologies and gasifier configurations employed in the industry, such as fixed-bed reactors with the cross draft, downdraft and updraft modes, entrained flow reactors, moving bed reactors, and fluidized bed reactors, including circulating fluidized bed and bubbling fluidized bed reactors (Liu et al., 2013a). The common gasification agents are air, steam, and oxygen, and the process can be categorized based on the gasification agent as air gasification, oxygen-rich air gasification, oxygensteam, air steam gasification, etc. (Dhanavath et al., 2018). Moreover, the process efficiency can be further enhanced by the use of catalysts. For example, $\mathrm{H}_{2}$ composition is increased by adding $\mathrm{CaO}$, which favors the forward reaction of the water-gas shift (WGS) reaction (Cao et al., 2021).

In a gasifier, the temperature can range from moderate temperatures in the drying zone $\left(400{ }^{\circ} \mathrm{C}\right)$ to very high temperatures in the combustion zone $\left(1185^{\circ} \mathrm{C}\right)$ (Saravanakumar et al., 2010). Owing to the simplicity and low capital cost, fix bed gasifier is the most common reactor design. Fluidized bed gasifiers have excellent mass and heat transfer characteristics (Erguidenler et al., 1997; Dhanavath et al., 2018). On the other hand, entrained flow gasifiers are capable of producing tar-free syngas. However, they are operated at a comparatively higher pressure and temperature and require feed pretreatments such as size reduction and drying (Salman and Omer, 2020). Consequently, the selection of a reactor design is specific to a particular application and needs to consider many aspects such as efficiency, product yield and quality, capital and operating cost, and process economics (Farzad et al., 2016). A sketch of a gasification process is given in Figure 7. 
Table 11.

Torrefaction reactor models developed for waste biomass.

\begin{tabular}{|c|c|c|c|c|}
\hline \multirow{2}{*}{ Biomass source } & \multirow{2}{*}{ Kinetic Model } & \multicolumn{2}{|c|}{ Reactor model } & \multirow{2}{*}{ Reference } \\
\hline & & Reactor type and model description & Main simplifying assumptions & \\
\hline $\begin{array}{l}\text { Oil farm empty fruit } \\
\text { bunches and mesocarp } \\
\text { fibers }\end{array}$ & Table 10; No 1 & $\begin{array}{l}\text { An unsteady state 2D heterogeneous CFD model using } \\
\text { an implicit finite difference scheme with cell } \\
\text { dimensions of } \Delta r=2.8 \mathrm{~mm} \text { and } \Delta \mathrm{z}=2.5 \mathrm{~mm} \text { (with a } \\
\text { total of } 900 \text { nodes) was developed for a standard retort. }\end{array}$ & $\begin{array}{l}\text { Intra-particle temperature and concentration gradients are } \\
\text { neglected. Secondary reactions within the reacting solid } \\
\text { bed are omitted. The heat transfer rate is uniform at the } \\
\text { external lateral surface and the bottom of the reactor. The } \\
\text { torrefaction reaction enthalpy is neglected. Mass diffusion } \\
\text { of gases inside the reactor is omitted. }\end{array}$ & $\begin{array}{l}\text { Talero et al. } \\
\text { (2019a) }\end{array}$ \\
\hline Oxytree pruned biomass & & $\begin{array}{l}\text { This study developed polynomial models in which the } \\
\text { model parameters of } 2 \text {-degree polynomials were } \\
\text { determined by the non-linear regression analysis using } \\
\text { raw data. }\end{array}$ & $\begin{array}{l}\text { Model parameters are assumed statistically significant } \\
\text { when the p-value is below } 0.05 \text {. }\end{array}$ & $\begin{array}{l}\text { Świechowski et } \\
\text { al. (2019) }\end{array}$ \\
\hline $\begin{array}{l}\text { Forest residue (Birch } \\
\text { branches) }\end{array}$ & Table 10; No 3 & $\begin{array}{l}\text { A steady-state model by Aspen Plus }{ }^{\circledR} \mathrm{v} 8.8 \text { was } \\
\text { proposed for torrefaction of forest residue. The stream } \\
\text { class and property methods used are, respectively, } \\
\text { MIXCISLD and Redlich-Kwong-Soave (RKS). A user- } \\
\text { defined hierarchy reactor was employed. }\end{array}$ & $\begin{array}{l}\text { Steady-state operation at atmospheric pressure and all } \\
\text { pressure drops are negligible. Raw and torrefied biomass } \\
\text { is assumed to be non-conventional solids. The ambient } \\
\text { temperature is taken as } 25^{\circ} \mathrm{C} \text {. }\end{array}$ & $\begin{array}{l}\text { Bach et al. } \\
\text { (2017) }\end{array}$ \\
\hline Wheat straw & Table 10; No 10 & $\begin{array}{l}\text { A process model was developed by Aspen Plus for } \\
\text { wheat straw torrefaction. Simulations were run for both } \\
\text { single batch and two batch reactor processes. The } \\
\text { torrefaction reactor was modeled by using the RSTOIC } \\
\text { block. }\end{array}$ & $\begin{array}{l}\text { The particles are assumed to have a uniform temperature } \\
\text { profile. The inlet hot oil temperature is } 350^{\circ} \mathrm{C} \text {. Nitrogen } \\
\text { gas flow is preheated to the reactor temperature. Heating } \\
\text { time is kept around } 1,500 \mathrm{~s} \text {. }\end{array}$ & $\begin{array}{l}\text { Nikolopoulos et } \\
\text { al. (2013) }\end{array}$ \\
\hline Common reed & Table 10; No 11 & $\begin{array}{l}\text { A CFD model based on the finite volume method was } \\
\text { developed by Ansys Fluent for torrefaction in a bench- } \\
\text { scale reactor. The turbulence effect is modeled by the } \\
\text { k- } € \text { model based on Boussinesq's closure hypothesis, } \\
\text { whereas the radiation is modeled by the surface-to- } \\
\text { surface (S2S) radiation model. }\end{array}$ & $\begin{array}{l}\text { It is assumed that all the reactions are first-order. Biomass } \\
\text { volume is assumed to be constant while the porosity } \\
\text { varies throughout the process. }\end{array}$ & $\begin{array}{l}\text { Patuzzi et al. } \\
\text { (2014) }\end{array}$ \\
\hline $\begin{array}{l}\text { Empty fruit bunches } \\
(\text { Palm) }\end{array}$ & & $\begin{array}{l}\text { An empirical model was developed by power model } \\
\text { fitting based on the least-squares method for } \\
\text { torrefaction of oil palm empty fruit bunches in a fixed } \\
\text { bed reactor. }\end{array}$ & & $\begin{array}{l}\text { Sukiran et al. } \\
(2020)\end{array}$ \\
\hline OFMSW & Table 10; No 12 & $\begin{array}{l}\text { A 3D CFD model based on the Eulerian-Eulerian } \\
\text { approach was developed by OpenFOAM for } \\
\text { continuous torrefaction of urban biowaste in a packed } \\
\text { bed reactor. The turbulence effect and radiation, gas- } \\
\text { phase homogeneous reactions, and gas and solid phase } \\
\text { heterogeneous reactions were included in the model. }\end{array}$ & $\begin{array}{l}\text { Solid and gas phases are considered to be continuums. } \\
\text { Gas-phase optical thickness is negligible. The effect of } \\
\text { particle size is negligible. Solid velocity is constant. Solid } \\
\text { particles are considered to be cubic. }\end{array}$ & $\begin{array}{l}\text { Perera et al. } \\
(2020)\end{array}$ \\
\hline
\end{tabular}

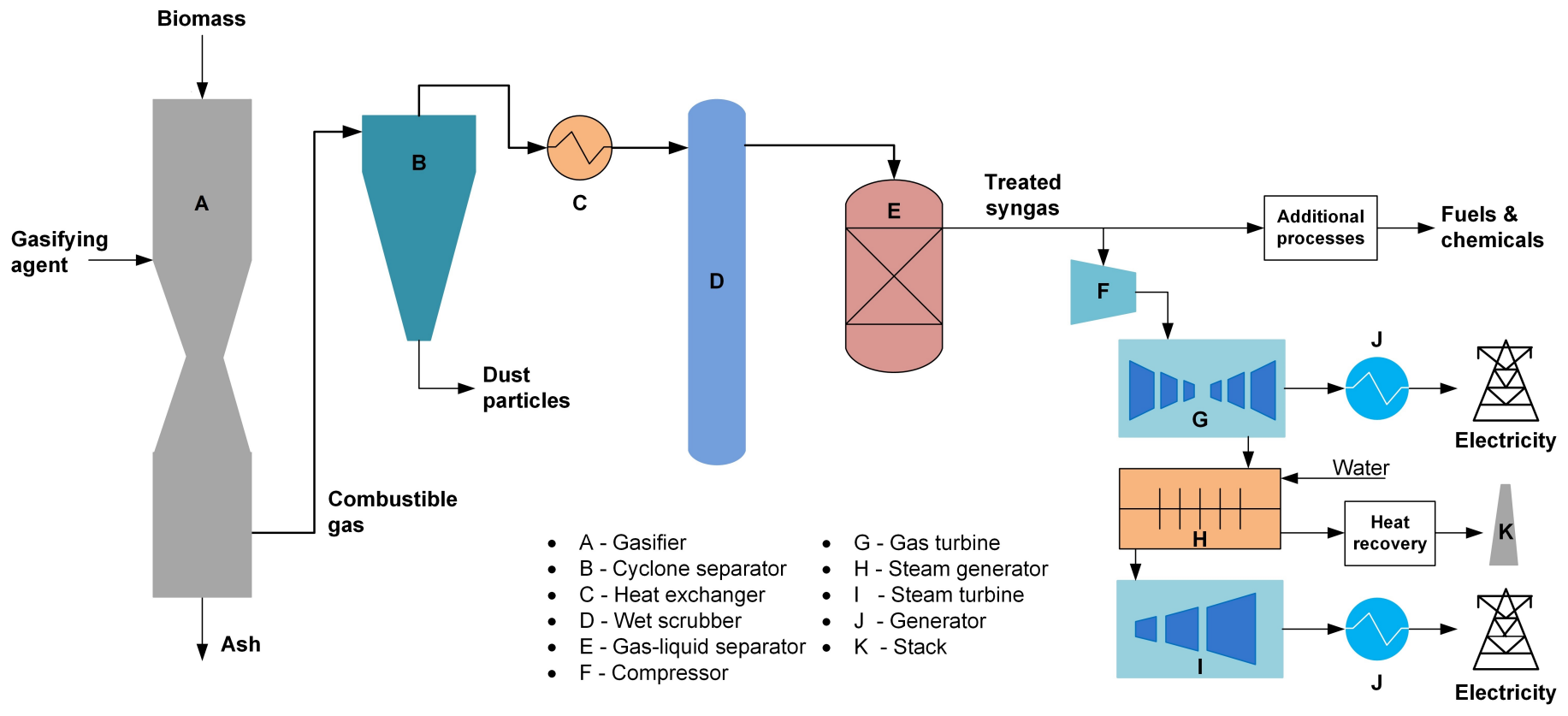

Fig. 7. A schematic representation of a biomass gasification process flow. 


\subsection{Gasification principle}

In biomass gasification, the stoichiometric air-to-fuel ratio typically varies between $6: 1$ to $6.5: 1$, and biomass is combusted under sub-stoichiometric conditions wherein the actual air-to-fuel ratio is around 1.5:1 to1.8:1 (Keche et al., 2015). Previous studies (Ergüdenler et al., 1997; Keche et al., 2015) have introduced gasification as a two-stage reaction process (oxidation and reduction), where drying, pyrolysis, and tar cracking undergo in the first stage or the oxidation reaction stage and gasification occurs in the second stage or the reduction reaction stage. Hence, there are four zones in the gasification process (i.e., drying, pyrolysis, combustion, and gasification), as depicted in Figure 8. Drying begins as biomass particles enter the furnace. It continues until the beginning of pyrolysis, which volatilizes biomass under substoichiometric oxidation conditions to generate char and volatiles such as $\mathrm{CO}$, $\mathrm{CO} 2 \mathrm{CH}_{4}, \mathrm{C}_{2} \mathrm{H}_{4}$, tar, etc., via complex reaction pathways. Next, the formed char undergoes a series of endothermic reduction reactions with combustion products in the gasification zone. Here, $\mathrm{H}_{2}$ and $\mathrm{CO}$ are generated in the hot-bed of char mainly via the char reaction with $\mathrm{H}_{2} \mathrm{O}$ and $\mathrm{CO}_{2}$ (Liu et al., 2013a). In the combustion zone, tars are cracked to form light hydrocarbons (Safarian et al., 2020). The gas species are partly consumed by the oxidation reactions due to the presence of oxygen in the combustion zone. Subsequently, until $\mathrm{O}_{2}$ is completely consumed, $\mathrm{CH}_{4}$ and $\mathrm{C}_{2} \mathrm{H}_{4}$ mole fractions decrease, and the $\mathrm{CO}_{2}$ mole fraction increases. Despite being partly consumed in the combustion zone, the $\mathrm{CO}$ mole fraction sustains without a significant drop since it is formed by the char reactions in the gasification zone. The $\mathrm{H}_{2}$ mole fraction usually increases in the axial direction due to the char reaction with $\mathrm{H}_{2} \mathrm{O}$ (Ramzan et al., 2011).

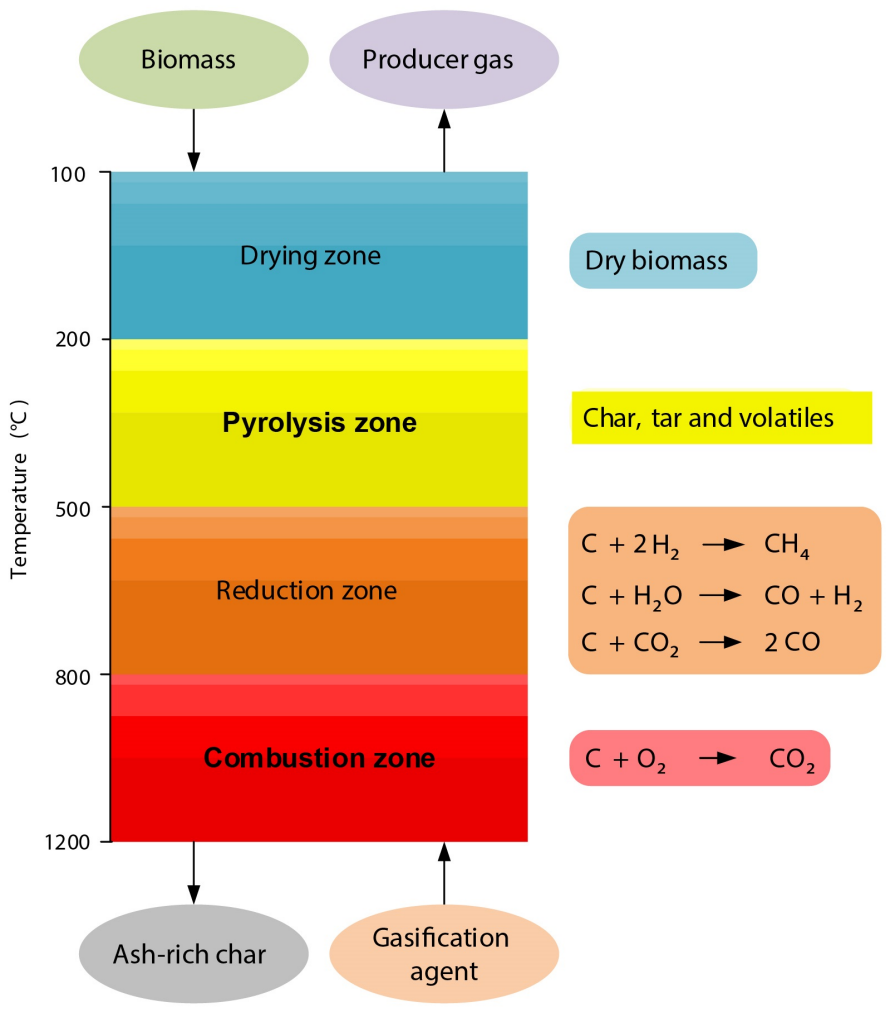

Fig. 8. Reaction zones and intermediate production formation of biomass gasification

At steady-state operation, biomass is consumed at a rate proportional to the reaction rate, making biomass flow velocity analogous to the reaction velocity. Pyrolysis usually occurs between $300-450^{\circ} \mathrm{C}$. As with increasing the ER, the amount of combustible gases increases to reach a peak and then falls. Hence, an optimum ER exists, at which the maximum amount of combustible gases is generated (Liu et al., 2013a). The gasifier temperature can sustain from the heat evolved from the exothermic combustion reactions in the oxidation zone, and certain endothermic reactions are driven by the evolved heat. The evolved heat is carried up to the gasification, pyrolysis, and drying zone by convection and diffusion to supply the energy required in those zones.

\subsubsection{Effects of process parameters on gasification}

From the modeling point of view, biomass gasification is comparatively a more complex process since it involves multi-scale and multi-physics processes, and it is influenced by various process parameters. Most of these influential parameters have interdependencies, and their impacts may be different at different reactions stages. Consequently, a pure discussion of the effects of process parameters independently is difficult. Nevertheless, the following contains a general analysis of the effects of process parameters on overall biomass gasification output (Wang and Shen, 2020). The gasification temperature is the most influential process parameter, upon which the process efficiency and product yield and quality depend Ghassemi and Shahsavan-Markadeh (2014) studied the effects of process parameters such as gasification temperature, ER, and moisture content via modeling analysis. They reported that cold gas efficiency (CGE) increased upon increasing the temperature. Further, it is more sensitive at lower temperatures, while HHV of syngas is insignificantly impacted. With increasing $\mathrm{ER}, \mathrm{H}_{2}$ content decreased due to the increased hydrogen oxidation, whereas $\mathrm{CO}$ content reached a maximum and then started to decline. When the feed moisture content was increased, the HHV of syngas decreased. However, this impact reduces at higher ERs. Further, the authors reported that with enriching the air with $\mathrm{O}_{2}$, the $\mathrm{HHV}$ of syngas improved. Fan et al. (2020) studied an industrial-scale circulating fluidized bed gasifier to identify the effects of different operating parameters. They reported that the CGE and the calorific value of product gas reached a maximum and then decreased with increasing temperature. For rice husk, the maximum CGE of $73.41 \%$ was obtained at $789{ }^{\circ} \mathrm{C}$, whereas the maximum calorific value of $5751 \mathrm{~kJ} \mathrm{Nm}^{-1}$ resulted at $814{ }^{\circ} \mathrm{C}$

Wang and Shen (2020) studied the effects of process parameters at particle scale using a coupled CFD and discrete element method approach According to their simulation results, particle size does not significantly impact the $\mathrm{H}_{2}$ and $\mathrm{CH}_{4}$ content, and it has a slight influence on $\mathrm{CO}$ and $\mathrm{CO}_{2}$ content. Moreover, they reported that higher initial bed temperatures caused higher gas temperature drops at bed exit, thus encouraging the production of $\mathrm{H}_{2}$ and $\mathrm{CO}$. With increasing the steam to biomass ratio (SBR), $\mathrm{H}_{2}$ and $\mathrm{CO}_{2}$ contents improve, whereas $\mathrm{CH}_{4}$ and $\mathrm{CO}$ content drop. The amount of tar present greatly impacts the quality of the product gas, and hence, it is very important to maintain gasification conditions such that tar formation is minimized. Hernández et al. (2013) investigated the effects of biomass/air ratio, temperature, and gasifying agent on tar formation by grape marc gasification in a drop-tube gasifier. Upon increasing the relative fuel/air ratio (ER), tar formation increased non-linearly due to the limited availability of oxygen to oxidize volatile matters. Further, the tar formation increased with decreasing the temperature and increasing the steam content as the gasifying agent. Although higher temperatures limit the tar formation, produced tars are progressively aromatized with increasing the temperature.

The product gas quality can be significantly improved by the use of catalysts. Sutton et al. (2001) reviewed the effect of catalysis on the product gas quality for biomass gasification. They introduced dolomite as an effective catalyst to remove hydrocarbons present in the product gas while improving the gas yield. Though it is prone to deactivation owing to carbon deposition and attrition, it can be easily replaced. On the other hand, alkali catalysts can greatly reduce the tar content and limit methane formation while accelerating gasification. Despite alkali catalysts being comparatively expensive and difficult to replace, ash generated from most biomass sources is rich in alkali metals, and hence it can be used as an effective catalyst. According to Yu et al. (2021), alkali and alkaline earth metals generally increase the gasification reactivity and gas yield while improving gas quality. However, the exact effect depends upon the gasification agent and other process parameters 


\subsection{Kinetic modeling}

There are many kinetic models in the literature, ranging from simple OD thermodynamic models based on chemical equilibrium and stoichiometry to complex models that consider kinetics, hydrodynamics, and particle distribution (Mansaray et al., 2000a). As per the perceived understanding, the models considering reaction kinetics generally closely reflect the actual reactions, thus leading to higher accuracy. Nevertheless, the applicability of kinetic data obtained via thermogravimetric analysis in gasification modeling is questionable since the experimental conditions under which kinetics are obtained and the actual gasification process conditions can be different. Moreover, kinetics are mainly derived from weight loss data, making them unable to estimate the product distribution (Mansaray et al., 2000a). On the other hand, equilibrium models provide an adequate representation of the gasification process, and thus most gasifier models have employed kinetic-free equilibrium models. Chemical equilibrium is usually explained by two approaches, i.e., minimization of Gibbs free energy and stoichiometric approach using equilibrium constants. The Gibbs free energy minimization approach, which is based on the elemental composition (which can be obtained from ultimate analysis data), requires an understanding of relatively complex mathematical theories, while the stoichiometric approach is comparatively simple in which reaction equilibrium is considered with equilibrium constant and stoichiometry for a clearly defined reaction mechanism (Jarungthammachote and Dutta, 2007; Silva and Rouboa, 2013). However, equilibrium models have better accuracy when gasification occurs under nearequilibrium conditions such as low flow velocity, long residence time, and low gasifier temperature gradient (Azzone et al., 2012).

Ergudenler and Ghaly (1992) investigated the reaction kinetics of wheat straw gasification and observed two distinct reaction regimes that were partially overlapped in the temperature range of $250-550{ }^{\circ} \mathrm{C}$. The thermal degradation rate in the first reaction zone was identified to be significantly higher than that of the second reaction zone. Kinetics for four different types of wheat straw was determined for both reaction stages. Further, it was identified that the lower activation energies compared to pure cellulose were due to the presence of inorganic material such as silica. This model fitted the experimental data with significant accuracy. Liu et al. (2013b) employed a single-step global reaction scheme for pyrolysis. However, pyrolysis kinetics needs to be experimentally determined to enhance the accuracy. Heterogeneous char reactions were modeled by a global reaction scheme that considered both the reaction kinetics and diffusion rate. This model can be further upgraded by including the WGS reaction with non-catalytic kinetics. A similar single-step global reaction pyrolysis model was used by Prasertcharoensuk et al. (2018). Ismail et al. (2016) built a kinetic model which includes drying, pyrolysis, gasification, and char combustion reactions. The pyrolysis sub-model is based on a first-order two-step parallel reaction mechanism. Moreover, Simone et al. (2013) constructed a kinetic model that considers moisture evaporation, biomass devolatilization, tar cracking, char combustion and gasification reactions, $\mathrm{CO}$, $\mathrm{H}_{2}$, and hydrocarbon combustion reactions, and WGS and methane reforming reactions. The study performed a sensitivity analysis on devolatilization kinetics and identified that kinetic parameters influence the reacting front position. Consequently, the devolatilization (pyrolysis) zone is noticeably separated from the combustion zone when fast kinetic is used. The model accuracy can be improved by employing a more realistic kinetic sub-model that takes into account biomass composition and thermal history.

As a result of the complexity involved in the hydrodynamic of biomass gasification, deriving reaction kinetics is more difficult. In contrast, equilibrium models are relatively simple and with sufficient accuracies for simulation applications. Most of the Aspen Plus ${ }^{\circledR}$ gasification models (Kartal and Özveren, 2020; Tungalag et al., 2020) have employed kinetic free equilibrium models based on the Gibbs free energy minimization approach. Gabbar et al. (2020) modeled gasification and combustion reactions and the chemical removal of contaminants by employing a OD thermodynamic model, which uses the Gibbs free energy minimization approach. Similarly, Mansaray et al. (2000a, b, and c) used a kinetic-free equilibrium model with the assumption of the rice husk's $\mathrm{H}, \mathrm{O}, \mathrm{N}$, and $\mathrm{S}$ contents reacting to $100 \%$ conversion. Moreover, Wang and Yan (2008a) employed an equilibrium model with a non-premixed combustion modeling approach based on the Gibbs free energy minimization, and the required data was obtained from the CHEMKIN database. On the other hand, some modeling studies (Azzone et al., 2012; Bhavanam and Sastry, 2013) have used an equilibrium model based on the stoichiometric approach (equilibrium constant approach). Silva and Rouboa (2013) employed a twostage equilibrium model based on the equilibrium constant approach, which considered heterogeneous equilibrium at or below carbon boundary point (CBP) and homogeneous equilibrium above the CBP separately. Balu and Chung (2012) used an equilibrium model based on the equilibrium constant approach. The chemical properties, given in NIST Chemistry WebBook were used for this model. The above kinetic models with the reaction mechanisms and the kinetic data are presented in Table 12.

\subsection{Reactor modeling}

Owing to the complexity of the overall gasification process, including biomass devolatilization, reaction rate kinetics, and hydrodynamics, equilibrium thermodynamic models are effective tools for analyzing gasification systems with a reasonable degree of accuracy. These models assume the chemical equilibrium for all reactions and steady-state operation with uniform temperature, which is not the case in real gasifiers (Kartal and Özveren, 2020). Zainal et al. (2001) developed a simple equilibrium mode based on the stoichiometric (equilibrium constant) approach to predict producer gas composition and calorific value for a downdraft gasifier. The study further investigated the effects of initial biomass moisture content and gasification temperature on the producer gas composition and the calorific value and revealed that the calorific value decreases when both the moisture content and gasification temperature increase. The model predictions were reasonably agreed with the experimental data. A similar model for MSW gasification in a downdraft gasifier was developed by Jarungthammachote and Dutta (2007) to predict producer gas composition. Though initial model predictions were in general agreement with the experimental data, the predictions for $\mathrm{CH}_{4}$ composition were significantly different, which was claimed to be due to the simplifying assumptions. Hence, the model was further improved by modifying equilibrium constants by adding extra coefficients. The modified model was used to predict the effect of moisture content on the reaction temperature, producer gas composition, and calorific value. As with increasing the moisture content, the mole fractions of $\mathrm{H}_{2}$ and $\mathrm{CO}_{2}$ increased while the mole fraction of $\mathrm{CO}$, the reaction temperature, and the calorific value decreased.

Bhavanam and Sastry (2013) developed an equilibrium model based on the stoichiometric approach to simulate solid waste gasification (MSW, animal waste, and agriculture waste) in a downdraft fixed bed reactor. The model can predict the syngas composition and investigate the effects of gasification temperature, ER, biomass moisture content on the syngas composition. As with increasing the moisture content, $\mathrm{H}_{2}$ content increased with the maximum between $28-30 \%$. The optimum temperature and ER corresponding to the maximum $\mathrm{H}_{2}$ and $\mathrm{CO}$ concentrations were between $800-900{ }^{\circ} \mathrm{C}$ and 0.3 , respectively. The model predictions were in good agreement with the experimental data found in the literature though significant deviations were observed when the ash content was higher. Nevertheless, these models are not capable of predicting the effect of hydrodynamics and reactor geometry. Similarly, Koroneos and Lykidou (2011) built an equilibrium model based on the stoichiometric approach to simulate the gasification of cotton stalks with moisture content between 0 to $30 \%$ at $800{ }^{\circ} \mathrm{C}$. The model can predict the producer gas composition and the calorific value. The authors also studied the effect of moisture content on the producer gas composition and the calorific value. They confirmed that with increasing the moisture content, $\mathrm{H}_{2}$ and $\mathrm{CH}_{4}$ contents increased while the $\mathrm{CO}$ content and the calorific value decreased. The model predictions were in close agreement with the experimental data.

A thermal-chemical equilibrium model (solved by the mathematical solver MAPLE) was constructed by Balu and Chung (2012) to simulate biomass (pine wood, horse manure, red oak, and cardboard) gasification in a trailer-scale downdraft gasifier. The model can predict the syngas composition, and it also investigated the effects of feedstock $\mathrm{C}, \mathrm{H}$, and $\mathrm{O}$ content variations on the thermal profiles and the efficiency. The thermodynamic efficiencies for the four feedstock types were in the lower $80 \%$. The model was validated by the existing literature, and the results were fairly reliable. The model prediction for $\mathrm{H}_{2}$ volume fraction was slightly higher, and the deviations of model predictions for cardboard were relatively large owing to its lower density. Even though the model predictions are based only on the reactor temperature, the properties vary both in space and time in an actual gasifier. Further, the model neglects the 
Table 12.

Gasification kinetic models which were already employed or have potential in reactor modeling for waste biomass.

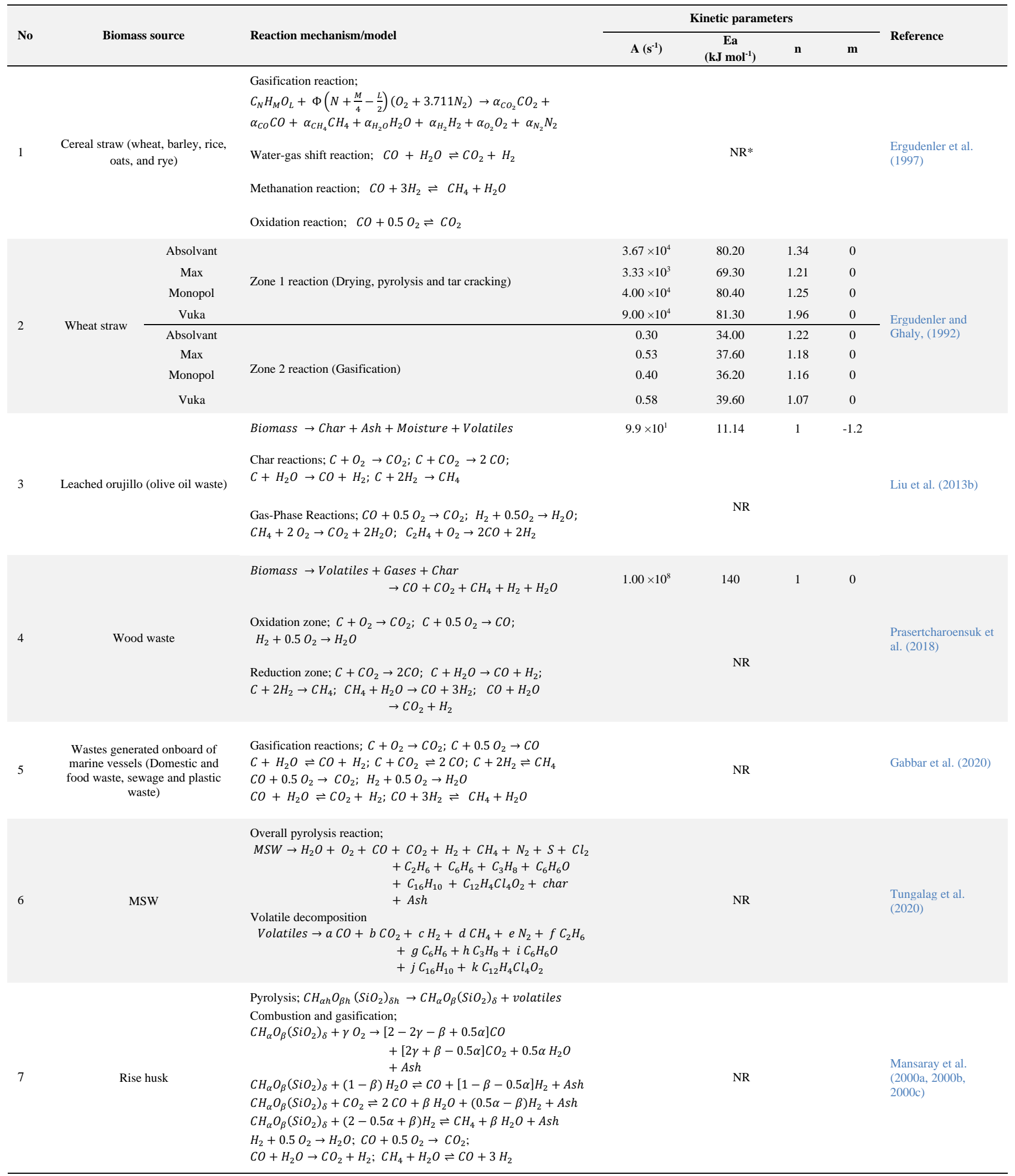

Please cite this article as: Perera S.M.H.D., Wickramasinghe C., Samarasiri B.K.T., Narayana M. Modeling of thermochemical conversion of waste biomass a comprehensive review. Biofuel Research Journal 32 (2021) 1481-1528. DOI: 10.18331/BRJ2021.8.4.3 
Table 12.

Continued.

\begin{tabular}{|c|c|c|c|c|c|c|c|}
\hline \multirow[b]{2}{*}{ No } & \multirow[b]{2}{*}{ Biomass source } & \multirow[b]{2}{*}{ Reaction mechanism/model } & \multicolumn{4}{|c|}{ Kinetic parameters } & \multirow[b]{2}{*}{ Reference } \\
\hline & & & $A\left(s^{-1}\right)$ & $\begin{array}{c}\text { Ea } \\
\left(\mathbf{k J} \text { mol}^{-1}\right) \\
\end{array}$ & $\mathbf{n}$ & $\mathbf{m}$ & \\
\hline 8 & $\begin{array}{l}\text { Food waste, MSW, } \\
\text { and poultry waste }\end{array}$ & $\begin{array}{l}\text { Gasification reactions; } \mathrm{C}+\mathrm{O}_{2} \rightarrow \mathrm{CO}_{2} ; \mathrm{H}_{2}+\frac{1}{2} \mathrm{O}_{2} \rightarrow \mathrm{H}_{2} \mathrm{O} \\
\mathrm{C}+\mathrm{H}_{2} \mathrm{O} \rightarrow \mathrm{CO}+\mathrm{H}_{2} ; \mathrm{C}+\mathrm{CO}_{2} \rightarrow 2 \mathrm{CO} \\
\mathrm{CO}+\mathrm{H}_{2} \mathrm{O} \rightarrow \mathrm{CO}_{2}+\mathrm{H}_{2} ; \mathrm{C}+2 \mathrm{H}_{2} \rightarrow \mathrm{CH}_{4} \\
0.5 \mathrm{~N}_{2}+1.5 \mathrm{H}_{2} \rightarrow \mathrm{NH}_{3} ; \mathrm{H}_{2}+\mathrm{S} \rightarrow \mathrm{H}_{2} \mathrm{~S}\end{array}$ & & NR & & & $\begin{array}{l}\text { Ramzan et al. } \\
(2011)\end{array}$ \\
\hline 9 & Dairy biomass and cattle biomass & $\begin{array}{l}\text { Steam reforming reaction; } \\
\qquad \begin{aligned} \mathrm{CH}_{h} \mathrm{O}_{o} \mathrm{~N}_{n} \mathrm{~S}_{s}+e\left[\mathrm{O}_{2}+3.76\right. & \left.\mathrm{N}_{2}\right]+\mathrm{fH}_{2} \mathrm{O} \\
& \rightarrow g \mathrm{CO}_{2}+h \mathrm{CO}+i \mathrm{CH}_{4}+j \mathrm{H}_{2} \mathrm{~S} \\
& +k N_{2}+l \mathrm{H}_{2}\end{aligned}\end{array}$ & & NR & & & $\begin{array}{l}\text { Gordillo et al. } \\
\text { (2009) }\end{array}$ \\
\hline 10 & $\begin{array}{l}\text { Wood, paddy husk, paper, and } \\
\text { MSW }\end{array}$ & $\begin{array}{l}\mathrm{C}+\mathrm{CO}_{2} \rightleftharpoons 2 \mathrm{CO} ; \mathrm{C}+\mathrm{H}_{2} \mathrm{O} \rightleftharpoons \mathrm{CO}+\mathrm{H}_{2} ; \mathrm{C}+2 \mathrm{H}_{2} \rightleftharpoons \mathrm{CH}_{4} \\
\mathrm{CO}+\mathrm{H}_{2} \mathrm{O} \rightleftharpoons \mathrm{CO}_{2}+\mathrm{H}_{2} \\
\text { Global gasification reaction; } \\
\begin{aligned} \mathrm{CH}_{1.44} \mathrm{O}_{0.66}+\mathrm{w} \mathrm{H}_{2} \mathrm{O}+\mathrm{m} \mathrm{O}_{2} & +3.76 \mathrm{~m} \mathrm{~N}_{2} \\
& \rightarrow x_{1} \mathrm{H}_{2}+x_{2} \mathrm{CO}_{2} \mathrm{x}_{3} \mathrm{CO}_{2}+x_{4} \mathrm{H}_{2} \mathrm{O} \\
& +x_{5} \mathrm{CH}_{4}+3.76 \mathrm{~m} \mathrm{~N}_{2}\end{aligned}\end{array}$ & & NR & & & Zainal et al. (2001) \\
\hline 11 & MSW & 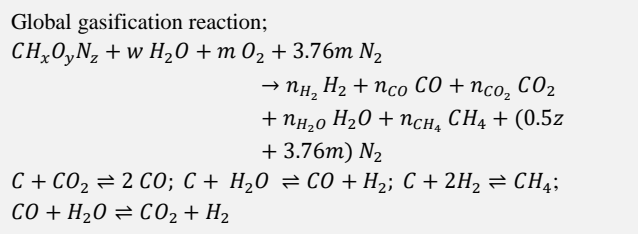 & & NR & & & $\begin{array}{l}\text { Jarungthammachote } \\
\text { and Dutta (2007) }\end{array}$ \\
\hline 12 & Pine residues & 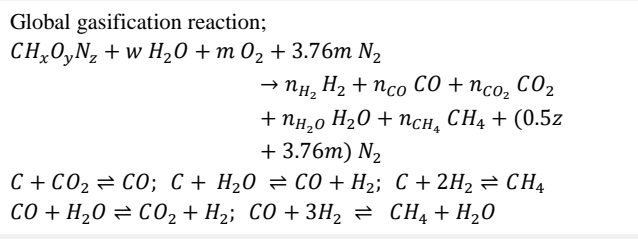 & & NR & & & $\begin{array}{l}\text { Silva and Rouboa } \\
\text { (2013) }\end{array}$ \\
\hline 13 & $\begin{array}{l}\text { Pine wood, horse manure, red } \\
\text { oak, and cardboard }\end{array}$ & $\begin{array}{l}\text { Global gasification reaction; } \\
\begin{aligned} \mathrm{CH}_{x} \mathrm{O}_{y} \mathrm{~N}_{z}+\mathrm{w} \mathrm{H}_{2} \mathrm{O}+\mathrm{mO}_{2} & +3.76 \mathrm{~m} \mathrm{~N}_{2} \\
& \rightarrow n_{\mathrm{H}_{2}} \mathrm{H}_{2}+n_{\mathrm{CO}} \mathrm{CO}+n_{\mathrm{CO}_{2} \mathrm{CO}_{2}} \\
& +n_{\mathrm{H}_{2} \mathrm{O}} \mathrm{H}_{2} \mathrm{O}+n_{\mathrm{CH}_{4}} \mathrm{CH}_{4}+(0.5 \\
& +3.76 \mathrm{~m}) \mathrm{N}_{2}\end{aligned} \\
\mathrm{CH}_{4}+\mathrm{H}_{2} \mathrm{O} \rightleftharpoons \mathrm{CO}+3 \mathrm{H}_{2} ; \mathrm{CO}+\mathrm{H}_{2} \mathrm{O} \rightleftharpoons \mathrm{CO}_{2}+\mathrm{H}_{2}\end{array}$ & & NR & & & $\begin{array}{l}\text { Balu and Chung } \\
\text { (2012) }\end{array}$ \\
\hline 14 & $\begin{array}{l}\text { Agriculture residue (corn stalks, } \\
\text { sunflower stalks and rapeseed } \\
\text { straw) }\end{array}$ & $\begin{array}{l}\text { Global gasification reaction; } \\
\mathrm{CH}_{x} \mathrm{O}_{y}+\alpha_{1} \mathrm{H}_{2} \mathrm{O}_{(l)}+\alpha_{2} \mathrm{H}_{2} \mathrm{O}_{(g)}+\alpha_{3} \mathrm{O}_{2}+\alpha_{4} \mathrm{~N}_{2} \rightarrow(1-\beta) \mathrm{C}_{(s)}+ \\
\beta_{1} \mathrm{H}_{2}+\beta_{2} \mathrm{CO}+\beta_{3} \mathrm{CO}_{2}+\beta_{4} \mathrm{H}_{2} \mathrm{O}+\beta_{5} \mathrm{CH}_{4}+\alpha_{4} \mathrm{~N}_{2} \\
\mathrm{C}+2 \mathrm{H}_{2} \rightleftharpoons \mathrm{CH}_{4} ; \mathrm{CO}+\mathrm{H}_{2} \mathrm{O} \rightleftharpoons \mathrm{CO}_{2}+\mathrm{H}_{2}\end{array}$ & & NR & & & $\begin{array}{l}\text { Azzone et al. } \\
(2012)\end{array}$ \\
\hline 15 & $\begin{array}{l}\text { MSW, animal waste, and } \\
\text { agricultural waste }\end{array}$ & $\begin{array}{l}\text { Global gasification reaction; } \\
\begin{aligned} \mathrm{CH}_{x} \mathrm{O}_{y} \mathrm{~N}_{z}+\alpha_{1} \mathrm{H}_{2} \mathrm{O}+\alpha_{2} & \left(\mathrm{O}_{2}+3.76 \mathrm{~N}_{2}\right) \\
& \rightarrow \beta_{1} \mathrm{CO}+\beta_{2} \mathrm{H}_{2}+\beta_{3} \mathrm{CO}_{2}+\beta_{4} \mathrm{H}_{2} \mathrm{O} \\
& +\beta \mathrm{CH}_{4}+\left(0.5 z+3.76 \alpha_{2}\right) \mathrm{N}_{2}\end{aligned} \\
\mathrm{C}+\mathrm{CO}_{2} \rightleftharpoons 2 \mathrm{CO} ; \mathrm{C}+\mathrm{H}_{2} \mathrm{O} \rightleftharpoons \mathrm{CO}+\mathrm{H}_{2} ; \\
\mathrm{CO}+\mathrm{H}_{2} \mathrm{O} \rightarrow \mathrm{CO}_{2}+\mathrm{H}_{2} ; \mathrm{C}+2 \mathrm{H}_{2} \rightleftharpoons \mathrm{CH}_{4}\end{array}$ & & NR & & & $\begin{array}{l}\text { Bhavanam and } \\
\text { Sastry (2013) }\end{array}$ \\
\hline 16 & Woody residue (vine pruning) & $\begin{array}{l}\text { Biomass } \rightarrow \alpha_{g} \text { Gas }_{1}+\alpha_{t} \text { Tar }+\alpha_{c} \text { Char } \\
\text { Tar } \rightarrow \text { Gas }_{2} ; \\
\mathrm{H}_{2} \mathrm{O}_{(l)} \rightarrow \mathrm{H}_{2} \mathrm{O}_{(g)} \\
\mathrm{C}+\gamma \mathrm{O}_{2} \rightarrow(2-2 \gamma) \mathrm{CO}+(2 \gamma-1) \mathrm{CO}_{2} \\
\mathrm{C}+\mathrm{CO}_{2} \rightarrow 2 \mathrm{CO} ; \mathrm{C}+\mathrm{H}_{2} \mathrm{O} \rightarrow \mathrm{CO}+\mathrm{H}_{2} ; \mathrm{C}+2 \mathrm{H}_{2} \rightarrow \mathrm{CH}_{4} \\
\mathrm{C}_{x} \mathrm{H}_{y}+(n+0.5 \mathrm{~m}) \mathrm{O}_{2} \rightarrow 0.5 \mathrm{~m} \mathrm{H}_{2} \mathrm{O}+n \mathrm{CO} ; 2 \mathrm{CO}+\mathrm{O}_{2} \rightarrow 2 \mathrm{CO}_{2} \\
2 \mathrm{H}_{2}+\mathrm{O}_{2} \rightarrow 2 \mathrm{H}_{2} \mathrm{O} ; \mathrm{CO}+\mathrm{H}_{2} \mathrm{O} \rightarrow \mathrm{H}_{2}+\mathrm{CO}_{2} \\
\qquad \mathrm{CH}_{4}+\mathrm{H}_{2} \mathrm{O} \rightarrow 3 \mathrm{H}_{2}+\mathrm{CO}\end{array}$ & $\begin{array}{l}3.00 \times 10^{3} \\
4.28 \times 10^{6} \\
5.13 \times 10^{10}\end{array}$ & $\begin{array}{c}69.00 \\
107.00 \\
88.00\end{array}$ & $\begin{array}{l}1 \\
1 \\
1\end{array}$ & $\begin{array}{l}0 \\
0 \\
0\end{array}$ & $\begin{array}{l}\text { Simone et al. } \\
(2013)\end{array}$ \\
\hline 17 & $\begin{array}{c}\text { Raw bamboo and torrefied } \\
\text { bamboo }\end{array}$ & $\begin{array}{l}\text { Drying zone; } \mathrm{H}_{2} \mathrm{O}_{(l)} \rightarrow \mathrm{H}_{2} \mathrm{O}_{(g)} \\
\text { Pyrolysis zone; } \mathrm{CH}_{x} \mathrm{O}_{y} \mathrm{~N}_{z} \rightarrow \mathrm{Char}+\text { Volatiles } \\
\text { Oxidation zone; } \mathrm{C}+0.5 \mathrm{O}_{2} \rightarrow 2 \mathrm{CO} ; \mathrm{C}+\mathrm{O}_{2} \rightarrow \mathrm{CO}_{2} \\
\text { Reduction zone; } \mathrm{C}+\mathrm{H}_{2} \mathrm{O} \rightarrow \mathrm{CO}+\mathrm{H}_{2} \\
\text { Boudouard reaction; } \mathrm{C}+\mathrm{CO}_{2} \rightarrow 2 \mathrm{CO} \\
\text { Shift reaction; } \mathrm{CO}+\mathrm{H}_{2} \mathrm{O} \rightleftharpoons \mathrm{H}_{2}+\mathrm{CO}_{2} \\
\text { Methanation reaction; } \mathrm{C}+2 \mathrm{H}_{2} \rightleftharpoons \mathrm{CH}_{4}\end{array}$ & & NR & & & Kuo et al. (2014) \\
\hline
\end{tabular}

Please cite this article as: Perera S.M.H.D., Wickramasinghe C., Samarasiri B.K.T., Narayana M. Modeling of thermochemical conversion of waste biomass a comprehensive review. Biofuel Research Journal 32 (2021) 1481-1528. DOI: 10.18331/BRJ2021.8.4.3 
Table 12.

Continued.

\begin{tabular}{|c|c|c|c|c|c|c|c|}
\hline \multirow[b]{2}{*}{ No } & \multirow[b]{2}{*}{ Biomass source } & \multirow[b]{2}{*}{ Reaction mechanism/model } & \multicolumn{4}{|c|}{ Kinetic parameters } & \multirow[b]{2}{*}{ Reference } \\
\hline & & & $\mathbf{A}\left(\mathrm{s}-^{-1}\right)$ & $\begin{array}{c}\text { Ea } \\
\left(\mathbf{k J ~ m o l}-^{1}\right) \\
\end{array}$ & $\mathbf{n}$ & $\mathbf{m}$ & \\
\hline 18 & Sewage sludge & $\begin{array}{l}\text { Sludge particles } \rightarrow \text { Volatiles }+\mathrm{Char}+\mathrm{Ash} \\
\text { Homogeneous reactions; } \mathrm{H}_{2}+0.5 \mathrm{O}_{2} \rightarrow \mathrm{H}_{2} \mathrm{O} ; \mathrm{CO}+0.5 \mathrm{O}_{2} \rightarrow \mathrm{CO}_{2} \\
\mathrm{CH}_{4}+2 \mathrm{O}_{2} \rightarrow \mathrm{CO}_{2}+2 \mathrm{H}_{2} \mathrm{O} ; \mathrm{CH}_{4}+\mathrm{H}_{2} \mathrm{O} \rightarrow \mathrm{CO}+3 \mathrm{H}_{2} \\
\mathrm{CO} \mathrm{H}_{2} \mathrm{O} \rightleftharpoons \mathrm{H}_{2}+\mathrm{CO}_{2} \\
\text { Heterogeneous reactions; } \mathrm{C}+\mathrm{CO}_{2} \rightarrow 2 \mathrm{CO} ; \mathrm{C}+0.5 \mathrm{O}_{2} \rightarrow \mathrm{CO} \\
\mathrm{C}+\mathrm{H}_{2} \mathrm{O} \rightarrow \mathrm{CO}+\mathrm{H}_{2}\end{array}$ & & NR & & & $\begin{array}{l}\text { Wang and Yan } \\
\text { (2008a) }\end{array}$ \\
\hline \multirow{6}{*}{19} & \multirow{6}{*}{ Coffee husks } & Biomass $\rightarrow$ Gas & $1.44 \times 10^{4}$ & 88.60 & 1 & 0 & \multirow{6}{*}{ Ismail et al. (2016) } \\
\hline & & Biomass $\rightarrow$ Tar & $4.13 \times 10^{6}$ & 112.70 & 1 & 0 & \\
\hline & & Biomass $\rightarrow$ Primary char & $7.38 \times 10^{5}$ & 106.50 & 1 & 0 & \\
\hline & & Tar $\rightarrow$ Gas & $4.28 \times 10^{6}$ & 107.50 & 1 & 0 & \\
\hline & & Tar $\rightarrow$ Secondary char & $1.00 \times 10^{5}$ & 107.50 & 1 & 0 & \\
\hline & & $\begin{array}{l}\text { Gasification reactions; } \mathrm{H}_{2}+0.5 \mathrm{O}_{2} \rightarrow \mathrm{H}_{2} \mathrm{O} ; \mathrm{CO}+0.5 \mathrm{O}_{2} \rightarrow \mathrm{CO}_{2} \\
\mathrm{CH}_{4}+2 \mathrm{O}_{2} \rightarrow \mathrm{CO}_{2}+2 \mathrm{H}_{2} \mathrm{O} ; \mathrm{CO}+\mathrm{H}_{2} \mathrm{O} \rightleftharpoons \mathrm{H}_{2}+\mathrm{CO}_{2} \\
\text { Heterogeneous reactions; } \mathrm{C}+0.5 \mathrm{O}_{2} \rightarrow 2 \mathrm{CO} ; \mathrm{C}+\mathrm{CO}_{2} \rightarrow 2 \mathrm{CO} \\
\mathrm{C}+\mathrm{H}_{2} \mathrm{O} \rightarrow \mathrm{CO}+\mathrm{H}_{2}\end{array}$ & \multicolumn{4}{|c|}{ NR } & \\
\hline 20 & $\begin{array}{l}\text { Waste biomass (wood waste, } \\
\text { domestic organic waste, and } \\
\text { verge grass) }\end{array}$ & $\begin{array}{l}\text { Gasification reaction; } \mathrm{C}+\mathrm{O}_{2} \rightarrow \mathrm{CO}_{2} ; \mathrm{C}+0.5 \mathrm{O}_{2} \rightarrow \mathrm{CO}_{2} ; \\
\mathrm{C}+2 \mathrm{H}_{2} \rightarrow \mathrm{CH}_{4} ; \mathrm{C}+\mathrm{CO}_{2} \rightarrow 2 \mathrm{CO} ; \mathrm{CH}_{4}+\mathrm{H}_{2} \mathrm{O} \rightarrow \mathrm{CO}+3 \mathrm{H}_{2} ; \\
\mathrm{CO}+\mathrm{H}_{2} \mathrm{O} \rightleftharpoons \mathrm{H}_{2}+\mathrm{CO}_{2}\end{array}$ & \multicolumn{4}{|c|}{ NR } & $\begin{array}{l}\text { Dahlquist et al. } \\
\text { (2013) }\end{array}$ \\
\hline
\end{tabular}

*NR: Not reporting.

tar formation and, therefore, does not consider the $\mathrm{CH}_{4}$ produced from the tar cracking and other volatiles.

Silva and Rouboa (2013) built a two-stage equilibrium model based on the stoichiometric approach (solved by using Matlab) to simulate oxygen-enriched air gasification of pine residues in a downdraft gasifier. The model was validated by the corresponding experimental data in the literature, and the model predictions for syngas composition had a fairly good agreement with the empirical literature data. The authors claimed that slight deviations were due to the simplifying assumptions as well as the neglect of drying, volatilization, and pyrolysis phenomena. The optimum temperature at the CBP was identified to be $908 \mathrm{~K}$ when the gasifying agent was air. The study revealed that the temperature at the CBP increased as with increasing the oxygen content in the gasifying agent (air) or increasing the operating pressure for all tested oxygen concentrations, and the effect of oxygen content was highlighted at values higher than $30 \%(\mathrm{v} / \mathrm{v})$ at the optimum gasification temperature. The temperature at the CBP decreased with increasing the biomass moisture content. However, it was observed that with increasing the oxygen content, $\mathrm{H}_{2}$ and $\mathrm{CO}$ composition decreased while $\mathrm{CO}_{2}$ increased. Most importantly, energetic and exergetic efficiencies were increased by increasing the oxygen content. Gordillo et al. (2009) developed a simple model to predict the molar composition of the product gas using two modeling approaches, i.e., atom balance model and equilibrium model. The model was also used to predict the effects of modified ER (ratio of stoichiometric oxygen to actual oxygen) and air steam ratio on the product gas composition. The study confirmed that steamrich gasifying agents produced $\mathrm{H}_{2}$ rich product gas mixture. Further, the experimental studies revealed that the heat capacity of the mixture increased upon adding steam, thus leading to a decrease in the peak bed temperature. And the peak temperature in the bottom of the bed linearly varied with both the modified ER and the air to steam ratio. The model based on the atom balance approach can be further improved by including the WGS equilibrium reactions.

An efficient gasification process can be achieved by employing fluidized bed gasifiers, which enhance heat transfer characteristics via vigorous mixing, thus leading to uniform temperature distribution, and comparatively higher conversions. However, owing to complex interactions of hydrodynamic and thermal conversion, accurate modeling of such gasifier configuration is challenging. On the other hand, empirical formulas derived from experiments are very limited to specific applications. Ergüdenler et al. (1997) developed a steady-state model for cereal straw gasification in a fluidized bed reactor. This model is kinetic-free and is primarily based on gas-phase equilibrium reactions, material and energy balances, and the two-phase theory. Prediction accuracy was substantially improved when tar formation was incorporated into the model. Tar yield was estimated by an empirical equation derived from Corella et al. (1989), while bubble characteristics and solids circulation, and minimum fluidization velocity were determined based on Gibilaro and Rowe (1974) and Goossens (1971), respectively. This model can be employed for other biomass with similar chemical and thermochemical properties and is capable of handling any type of biomass with a given distribution function since it is kinetic-free. However, this model neglects char conversion in the freeboard and the formation of other hydrocarbons except for $\mathrm{CH}_{4}$. This model can be upgraded, taking those neglected into consideration for higher accuracy. On the other hand, Altafini et al. (2003) built equilibrium models based on the Gibbs free energy minimization approach by SYNGAS routine (coded by FORTRAN language) and CycleTempo program (non-complex and complex models) for wood waste gasification. Sensitivity analysis was performed by the three models to predict the effect of moisture content on producer gas composition and LHV, carbon conversion efficiency (CCE), and CGE. Despite $\mathrm{H}_{2}$ composition being beyond the values reported in the literature, all models predicted the producer gas composition with agreeable accuracy at an equilibrium temperature around $800{ }^{\circ} \mathrm{C}$.

Kuo et al. (2014) constructed an equilibrium model based on the Gibbs free energy minimization approach by Aspen Plus ${ }^{\circledR}$ to simulate gasification of raw and torrefied bamboo in a downdraft fixed bed reactor. The study investigated the effect of modified ER and steam supply ratio on the CGE and carbon conversion. The carbon conversion for raw bamboo was higher than $90 \%$ for all ERs and steam supply ratios tested, and the maximum syngas yield and CGE was obtained for raw bamboo at ER of 0.2 and steam supply ratio of 0.9 . The model was validated by the experimental data in the literature, and the model predictions were in good agreement with the maximum relative errors for $\mathrm{H}_{2}, \mathrm{CO}$, and $\mathrm{CO}_{2}$ concentrations being below 9\%. Similarly, Dahlquist et al. (2013) developed an equilibrium model based on the Gibbs free energy minimization approach by Aspen Plus® to simulate waste biomass gasification. The model was combined with a statistical model (partial least square model) to predict the gas composition. The model revealed that the gasification temperature was reduced by decreasing the SBR. The model was validated with experimental data, and the model predictions were in reasonable agreement with the experimental data.

Keche et al. (2015) developed a process model by Aspen Plus ${ }^{\circledR}$ to simulate steady-state gasification of four biomass types (babul wood, neem wood, mango wood, and bagasse) in a downdraft gasifier. This simulation employed a kinetic-free equilibrium reaction model. The model results for 
$\mathrm{H}_{2}$, $\mathrm{CO}$, and $\mathrm{CO}_{2}$ composition are reasonably fitted with experimental data, while $\mathrm{CH}_{4}$ composition is under-predicted. Further, this study investigated the gas conversion efficiencies for the above biomass types and predicted the gas yield and the calorific value. Similarly, Dhanavath et al. (2018) constructed a process model by Aspen Plus ${ }^{\circledR}$ to simulate the steady-state operation of oxygen-steam gasification of biomass (Karanja press seed cake, rice husk, sawdust, and sunflower husk) in a fixed bed updraft gasifier reactor. This study performed a sensitivity analysis for reactor temperature, ER, and SBR, and also the carbon conversion and CGE were investigated. Subsequently, it was identified that $\mathrm{CO}$ and $\mathrm{H}_{2}$ concentrations, carbon conversion, and CGE increased with increasing temperature at constant ER and SBR values. A CGE as high as $95 \%$ with a high $\mathrm{LHV}$ of $\sim 12 \mathrm{MJ} / \mathrm{Nm}^{3}$ was achieved at a temperature of $1000{ }^{\circ} \mathrm{C}$, and the optimum ER and SBR values were respectively 0.23 and 0.3 . The model predictions and the experimental data were generally agreed with a maximum variation of $\pm 4 \%$, despite the concentration of $\mathrm{CH}_{4}$ at $800{ }^{\circ} \mathrm{C}$ being considerably different. A process model by Aspen Plus ${ }^{\circledR}$ was developed by De Kam et al. (2009) to simulate integrated biomass-fueled combined heat and power systems at an ethanol plant for distiller's dried grains with solubles. A fluidized bed gasification system was modeled. It was concluded that gasification is an important system since the feedstock has high nitrogen content and $\mathrm{NO}_{\mathrm{x}}$ emission is low for the synthesis gas combustion.

As per the perceived understanding, steam-gasification has better performance in producing $\mathrm{H}_{2}$ from biomass gasification due to higher $\mathrm{H}_{2}$ production than other techniques such as air-gasification and expensive oxygen-rich gasification. Steam reforming reactions are promoted in the steamgasification to produce $\mathrm{H}_{2}$-rich gas mixtures. Despite having a major challenge of water vapor generation, which negatively impacts the economic feasibility, it has a great potential to become economically viable with the recent research findings. Cao et al. (2021) developed a model by Aspen Plus ${ }^{\circledR}$ to simulate airsteam gasification of biomass in a fluidized bed gasifier reactor. The model is based on a multi-composition multi-step kinetic model with the primary focus of producing cleaner hydrogen-enriched syngas. This study investigated the effects of gasification temperature, ER, and SBR on gasification performance, including gas composition, dry gas yield, and tar yield. The optimum gasification temperature was identified to be $800{ }^{\circ} \mathrm{C}$. Tar yield decreased with increasing the ER from 0.19 to 0.23 , while dry gas yield had a peak of 2.43 $\mathrm{Nm}^{3} \mathrm{~kg}^{-1}$ at the ER of 0.21 . On the other hand, dry gas yield steadily increased with increasing the SBR from 0.61 to 2.7 while the tar yield slightly decreased. The model results were in good agreement with the experimental data. The study observed that the producer gas had higher $\mathrm{H}_{2}$ content and calorific value when the steam was used as the gasification agent.

Mansaray et al. (2000a, b, and c) built two mathematical models (onecompartment model and two-compartment model) by Aspen Plus® to simulate the steady-state gasification of rice husk in a fluidized bed gasifier reactor. The one-compartment model neglected the hydrodynamic complexity of the gasifier, while the two-compartment model took the complex hydrodynamics that existed within the gasification chamber into account, thus determining the carbon conversion in the core and annular regions separately. These kineticfree models can predict parameters such as reactor temperature, gas composition and HHV, the overall carbon conversion, and the effects of bed height, fluidization velocity, ER, $\mathrm{O}_{2}$ concentration in the fluidizing gas, and rice husk moisture content under various operating conditions. The models can be used for other types of biomass with similar thermal and chemical properties, and they can be further upgraded by including char gasification reactions in the freeboard. The two-compartment model was experimentally validated for various operating and design parameters such as bed height, fluidization velocity, and ER. Except for the overall carbon conversion, the model predictions for core, annulus, and exit temperatures, gas composition, and HHV were reasonably agreed with the experimental data.

Ramzan et al. (2011) developed a steady-state kinetic-free equilibrium model by Aspen Plus ${ }^{\circledR}$ to simulate steady-state hybrid biomass gasification for three biomass types (food waste, MSW, and poultry waste). The study investigated the effects of gasification temperature, ER, steam injection, and biomass moisture content on syngas composition and HHV, and CGE. It identified that the $\mathrm{CO}_{2}$ and $\mathrm{H}_{2}$ compositions of product gas increased with increasing temperature while they decreased with increasing ER. Further, the study revealed that the higher the moisture content, the lower the CGE. And the $\mathrm{H}_{2}$ production was favored by the steam injection, with the optimum SBR being in the range of $0.15-3$. The highest CGE of $71 \%$ was obtained for food waste, whereas MSW and poultry waste had lower CGE of 53\% and $45 \%$, respectively. The model predictions for food waste and MSW were in good agreement with experimental data, while the prediction for poultry waste had discrepancies that were argued to result from its specific composition. However, equilibrium models have some downsides, such as the inability to consider solid carbon in equilibrium gasification reactions and underestimating the $\mathrm{CH}_{4}$ content. As a result, some studies have incorporated correction systems based on the empirical data with the equilibrium models to mitigate or eliminate those drawbacks. Such an equilibrium model for gasification of agriculture residue (corn stalks, sunflower stalks, and rapeseed straw) in a downdraft gasifier was developed by Azzone et al. (2012). The model has a correction factor in introducing the solid carbon that takes part in the equilibrium reactions. The model was validated by the literature data. Although the model overestimated the $\mathrm{H}_{2}$ content and underestimated $\mathrm{CH}_{4}$ content, the overall model results were fitted reasonably with the experimental data.

ANN is a statistical technique that does not require a mathematical interpretation of the system. ANN models are extensively used in engineering applications for predicting system behaviors. It is an effective tool especially, in modeling complicated nonlinearities present in biomass gasification. However, ANN models require a huge number of data for more accurate predictions (Kartal and Özveren, 2020). Kartal and Özveren (2020) developed a model by Aspen Plus ${ }^{\circledR}$ to simulate biomass gasification in a circulating fluidized bed gasifier under a steam atmosphere. The study investigated the effects of gasification temperature, steam feed rate, SBR, and biomass source on syngas' LHV. The model predictions were with an acceptable margin of error compared to the experimental data. This Aspen Plus ${ }^{\circledR}$ model was combined with a novel ANN model to develop a universal deep learning model to predict the LHV of syngas produced from gasification of any type of biomass. The ANN model, which is faster and easy to handle, can fairly accurately estimate the LHV of syngas derived from any kind of biomass source.

The microwave plasma gasification, which usually operates at very high temperatures and breaks biomass down into elemental forms by active species such as radicals, electrons, and ions, is perceived to be an efficient technology since it increases the conversion efficiency without a need for catalysts. Moreover, microwave-induced plasmas consume less energy compared to arc plasmas (Sanlisoy and Carpinlioglu, 2017). Tungalag et al (2020) developed a steady-state model by Aspen Plus ${ }^{\circledR}$ to simulate the microwave plasma gasification of MSW. This study investigated the effect of the gasifying agent, SBR, and gasification temperature on product gas composition and temperature, heating value, and gasification efficiency. It was reported that the maximum carbon conversion ratio achieved was above $98 \%$, and the optimum ratio of $\mathrm{H}_{2} / \mathrm{CO}$ of 1.7 was obtained at a steam injection rate of $200-250 \mathrm{~kg} \mathrm{~h}^{-1}$. The simulation results were acceptably compliant with the experimental data despite the predicted syngas yield being noticeably different due to the Gibbs energy minimization approach.

Gabbar et al. (2020) developed a system model to simulate a single-stage plasma gasification system for waste generated onboard a marine vessel (a mixture of food waste, sewage, and plastic waste). This model is claimed to have good feedstock flexibility. The highest CGE was obtained for the highest sewage sludge concentration of $33 \%$. Further, a sensitivity analysis was performed on the syngas composition and the combustion temperature, and it was found that the average optimized plasma air and average optimized combustion air mass flow rates were respectively 201.1 and $831.8 \mathrm{~kg} \mathrm{~h}^{-1}$ for solid waste and sewage sludge flow rate of $300 \mathrm{~kg} \mathrm{~h}^{-1}$. The polygeneration, which integrates different processes to produce multiple value-added products simultaneously to increase the overall process efficiency, is an attractive technique to improve the commercial viability of waste-to-energy conversion processes. Salman and Omer (2020) discussed the gasification-based polygeneration of biofuels such as methane, methanol, gasoline, diesel, dimethyl ether, and ammonia along with district heating and power from MSW and refuse-derived fuel and developed a process model by Aspen Plus ${ }^{\circledR}$ for three different types of gasifier reactors (entrained flow gasifier, circulating fluidized bed gasifier, and dual fluidized bed gasifier). The model results indicated higher energy efficiency for the entrained flow gasifier when district heat was produced alongside power and biofuels. Meantime, higher energy efficiencies for the circulating fluidized bed gasifier and the dual fluidized bed gasifier were observed when only power and biofuels were produced. The CGE in the range $79-84 \%$ was achieved in this study. 
Industrial full-scale downdraft gasifiers usually have a restricted section called the throat which plays a critical role in preventing tar formation. However, most of the available models in literature do not consider this feature. Simone et al. (2013) developed a distributed 1D model to simulate the gasification of woody residue in a throated downdraft gasifier. The model was validated by data received from a pilot-scale reactor, and the model results satisfactorily agreed with the experimental data except for the peak gas-phase temperature and the solid temperature at the last portion of the gasifier, probably due to excessive thermal dispersion and faster reaction kinetics, respectively. The study evaluated the effects of biomass loading rate and moisture content on the gasifier performance. The authors emphasized that the stable steady-state operation of the gasifier is contingent upon the cold biomass enthalpy and the counter-current radiative heat fluxes from the oxidation zone.

Higher the tar content in the produced gas lesser the quality, so expensive gas cleaning equipment will be required. The combustion of pyrolysis products in a lean air supply, called flaming pyrolysis, tends to result in $\mathrm{CO}$ and $\mathrm{H}_{2}$ instead of $\mathrm{CO}_{2}$ and $\mathrm{H}_{2} \mathrm{O}$, and it consumes tars, thus achieving cleaner gas from gasification. Some studies perceive that cross draft gasifiers have more satisfactorily performance considering the overall gasifier performance. Saravanakumar et al. (2010) developed a flaming pyrolysis model of fixed bed cross draft gasifier for long-stick wood and conducted a comparative analysis between cross draft and updraft modes. This study found that the flaming pyrolysis time for long-stick wood is $1.6 \mathrm{~min}$, and also observed that the gas yield increases with the inlet air velocity. The model results were fairly fitted with experiment results. The efficiency of the cross-draft gasifier was around $79 \%$, and the produced gas quality was better than the updraft mode, mainly due to the low tar content. Relatively lower pyrolysis times were observed for the cross-draft mode compared to the top-lit and downdraft modes. Further, it was observed that the ash content for the cross-draft mode was lower compared to the bottom-lit mode, and they are suitable for high inlet air velocities.

Ismail et al. (2016) developed a 2D CFD model based on the EulerianEulerian approach to simulate gasification of coffee husk in a fluidized bed reactor. The model analyzed the effects of ER and biomass moisture content on the syngas composition and the gasification temperature. As with increasing the ER, the heating value of syngas reduced, and the maximum CGE was obtained when the ER was 0.3. The model was validated via the experimental data obtained from a semi-industrial reactor, and the model predictions were in good agreement with the experimental data. Since the structures of fluidizedbed gasifiers are sometimes non-axisymmetric, 2D models are insufficient to simulate the actual gasification process. Liu et al. (2013b) constructed a 3D CFD model by Fluent 14.0 to simulate the steady-state operation of a circulating fluidized-bed gasifier for olive oil waste. This model, which is gridindependent, is based on the Eulerian-Eulerian approach. The model can accurately predict the locations of pyrolysis and combustion zone, and gasification zone within the gasifier. This study observed that the gasifier temperature promptly reached a peak in the pyrolysis and combustion zone due to a large amount of combustion heat in contrast to the temperature drop in the gasification zone due to endothermic gas-phase reactions. The simulation results were in good agreement with experimental data; the model overpredicted the peak temperature, though. This study emphasized the significance of thermal radiation for the model accuracy and further investigated the effect of ER.

Some studies have reported that the syngas produced from downdraft gasifiers generally have low tar concentration, thus having a higher quality than the other gasifier configurations. Prasertcharoensuk et al. (2018) developed a 3D CFD model based on the Eulerian-Eulerian approach by Ansys Fluent 16.1 to simulate a throat downdraft gasifier for hydrogen production. This model is mesh-independent and was used to investigate the effects of throat diameter and position of the air inlet nozzles on the temperature profile and the produced gas properties. It identified a significant impact on both the temperature and the gas properties. The highest concentration of $\mathrm{H}_{2}(31.2 \%$ mol $)$ and $\mathrm{H}_{2} / \mathrm{CO}$ ratio (1.25) were obtained at a throat diameter to reactor diameter ratio of 0.4 when the air inlet nozzle was positioned $10 \mathrm{~cm}$ above the throat. The model predictions and experimental data were well-agreed, with the deviation being less than 5\%. It can further be modified to predict the syngas compositions under various operating conditions for different biomass. Wang and Yan (2008a) built a 3D CFD model based on the Eulerian-Lagrangian approach by Fluent 6.1 to simulate sewage sludge gasification in a fluidized bed gasifier. The model is capable of providing detailed information on product composition, temperature profiles, freeboard height, etc. The study investigated the effects of temperature and ER on syngas quality. The authors emphasized that the model accuracy can be further enhanced by understanding and incorporating complex pyrolysis behaviors, which may be present in the real process. The model was validated by the experimental data in the literature, and the model results were in good agreement with the experimental data. The modeling techniques and basic assumptions for the above gasification reactor models are listed in Table 13.

\section{Combustion}

\subsection{Combustion process}

Waste biomass combustion is a popular technology for waste-to-energy plants. It is a complex process with accompanying sub-processes such as drying, devolatilization, gasification, and gas and solid phase combustion (Chartier et al., 2007). Major benefits of waste combustion are energy generation, reduction of waste volume, ensuring hygiene, etc. A majority of remaining residue after the combustion is non-hazardous and can be used in other applications, such as improving soil fertility (Lombardi et al. 2013). For instance, Osman et al. (2020) reported that the residue from the combustion of pomace is rich in potassium and phosphorous, and it has a huge potential in the fertilizer industry. Biomass combustion is applied in a wide range of applications ranging from industrial to domestic scales such as pilot-scale and large-scale boilers, industrial drying applications (e.g., tea withering, tobacco curing, rubber sheet drying, etc.), furnaces, kilns, and stoves (Elorf et al., 2019). Further, biomass and fossil fuel co-combustion are often employed to lower pollutant emissions and improve process economics.

Unless the combustion is properly controlled, it may lead to operational and environmental issues. For instance, corrosion and erosion of refractory (Al-Qayim et al., 2019) and pollutant emissions can be highlighted (Chartier et al., 2007). One of the most common applications of biomass combustion is the incineration of MSW, where MSW is reduced into ash while generating energy. And MSW incineration is accompanied by the release of pollutants such as $\mathrm{SO}_{\mathrm{x}}, \mathrm{NO}_{\mathrm{x}}$, heavy metals, etc., and therefore, controlling measures are mandatory to prevent such releases into the environment. Another popular application is healthcare waste incineration. Healthcare waste is highly contaminated with pathogens and bacteria, and it requires to be thermally treated to ensure safe disposal (Lombardi et al., 2013). Mathematical modeling and simulation allow us to get a broader quantitative insight into the real physicochemical phenomena involved in the process, thus making them effective tools for combustor designs and upgrades, process control, and optimization (Asthana et al., 2010).

\subsection{Combustion principle}

The three most influential factors controlling the combustion process, also called the 3T's of combustion phenomenon, are temperature, retention time, and turbulence. In addition, intra-particle and extra-particle mass transfer resistances for the oxidizing agent are critical factors that affect the combustion rate. The intra-particle mass and heat transfer resistances also play a crucial role in determining the devolatilization rate (Rozainee et al., 2010). During the combustion, biomass undergoes a few reaction phases releasing various gases to form ash while generating energy as heat. Several gases are released at each reaction stage. The heat energy is usually converted to electricity via a combined heat and power plant. The raw biomass is dried in the first phase and then devolatilized in the second phase. Next, it starts to release volatile gases such as $\mathrm{CH}_{4}, \mathrm{H}_{2}, \mathrm{CO}, \mathrm{CO}_{2}$, $\mathrm{H}_{2} \mathrm{O}$, etc., and it forms solid char. This phase is often called pyrolysis despite the presence of oxygen. The released gases are combusted with the oxygen that came in with the primary air, and also, the formed char burns with the available oxygen or otherwise gasifies with $\mathrm{H}_{2} \mathrm{O}$ and $\mathrm{CO}_{2}$ (Asthana et al., 2010)

\subsection{Kinetic modeling}

Lombardi et al. (2013) constructed a kinetic model for healthcare waste incineration. The model included moisture evaporation, pyrolysis, and combustion of char, volatiles, and CO. Pyrolysis kinetics was modeled based on a first-order global reaction scheme in which biomass is 
Table 13.

Gasification reactor models developed for waste biomass.

\begin{tabular}{|c|c|c|c|c|}
\hline \multirow{2}{*}{ Biomass source } & \multirow{2}{*}{ Kinetic Model } & \multicolumn{2}{|c|}{ Reactor model } & \multirow{2}{*}{ Reference } \\
\hline & & Reactor type and model description & Main simplifying assumptions & \\
\hline
\end{tabular}

Reactor type and model description
A steady-state kinetic free model based on gas-phase

equilibrium reactions, material and energy balances, and the two-phase theory was developed for gasification of cereal
Cereal straw (wheat, barley, rice, oats, and rye)

Table 12; No 1 predict steady-state performance (reactor temperature, composition, HHV, and mass flow rate of produced gas) over a wide range of process conditions. The compartment temperatures were determined by using a numerical iteration (bi-section) technique.

A flaming pyrolysis model of fixed bed cross draft gasifier for long-stick wood gasification was developed. The modeling was done by dividing the gasifier into basically three zones (fuel reserve, flaming pyrolysis zone, and char reduction zone).

A 3D steady-state CFD model was developed by Fluent 14.0 for gasification of olive oil waste in a circulating fluidizedbed reactor. This CFD model is based on Eulerian-Eulerian

Leached orujillo (olive oil waste)

Table 12; No 3 bed reactor. This CFD model is based on Eulerian-Eulerian
Approach, and it is integrated with the P1 radiation model an the $k-\varepsilon$ turbulence model coupled with the kinetic theory of granular flow. Further Gidaspow model was used to define the drag force.

Babul wood, neem wood, mango wood, bagasse

A process model was developed by Aspen Plus $®$ for gasification of biomass in a fixed bed downdraft reactor gasifier. This employed an equilibrium model.

A process model was developed by Aspen Plus ${ }^{\circledR}$ Oxygensteam gasification of biomass in a fixed bed reactor. This employed an equilibrium model. HCOALGEN and DCOALIGT modules were used to estimate the

Karanja press seed cake rice husk, saw dust, and sunflower husk

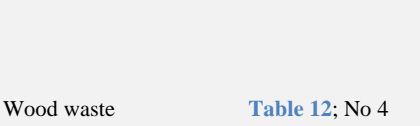
nonconventional properties of biomass and ash, wherea biomass decomposition into conventional components and gasification were respectively simulated by using RYIELD and RGIBBS blocks.

A 3D CFD model was developed by Ansys Fluent 16.1 for a throat downdraft gasifier for hydrogen production. The model is based in the Eulerian-Eulerian, and it is integrated with the standard k- $\varepsilon$ model to simulate the turbulence effect. The pressure-velocity coupling was solved by the SIMPLE algorithm scheme, and the second-order upwind scheme was used for discretization.
Wastes generated onboard of marine vessels (Domestic and Table 12; No 5 food waste, sewage and plastic waste)
A model developed by Aspen Plus ${ }^{\circledR}$ for a plasma-Based Waste Gasification System. MATLAB was used to postprocess the simulation results obtained. Gasification and combustion reactions and the chemical removal of contaminants were modeled by using Gibbs reactors.
A model developed by Aspen Plus ${ }^{\circledR}$ for circulating fluidized bed gasifier. To accurately predict LHV of syngas, it was combined with a deep learning model with a 6-12-1 tangent sigmoid architecture which uses a novel ANN model regularized with the Levenberg-Marquardt algorithm. In the model, Gibbs reactors were employed for gasification.

A process model was developed by Aspen Plus ${ }^{\circledR}$ for simulation of gasification-based polygeneration processes of MSW. Three types of gasifiers (entrained flow gasifier, circulating fluidized bed gasifier, and dual fluidized bed gasifier (DFBG)) were modeled. Waste decomposition and gasification were respectively modeled by RYIELD and RGIBBS blocks. For the DFBG reactor, an additional block RSTOICH was used to model the char combustion.
Steady-state operation. The reactor feeding rate is constant. It is assumed that the fuel is distributed uniformly in the bed. It is considered that both the fuel conversion and gas formations occur in the dense bed. All the homogeneous reactions are assumed to attain equilibrium. A plug flow is assumed in the gas phase. Perfect mixing is assumed in each compartment. No other component except for $\mathrm{CO}_{2}, \mathrm{CO}, \mathrm{CH}_{4}$, $\mathrm{H}_{2} \mathrm{O}, \mathrm{H}_{2}, \mathrm{O}_{2}$, and $\mathrm{N}_{2}$ exists in the product gas.

It is assumed that $\mathrm{CO}, \mathrm{O}_{2}$, and $\mathrm{H}_{2} \mathrm{O}$ are sufficient for a threebody collision which in turn forms $\mathrm{CO}$ to $\mathrm{CO}_{2}$. Moisture in the char region is neglected. Wood properties are calculated from average values.

A steady-state operation. Tar formation is neglected. The water-gas shift (WGS) reaction is omitted. The solid phase is Liu et al. (2013b) treated as a continuum.

Steady-state operation. Reactions are considered to reach the chemical equilibrium. Heat exchange in the fixed bed is assumed to be ideal and isothermal. At equilibrium, it is considered that the heat exchange is instantaneous. Tars in the syngas are neglected. Char consists only of carbon and ash. Ash is inert.

The gasifier is operated in a steady state with uniform temperature and pressure. Reactions are considered to reach the chemical equilibrium. Heat loss in the gasification block is negligible (isothermal conditions). Gas-phase is assumed to behave like an ideal gas mixture. It is assumed that carbon conversion efficiency is $100 \%$ and the feedstock is instantaneously dried and devolatilized.

Steady-state operation and continuous biomass feed rate (1 $\left.\mathrm{kg} \mathrm{hr}^{-1}\right)$. The feedstock moisture content is considered to reduce below $10 \%$ wt before it reaches the pyrolysis zone. The air is introduced from the nozzle at a constant temperature of $350 \mathrm{~K}$. The solid phase is treated as a continuum (continuous phase). The reactor wall is insulated, and heat losses are neglected. A No-slip boundary condition is assumed at the reactor wall. ER is kept constant at 0.25 .

Steady-state operation at atmospheric pressure. OD thermodynamic is assumed. The feedstock is perfectly mixed and introduced at ambient conditions $\left(1\right.$ bar and $\left.25^{\circ} \mathrm{C}\right)$. The temperature distribution is uniform. The gasifier reaction is considered to be isothermal at a constant volume. Tar and char formations are neglected. Compounds such as Dioxins, furans, tars, and heavy metals are ignored in the model. Gasification is considered to occur instantaneously. The main volatiles in the product stream are $\mathrm{H}_{2}, \mathrm{CO}, \mathrm{CO}_{2}, \mathrm{CH}_{4}$, and $\mathrm{H}_{2} \mathrm{O}$. The vapour phase follows the ideal gas laws. Liquid mixing is ideal.

It is assumed the gasifier operated at steady-state and isothermal conditions. The main volatile products from the biomass devolatilization are $\mathrm{CO}, \mathrm{CO}_{2}, \mathrm{H}_{2}, \mathrm{O}_{2}, \mathrm{H}_{2} \mathrm{O}$, and $\mathrm{CH}_{4}$. Tar and other heavy hydrocarbons are negligible. Ash is inert. Char is considered to consist only of carbon and ash. All the reactions occur instantaneously and reach the chemical equilibrium.

Equilibrium conditions based on the minimization of the Gibbs free energy approach were assumed.
Ergudenler et al. (1997)

Saravanakumar et al. (2010)
Keche et al. (2015)

Dhanavath et al. (2018)
Prasertcharoensuk et al. (2018)

Gabbar et a (2020)

Kartal and Özveren (2020)
Wood, paddy husk, paper, and MSW
Table 12; No 10 in a downdraft gasifier reactor.
Zainal et al. (2001) equilibrium 
Table 13.

Continued.

\begin{tabular}{|c|c|c|c|c|}
\hline \multirow{2}{*}{ Biomass source } & \multirow{2}{*}{ Kinetic Model } & \multicolumn{2}{|c|}{ Reactor model } & \\
\hline & & Reactor type and model description & Main simplifying assumptions & sererence \\
\hline
\end{tabular}

MSW

Table 12; No 6

Pine sawdust

Table 12; No 7

Distiller's dried grains with solubles

Food waste, MSW, and poultry waste

Table 12; No 8

An equilibrium model was developed by Aspen Plus ${ }^{\circledR}$ for steam plasma gasification of MSW. The model consists of four blocks, i.e., RStoic, SEP, RYIELD, and RBIGBBS. HCOALGEN and DCOALIGT blocks were respectively used to determine the enthalpy and density of unconventional components. Drying and decomposition of volatiles were modeled by FORTRAN subroutine in Aspen Plus®.

A model was developed by Aspen Plus® for air-steam gasification of biomass in a fluidized bed gasifier. The mode considers three stages of decomposition, volatiles combustion, and char gasification in separate reactor blocks.

Two models (single-compartment model and twocompartment model) were developed by Aspen Plus ${ }^{\circledR}$ for gasification of rice husk in a fluidized bed gasifier reactor. RGIBBS and RYIELD block was used to model the biomass decomposition and gasification, respectively.

A process model was developed by Aspen Plus ${ }^{\circledR}$ for the integrated biomass-fueled combined heat and power systems, including air-gasification of biomass in a fluidized bed reactor. RYIELD, RSTOIC, and RGIBBS blocks were used to model biomass devolatilization, gas distribution shift, and gasification separately.

A steady-state kinetic free equilibrium model was developed by Aspen Plus ${ }^{\circledR}$ for simulation of hybrid biomass gasification. The model consists of three stages in which drying, devolatilization, and gasification were modeled by RStoic,

RYield, RGibbs blocks, respectively. A FORTRAN statement in the calculator block was used to specify the yield distribution.

An equilibrium model was developed for MSW gasification in a downdraft gasifier reactor. The temperature and species

MSW

Table 12; No 11 method.

A mathematical model was developed for adiabatic fixed-be gasification using an air-steam mixture as an oxidizing agent The molar compositions of the product gas were predicted by

Dairy biomass an

Table 12; No 9 cattle biomass equilibrium model). The numerical solution for the equilibrium model was achieved by using the NASA equilibrium code PC version.

An equilibrium model was developed for wood waste gasification, and it was solved through a routine implemented

Wood waste (saw dust) (SYNGAS) coded by the FORTRAN language. A globally convergent strategy combined with the rapid local convergence of the Newton-Raphson method was used.

A two-stage equilibrium model was developed by using Matlab for oxygen air enriched gasification of pine residues in a downdraft gasifier reactor. Heterogeneous equilibrium at or below carbon boundary point (CBP) and homogeneous equilibrium above the CBP were separately considered in two stages.

A thermal-chemical equilibrium model based on the

Pine wood, horse

manure, red oak, and Table 12; No 13 cardboard stoichiometric approach for biomass gasification in a trailerscale downdraft gasifier. The numerical model was solved by the mathematical solver MAPLE.

An equilibrium model based on the stoichiometric approach

Cotton stalks

Table 12; No 10 gasifier.

An equilibrium model based on the stoichiometric approach was developed for the gasification of agriculture residue in a was developed for the gasification of agriculture residue in a
downdraft gasifier. The model includes a correction factor to represent the solid carbon that takes part in the equilibrium gasification reactions.

(corn stalks, sunflower

stalks, and rapeseed

Table 12; No 14
A steady-state operation at isothermal conditions and uniform pressure. Chemical equilibrium is assumed. Volatiles are considered to decompose based on the proximate analysis into gaseous species, char, tar, and ash.

A steady-state operation at atmospheric pressure. All gases are assumed to behave like ideal gases. Char is considered to consist only of carbon black. Heat losses are neglected. The presence of any other substance in the product stream other than $\mathrm{CO}, \mathrm{CO}_{2}, \mathrm{H}_{2}, \mathrm{CH}_{4}, \mathrm{H}_{2} \mathrm{O}$, and $\mathrm{N}_{2}$ is insignificant.

All reactions are assumed to reach the chemical equilibrium. It is assumed that the $\mathrm{H}, \mathrm{O}, \mathrm{N}$, and $\mathrm{S}$ contents of the rice husk react to $100 \%$ conversion. The char conversion is assumed to take place only in the core and annular regions of the dense bed, and any conversion in the freeboard region is neglected. The biomass moisture is assumed to evaporate instantaneously, allowing drying to be lumped with pyrolysis.

A steady-state operation at isothermal conditions under ambient pressure. All fuel sulfur and chlorine are assumed to initially produce $\mathrm{H}_{2} \mathrm{~S}$ and $\mathrm{HCl}$, respectively, whereas $5 \%$ of the fuel nitrogen produces $\mathrm{HCN}$, and the remaining nitrogen forms $\mathrm{NH}_{3}$.

Tungalag et al. (2020)

De Kam et al (2009)

(2000a, b, c)

Cao et a (2021)

A steady-state operation at isothermal conditions. Chemical equilibrium is assumed. All sulfur produces $\mathrm{H}_{2} \mathrm{~S}$. The formation of nitrogen oxides is insignificant, and it is considered only the formation of $\mathrm{NH}_{3}$

All reactions are assumed to be in thermodynamic equilibrium The gasification process is assumed to be adiabatic. All gases are assumed to be ideal. Tar and residue are neglected.

The product stream is a mixture of gases with major compounds as $\mathrm{CO}_{2}, \mathrm{CO}, \mathrm{CH}_{4}, \mathrm{H}_{2}$, and $\mathrm{N}_{2}$, and other compounds present in trace amounts. The chemical equilibrium under adiabatic conditions is assumed. For the equilibrium model, the presence of $\mathrm{H}_{2} \mathrm{O}$ was neglected.

Chemical equilibrium is assumed. Tar is insignificant and hence neglected.

Altafini et al. (2003)

It is considered that the reactor to be $0 \mathrm{D}$. The reactor is perfectly insulated, and heat losses are insignificant. Perfect mixing and uniform temperature are assumed. All reactions reach equilibrium. Tar is neglected. No unconverted solid carbon above the CBP.

Steady-state operation under adiabatic conditions. The thermodynamic equilibrium is assumed. The reactor is perfectly insulated, and heat losses are neglected. Biomass is considered to consist of $\mathrm{C}, \mathrm{H}$, and $\mathrm{O}$, and the presence of other minerals is neglected. All solid carbon is assumed to be converted to syngas composed only of $\mathrm{H}_{2}, \mathrm{CO}, \mathrm{CO}_{2}, \mathrm{H}_{2} \mathrm{O}, \mathrm{CH}_{4}$, and $\mathrm{N}_{2}$. Tars are neglected. The gas-phase behaves like an ideal gas mixture.

Adiabatic conditions. All chemical reactions reach equilibrium. Perfect mixing is assumed, and hence the temperature is uniform. Tar formation is neglected.

Steady-state operation under uniform temperature and pressure. Biomass is composed only of $\mathrm{C}, \mathrm{H}$, and $\mathrm{O}$. Chemical

equilibrium is assumed. Feedstock enters the reactor at the same temperature and pressure. The gas-phase behaves like an ideal gas mixture. The product gas is only composed of $\mathrm{CO}, \mathrm{H}_{2}, \mathrm{CO}_{2}$, $\mathrm{CH}_{4}$ and $\mathrm{H}_{2} \mathrm{O}$, and $\mathrm{N}_{2}$.
Balu and

Chung (2012)

Koroneos and Lykidou (2011)

Azzone et al (2012) 
Table 13.

Continued.

\begin{tabular}{lll}
\hline Biomass source & Kinetic Model & React \\
\cline { 3 - 3 } & & Reactor type and model description \\
\hline MSW, animal waste, & Table 12; No 15 & $\begin{array}{l}\text { An equilibrium model based on the stoichiometric approach } \\
\text { was developed for gasification of solid waste in a downdraft } \\
\text { fixed bed reactor }\end{array}$
\end{tabular}

and agricultural waste Table 12; No 15 fixed bed reactor.

\begin{tabular}{|c|c|c|}
\hline $\begin{array}{l}\text { Woody residue (vine } \\
\text { pruning) }\end{array}$ & Table 12; No 16 & $\begin{array}{l}\text { A distributed 1D model was developed for the gasification of } \\
\text { woody residue in a throated downdraft gasifier. The } \\
\text { numerical model was solved by solved using the software } \\
\text { gPROMS (Process System Enterprise). }\end{array}$ \\
\hline
\end{tabular}

gPROMS (Process System Enterprise).

An equilibrium model based on the Gibb free energy minimization approach was developed by Aspen Plus ${ }^{\circledR}$ v7.3 for raw and torrefied biomass in a downdraft fixed bed

Raw bamboo and torrefied bamboo

Table 12; No 17 gasifier. Non-conventional properties enthalpy and density were determined by HCOALGEN and DCOALIGT in Aspen. Drying, vapor-liquid equilibrium, devolatilization and gasification, and combustion were modeled by respectively RYield, RStoic, Flash2, and RGibbs blocks.

A 3D CFD model based on the Eulerian-Lagrangian method was developed by Fluent 6.1 for sewage sludge gasification in a fluidized bed reactor. Chemical reactions and turbulence were modeled by using the non-premixed combustion model and standard k- $\varepsilon$ turbulence model, respectively.

A 2D CFD model based on the Eulerian-Eulerian method wa developed for gasification of coffee husk in a fluidized bed reactor. The developed model (COMMENT-Code) was

Coffee husks

Table 12; No 19

The numerical model is solved by using the SIMPLE

algorithm. Partial differential equations are discretized by the Upwind Difference Scheme.

An equilibrium model based on the Gibbs free energy minimization approach was developed by Aspen Plus ${ }^{\circledR}$ for

Waste biomass (wood waste, domestic organic Table 12; No 20 biomass gasification. The model was combined with a partial least square model to predict the gas composition. Gasification was modeled by RGIBBS block in Aspen Plus ${ }^{\circledR}$. waste, and verge grass)

Main simplifying assumptions
Reference

All reactions reach the chemical equilibrium. All carbon in biomass is considered to be converted into gaseous forms. Ash is inert. The gas-phase behaves like an ideal gas mixture. The Bhavanam and reaction is auto-thermal. Adiabatic operation and heat losses are Sastry (2013) neglected. Sulfur and chlorine in the biomass are negligible. Biomass is composed only of $\mathrm{C}, \mathrm{H}, \mathrm{O}$, and $\mathrm{N}$.

The reactor operates close to vacuum conditions. Gas properties are determined at a constant pressure of $1 \mathrm{~atm}$. Biomass particles are spherical in shape and uniform in size $(\mathrm{d}=0.02$ $\mathrm{m})$. Particles are thermally thin. The void fraction along the gasifier is assumed to be constant at 0.5 . No momentum equations are applied in the model.

Steady-state operation at isothermal conditions.

Thermodynamic equilibrium is assumed. All reactions reach the chemical equilibrium. The feedstock is at $25^{\circ} \mathrm{C}$ and $1 \mathrm{~atm}$. The product gas mixture is composed of $\mathrm{H}_{2} \mathrm{O}, \mathrm{N}_{2}, \mathrm{H}_{2}, \mathrm{CO}, \mathrm{CO}_{2}$, and $\mathrm{CH}_{4}$, and it behaves like an ideal gas mixture. $\mathrm{S}$ content in the biomass is negligible. Char consists only of carbon and ash. Tar formation is neglected.

Diffusivities of gas species are equal. Ash is inert.

Devolitilization occurs instantaneously. All reactions reach the Wang and Yan chemical equilibrium.

The mixing rate inside the bed is proportional to the pressure drop across the bed. The particle size is uniform. Ash is in the gas phase. A no-slip condition is assumed at the wall. The horizontal components of the gas and particle velocities are considered to be zero.

All reactions attain the chemical equilibrium. 
Table 14.

Combustion kinetic models which were already employed or have potential in reactor modeling for waste biomass.

\begin{tabular}{|c|c|c|c|c|c|c|c|}
\hline \multirow{2}{*}{ No } & \multirow{2}{*}{ Biomass source } & \multirow{2}{*}{ Reaction mechanism/model } & \multicolumn{4}{|c|}{ Kinetic parameters } & \multirow{2}{*}{ - Reference } \\
\hline & & & $A\left(s^{-1}\right)$ & $\mathrm{E}_{\mathrm{a}}\left(\mathrm{kJ} \mathrm{mol}^{-1}\right)$ & $\mathbf{n}$ & $\mathbf{m}$ & \\
\hline 1 & MSW & $\begin{array}{l}\mathrm{H}_{2} \mathrm{O}_{(l)} \rightarrow \mathrm{H}_{2} \mathrm{O}_{(g)} \\
\text { Volatiles } \rightarrow \alpha_{1} \mathrm{CH}_{4}+\alpha_{2} \mathrm{H}_{2}+\alpha_{3} \mathrm{CO}+\alpha_{4} \mathrm{CO}_{2}+\alpha_{5} \mathrm{H}_{2} \mathrm{O} \\
\mathrm{CH}_{4}+1.5 \mathrm{O}_{2} \rightarrow \mathrm{CO}+2 \mathrm{H}_{2} \mathrm{O} ; \mathrm{CO}+0.5 \mathrm{O}_{2} \rightarrow \mathrm{CO}_{2} ; \mathrm{H}_{2}+0.5 \mathrm{O}_{2} \rightarrow \mathrm{H}_{2} \mathrm{O} \\
\mathrm{C}+\gamma \mathrm{O}_{2} \rightarrow(2 \gamma-1) \mathrm{CO}_{2}+2(1-\gamma) \mathrm{CO} \\
\mathrm{C}+\mathrm{H}_{2} \mathrm{O} \rightarrow \mathrm{CO}+\mathrm{H}_{2} ; \mathrm{C}+\mathrm{CO}_{2} \rightarrow 2 \mathrm{CO}\end{array}$ & & $\mathrm{NR}^{*}$ & & & Asthana et al. (2010) \\
\hline 2 & MSW & $\mathrm{C}_{m} \mathrm{H}_{n}+1.5 \mathrm{O}_{2} \leftrightharpoons \mathrm{CO}+2 \mathrm{H}_{2} \mathrm{O} ; \mathrm{CO}+0.5 \mathrm{O}_{2} \leftrightharpoons \mathrm{CO}_{2}$ & & NR & & & Chartier et al. (2007) \\
\hline 3 & Healthcare waste & $\begin{array}{l}\mathrm{H}_{2} \mathrm{O}_{(l)} \rightarrow \mathrm{H}_{2} \mathrm{O}_{(g)} \\
\text { Biomass } \rightarrow \text { Char }+ \text { Volatiles } \\
\mathrm{C}_{a} \mathrm{H}_{b} \mathrm{O}_{c} \mathrm{~N}_{d} \mathrm{~S}_{e}+\alpha_{1} \mathrm{O}_{2}+3.76 \alpha_{1} \mathrm{~N}_{2} \rightarrow \beta_{1} \mathrm{CO}+\gamma_{1} \mathrm{H}_{2} \mathrm{O}+\left(P_{1}+3.76 \alpha_{1}\right) \mathrm{N}_{2}+\mu_{1} \mathrm{SO}_{2} \\
\mathrm{C}_{x} \mathrm{H}_{y} \mathrm{O}_{z} \mathrm{~N}_{w} \mathrm{~S}_{u}+\alpha_{2} \mathrm{O}_{2}+3.76 \alpha_{2} \mathrm{~N}_{2} \rightarrow \beta_{2} \mathrm{CO}+\gamma_{2} \mathrm{H}_{2} \mathrm{O}+\left(P_{2}+3.76 \alpha_{2}\right) \mathrm{N}_{2}+\mu_{2} \mathrm{SO}_{2} \\
\mathrm{CO}+0.5 \mathrm{O}_{2} \rightarrow \mathrm{CO}_{2}\end{array}$ & & NR & & & $\begin{array}{l}\text { Lombardi et al. } \\
\text { (2013) }\end{array}$ \\
\hline 4 & Maize & 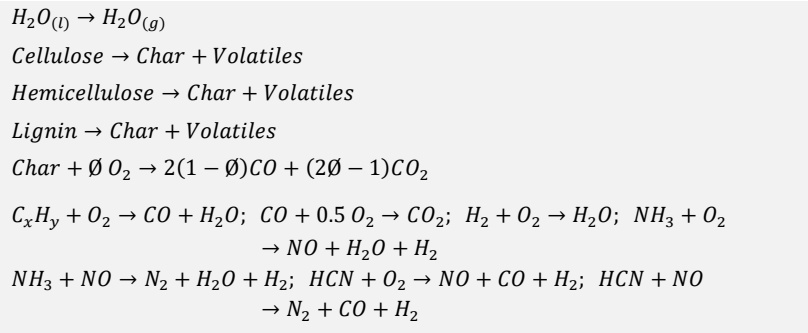 & $\begin{array}{l}9.00 \times 10^{11} \\
3.74 \times 10^{5} \\
1.60 \times 10^{-3}\end{array}$ & $\begin{array}{c}128.50 \\
75.47 \\
15.00\end{array}$ & $\begin{array}{l}1 \\
1 \\
1\end{array}$ & $\begin{array}{l}0 \\
0 \\
0\end{array}$ & Miltner et al. (2008) \\
\hline 5 & $\begin{array}{l}\text { Sawdust and rice } \\
\text { husk }\end{array}$ & $\begin{array}{l}\mathrm{H}_{2} \mathrm{O}_{(l)} \rightarrow \mathrm{H}_{2} \mathrm{O}_{(g)} \\
\text { Biomass } \rightarrow \mathrm{H}_{2}+\mathrm{CO}+\mathrm{CO}_{2}+\mathrm{H}_{2} \mathrm{O}+\mathrm{CH}_{4}+\mathrm{Char}+\text { Ash } \\
\text { Char }+\emptyset \mathrm{O}_{2} \rightarrow 2(1-\emptyset) \mathrm{CO}+(2 \emptyset-1) \mathrm{CO}_{2} \\
\mathrm{CH}_{4}+2 \mathrm{O}_{2} \rightarrow \mathrm{CO}_{2}+2 \mathrm{H}_{2} \mathrm{O} ; \mathrm{CO}+0.5 \mathrm{O}_{2} \rightarrow \mathrm{CO}_{2} \\
\mathrm{H}_{2}+0.5 \mathrm{O}_{2} \rightarrow \mathrm{H}_{2} \mathrm{O} ; \mathrm{CO}+\mathrm{H}_{2} \mathrm{O} \leftrightharpoons \mathrm{H}_{2}+\mathrm{CO}_{2}\end{array}$ & & NR & & & $\begin{array}{l}\text { Wickramasinghe et } \\
\text { al. (2018) }\end{array}$ \\
\hline 6 & Olive waste & Biomass $\rightarrow \alpha$ Volatiles $+(1-\alpha)$ Char & $1.43 \times 10^{4}$ & 88.6 & 1 & 0 & Elorf et al. (2019) \\
\hline 7 & Straw & $\begin{array}{l}{\text { Biomass } \rightarrow \text { Volatiles }_{1}} \text { Biomass } \rightarrow \text { B } \\
B \rightarrow \text { Volatiles }_{2} \\
B \rightarrow \text { Char } \\
\mathrm{CH}_{2.25} \mathrm{O}_{1.05}+0.54 \mathrm{O}_{2} \rightarrow \mathrm{CO}+1.12 \mathrm{H}_{2} \mathrm{O} ; \mathrm{CO}+0.5 \mathrm{O}_{2} \rightarrow \mathrm{CO}_{2}\end{array}$ & $\begin{array}{l}1.10 \times 10^{5} \\
1.20 \times 10^{3} \\
1.20 \times 10^{3} \\
2.82\end{array}$ & $\begin{array}{l}75.10 \\
53.56 \\
66.53 \\
27.61 \\
\text { NR }\end{array}$ & $\begin{array}{l}1 \\
1 \\
1 \\
1\end{array}$ & $\begin{array}{l}0 \\
0 \\
0 \\
0\end{array}$ & Mandø et al. (2010) \\
\hline 8 & Forest residue & $\begin{array}{l}\text { Biomass } \rightarrow \text { Char }+ \text { Volatiles } \\
\mathrm{C}+0.5 \mathrm{O}_{2} \rightarrow \mathrm{CO} ; \mathrm{C}+\mathrm{CO}_{2} \rightarrow 2 \mathrm{CO} ; \mathrm{C}+\mathrm{H}_{2} \mathrm{O} \rightarrow \mathrm{CO}+\mathrm{H}_{2} \\
\mathrm{CH}_{4}+\mathrm{O}_{2} \rightarrow \mathrm{CO}+2 \mathrm{H}_{2} ; \mathrm{CH}_{4}+\mathrm{H}_{2} \mathrm{O} \rightarrow \mathrm{CO}+3 \mathrm{H}_{2} \\
\mathrm{H}_{2}+0.5 \mathrm{O}_{2} \rightarrow \mathrm{H}_{2} \mathrm{O} ; \mathrm{CO}+\mathrm{H}_{2} \mathrm{O} \rightarrow \mathrm{CO}_{2}+\mathrm{H}_{2}\end{array}$ & & NR & & & Mueller et al. (2005) \\
\hline
\end{tabular}

* NR: Not reporting

\subsection{Reactor modeling}

A rotary kiln is perceived to be more suitable for the combustion of heterogeneous feed waste, and Lombardi et al. (2013) developed a 1D mathematical model to simulate incineration of healthcare waste in a rotary kiln. The model can predict gas and solid phase temperatures, amount of burned and unburned waste, amount of produced and burned char, volatile compounds, LHV and HHV of char and volatiles, and effects of input waste flow rate, excess air ratio, and refractory and insulator materials. According to the model predictions, the temperature at the last part of the kiln was around $920-930{ }^{\circ} \mathrm{C}$, whereas the external temperature was about $200{ }^{\circ} \mathrm{C}$. Further, the study revealed that changes in the refractory properties only caused slight changes in the internal and external kiln temperatures. The model predictions for the external temperature were in good agreement with the experimental data. This model work can be effectively used for preliminary designing of incinerator combustion chambers. Asthana et al. (2010) developed a 2D steady-state model to simulate on-grate MSW incineration. The model incorporates drying, pyrolysis, oxidation of the pyrolysis gases, char gasification and combustion, bed shrinkage, and stirring of the bed, and it can predict the temperature profiles, gas and solid compositions, reaction rates, gas velocity, etc. The study identified five zones (fresh feed, dried feed, pyrolysis, char, and ash) inside the incinerator. Further, this model can be used to optimize process parameters as well as predict pollutant formation. The model was validated by the experimental results received from a batch incinerator, and the model predictions were in good agreement. However, validating the model by data collected from a full-scale incinerator operating at a steady state will reinforce the model's validity for similar commercial applications.

Circulating fluidized beds are attractive over the conventional bubbling (turbulent fluidized beds) combustors mainly due to the higher efficiency of gas-solid contact and the reduced gas and solid phase axial dispersions. Gungor (2008) developed a 2D two-phase model to simulate biomass combustion (olive cake, rice husk, and wood) in a circulating fluidized bed reactor. The model can predict gas and solid phase temperatures, particle size distribution, void fraction, the axial and radial distribution of voidage, velocity, pressure drop, and gas and solid phase compositions. Further, the study investigated the effects of superficial velocity, air ratio, and primary to secondary air ratio on the bed temperature and the overall $\mathrm{CO}$ and $\mathrm{NO}_{\mathrm{x}}$ emissions and revealed that with increasing the air ratio, the $\mathrm{CO}$ 
concentration sharply decreased while the $\mathrm{NO}_{\mathrm{x}}$ concentration slightly increased. When the air ratio further increased beyond $60 \%$, the CO concentration increased due to the incomplete combustion resulting from the insufficient residence time. The model predictions were validated against the existing literature data of two small-scale and commercial-scale combustors cases and found good compatibility. However, more detailed validation experiments may be required to ensure accuracy. A CFD model based on the multi-purpose CFD code (Åbo Akademi Furnace Model) was developed by Mueller et al. (2005) to simulate the combustion of forest residue in a bubbling fluidized bed reactor. The model can predict temperature distribution, velocity, volatile release, water release, and solid and gas compositions. However, although the model elaborates in-flight and in-bed biomass conversion while guarantying closed energy and mass balance, it needs to be validated with detailed experiments to verify the accuracy.

Bugge et al. (2015) developed a CFD model by Ansys Fluent 15 to simulate staged air combustion of wood waste in a grate-fired lab-scale multi-fuel reactor. The primary focus of this model is to predict $\mathrm{NO}_{\mathrm{x}}$ formation. The study employed three gas-phase reaction mechanisms (with 81 species, 49 species, and 36 species) for comparison. The model can also predict the temperature and component mass flow rates. The study revealed that $\mathrm{NO}$ accounted for about $98 \%$ of the total fixed nitrogen, and the remains mainly consisted of $\mathrm{NO}_{2}$. Further, a higher $\mathrm{NO}_{\mathrm{x}}$ reduction was observed at a primary, excess air ratio of 0.8 . Out of the three reaction mechanisms employed, a detailed mechanism with 81 species predicted the nitrogen components in the primary zone with comparatively higher accuracy, whereas both skeletal mechanisms with 49 and 36 species overpredicted the total fixed nitrogen content at the outlet by about $20 \%$. Moreover, the 49 species mechanism was more compatible with the kinetics of the detailed model compared to the 36 species mechanism. Nevertheless, this model needs to be validated with rigorous experiments to assure its applicability to commercial applications.

Chartier et al. (2007) built a CFD model to simulate incineration of MSW. The model was implemented for two plant simulations in which a detailed model to predict basic phenomena involved in the waste biomass combustion was first simulated while the first pass of the boiler was optimized in the second simulation. The model can predict temperature profiles, flow velocities, temperature, and species concentration. The model predictions for gas composition and temperature on a global scale accurately matched the experimental data. The relative difference for gas composition and temperature were respectively lower than $4 \%$ and $2 \%$ when the measurement uncertainty was in the order of 5\%. Also, the model predictions of the second simulation for temperatures of the furnace and the first pass satisfactorily agreed with the experimental data with a deviation of less than $10 \%$. For optimization purposes, further simulations were run with modifications for tertiary air injection, total airflow rate, primary and secondary air flow rate ratio, and secondary air injection configuration. The results revealed that the secondary air injection configuration, which includes the number, position, and angle of nozzles, has the highest impact on improving the turbulence conditions. This model can further be improved by employing a more detailed and realistic kinetic scheme.

Shiehnejadhesar et al. (2015) constructed a CFD model by Ansys Fluent 15 to simulate biomass combustion in a grate furnace. Simulations were performed for three different reaction models, i.e., eddy dissipation model, eddy dissipation concept (EDC), and hybrid model (EDC/finite rate kinetics model). Further, the hybrid gas-phase reaction model was integrated with a gas streak model. The model revealed that the streaks affect flue gas temperature, $\mathrm{O}_{2}$ distribution, $\mathrm{CO}$ emissions, and the reacting radical formation. Moreover, streaks strongly influence the spatial distributions of the species such as $\mathrm{NH}_{3}$, $\mathrm{HCN}$, and $\mathrm{NO}$, and the hybrid-streak model-predicted $\mathrm{NO}_{\mathrm{x}}$ emission matched the experimental data with higher accuracy, thus proving its potential for accurate $\mathrm{NO}_{\mathrm{x}}$ prediction. Nevertheless, more detailed validation may guarantee the applicability of the model on a commercial scale. Miltner et al. (2008) developed a CFD model to simulate the combustion of maize bales. The model can predict solid composition, flue gas composition, flow velocities, and temperature. In this modeling study, flue gas recirculation rate, overall ER, and combustion chamber design were optimized to reduce pollutant emission (volatile organic compounds, $\mathrm{CO}$, and $\mathrm{NO}$ ). Further, the presence of flow dead zones and vortices was determined through flow field calculations inside the combustion chamber. Instead of using constant generation characteristics, the model can be further upgraded to have an operation-dependent composition of the volatiles. A detailed reaction mechanism with all the significant chemical reactions will further improve the overall accuracy. Also, experimental validation of the model is required to assure the accuracy of the model.

Mand $\varnothing$ et al. (2010) developed a CFD model by Fluent 6.3 to simulate the combustion of straw in a multifuel low- $\mathrm{NO}_{\mathrm{x}}$ burner. The model can predict temperature, solid composition, gas-phase composition, and axial velocity. The study investigated the influence of particle size, turbulence modulation model, and wall-collision model on model predictions. According to the model predictions, smaller particle size distributions and devolatilization kinetics had less influence over the amount of unburned char, while larger particle size distributions had a higher deteriorating effect owing to the flame blowoff. Further, comparatively longer flame and smaller recirculation zones were observed for the given airflow specifications. This model needs to be validated to assure accuracy. Rozainee et al. (2010) developed a CFD model by Fluent to simulate rice husk combustion in a bubbling fluidized bed reactor. The primary focus of this modeling study was to determine the trajectories and residence time of burning particles at four different secondary airflow rates $(25 \%, 35 \%, 50 \%$, and $80 \%$ of the primary airflow rate). The model can predict the mass-loss history of the particle, temperature along the reactor, the residual carbon content in ash, velocity, and residence time distribution (RTD) of the particles, as well as particle trajectories. The highest average bed temperature of $680^{\circ} \mathrm{C}$ accompanied by the lowest residual carbon content of $2.7 \mathrm{wt} \%$, was observed when the secondary air flow rate was $80 \%$ of the primary airflow rate. This was mainly due to the recirculating zone located closer to the feeding port, which increases the particle residence time. The model predictions for the residual carbon content in ash were compatible with the experimental data. This model elaborates the impact of the secondary air flow rate on the efficiency of the fluidized bed combustor and can be used in modifying and optimizing commercial combustors.

Wickramasinghe et al. (2018) developed a 2D CFD model based on the Eulerian-Lagrangian method by OpenFOAM to simulate the combustion of sawdust and rice husk in a suspension combustor with two chambers. The prime purpose of the second chamber was to improve the turbulent mixing. The model can predict temperature profile, velocity profile, turbulent kinetic energy, particle diameter variation, residence time variation, gas composition, and solid composition. The maximum temperature of $1380^{\circ} \mathrm{C}$ and the highest turbulence were observed at the second chamber. The optimum air velocity was identified to be $5.5 \mathrm{~m} \mathrm{~s}^{-1}$ at $65 \%$ of excess air for a biomass feeding rate of $0.00171 \mathrm{~kg} \mathrm{~s}^{-1}$. At the optimum conditions, exhaust gas contained an $\mathrm{O}_{2}$ mass fraction of $10.43 \%$ (dry basis), while $\mathrm{CO}$ and unburned species were present in trace amounts. The model predictions for the temperature were in good agreement with the experimental data. This model can effectively be used for the optimization of similar dualchamber suspension combustors. Nevertheless, a more detailed validation may guarantee the model's accuracy. In addition, this model can be modified to see the potential of introducing some air at the second chamber to upgrade the combustor design for achieving lower emissions.

A 3D CFD model by Ansys 14 was built by Elorf et al. (2019) to simulate the combustion of olive waste in a pilot-scale vertical combustor. Two cases for parallel and perpendicular particle injection were simulated separately. The model can predict temperature profiles, axial velocity, turbulence kinetic energy, gas composition, particle trajectory, and the effect of injection type on the pulverized biomass flame. According to the model predictions, the maximum temperature recorded inside the combustor was about $1560 \mathrm{~K}$ for both cases. Further, it was observed that the $\mathrm{CO}_{2}$ and $\mathrm{NO}_{x}$ concentrations in the exhaust gas were comparatively lesser for the case of perpendicular injection than the parallel injection. Proper validation of the model may allow it to be used for designing and optimization of commercial-scale combustors. The above combustor reactor models with their basic assumptions and modeling techniques are listed in Table 15.

\section{Hydrothermal carbonization (HTC)}

The hydrothermal conversion can be categorized into HTC, HTL, and hydrothermal gasification. It converts biomass into low molecular products using subcritical or supercritical water conditions, and the conversion occurs via a series of physiochemical reactions (Gao et al., 2012). The hydrothermal conversion has more advantages over thermal processes in processing wet biomass owing to the following reasons. The energyconsuming pre-drying is not required as water takes part both as a reactant 
Table 15.

Combustion reactor models developed for waste biomass.

\begin{tabular}{|c|c|c|}
\hline \multirow{2}{*}{ Biomass source } & \multirow{2}{*}{ Kinetic Model } & \multirow[b]{2}{*}{ Reactor type and model description } \\
\hline & & \\
\hline MSW & Table 14; No 1 & $\begin{array}{l}\text { A 2D steady-state model for On-Grate MSW incineration was } \\
\text { developed and named GARBED-ss. The model considered all } \\
\text { three forms of heat transfer by convection, conduction, and } \\
\text { radiation and included drying, pyrolysis, oxidation of the pyrolysis } \\
\text { gases, char gasification and combustion, bed shrinkage, and } \\
\text { stirring of the bed. }\end{array}$ \\
\hline Wood waste & & $\begin{array}{l}\text { A CFD model was developed by Ansys Fluent } 15 \text { for the } \\
\text { combustion of wood waste in a grate-fired lab-scale multi-fuel } \\
\text { reactor. The turbulence combustion coupling was included by } \\
\text { using a k- } \varepsilon \text { turbulence model and the eddy dissipation concept } \\
\text { (EDC). And the radiation heat transfer was modeled by the discrete } \\
\text { ordinates method (DO) combined with the Moss \& Brookes soot } \\
\text { model. }\end{array}$ \\
\hline MSW & Table 14; No 2 & $\begin{array}{l}\text { A steady-state CFD model was developed by Fluent software for } \\
\text { incineration of MSW. Turbulence and radiation were modeled by } \\
\text { the k- } \varepsilon \text { realizable turbulence model and the P1 model, respectively. } \\
\text { The conversion rate of species was predicted by using the mixed- } \\
\text { controlled Eddy-Dissipation model. }\end{array}$ \\
\hline
\end{tabular}

A 1D steady-state mathematical model based on the finite volume method was developed for healthcare waste incineration in a rotary kiln. The model considered all radiation heat exchanges.

A CFD model was developed by Ansys Fluent 15 for biomass combustion in a grate furnace. A gas streak model was integrated with a gas phase combustion model. Laminar to turbulent flow conditions were modeled by using the SST k- $\varepsilon$ low Reynolds turbulence model. Thermal decomposition of the biomass was modeled by using an empirical model developed by BIOS in cooperation.

A two-phase 2D model was developed for biomass combustion in circulating fluidized bed reactor. The tailor-made program was coded by Fortran language. The governing equations were discretized by using the backward-difference scheme, and the solution was achieved by the Gauss-Seidel iteration combined with the Newton-Raphson.

A CFD model was developed by FLUENT 6 for biomass

Maize (compressed bale)

Table 14; No 4 A turbulence effect was modeled by the SST-k- $\varepsilon$ turbulence model. Further, reaction rate and reactant transport were coupled by using the EDC.

A 2D CFD model based on the Eulerian-Lagrangian approach was developed by OpenFOAM software for the combustion of sawdus Sawdust and paddy Table 14; No 5 in a suspension biomass combustor with two chambers. Gauss husk linear and Gauss limited linear schemes were used for discretization. Overall reaction rates limited by both temperature and turbulent mixing were determined based on the EDC.

A 3D CFD model was developed by Ansys 14 for olive waste combustion in a vertical combustor. Flow turbulence, turbulencechemistry interactions, particle motion, and radiation were modeled respectively by $k-\varepsilon$ model, non-premixed combustion model with the mixture fraction PDF, discrete phase model DPM, and P1 model.

A CFD model by Fluent 6.3 was developed for the combustion of straw in a low-NO burner. Turbulence, particle-trajectories, and Straw Table 14; No 7 influence of particles on the gas-phase momentum were respectively modeled by the standard k- $\varepsilon$ model, the standard particle dispersion model of Fluent, and the PSI-Cell model.

A CFD model based on the multi-purpose CFD code (Åbo Akademi Furnace Model) was developed for the combustion of Forest residue Table 14; No 8 forest residue in a bubbling fluidized bed reactor. Turbulence and radiation heat transfer were modeled by the standard k- $\varepsilon$ model, the discrete ordinates radiation model, respectively.

Main simplifying assumptions
Steady-state operation. When stirring is not considered, feed
flows at a contact rate to the moving grate parallel to the grate.
Primary air is injected under the moving grate. The solid bed
is assumed to be a porous medium composed of spherical
particles. Particle volume is assumed to remain constant while
porosity changes as with the degradation.

Reference porosity changes as with the degradation.

Bugge et al. (2015)

Steady-state operation. Kinetics is assumed to be infinitely rapid. Temporal operation fluctuations are neglected.

Steady-state operation at stationary conditions. The mass $\mathrm{O}, \mathrm{N}$, and $\mathrm{S}$. Limiting conditions apart from kinetics such as gas-phase imperfect mixing and the tumbling, sliding movement, and surface renewal of the solids are neglected. The combustion chamber remains under standard operating conditions. Feedstock entering velocity to the rotary kiln is constant. Waste composition is assumed to be homogeneous.

The bed is ideally packed with spherical pellet particles. The primary air is uniformly injected. It is assumed that the flow pattern in the furnace is not influenced by the $\mathrm{NO}_{\mathrm{x}}$ formation reactions. The number of particles and the horizontal velocity on the grate are considered to be constant along the grate. The particle entrainment and the fragmentation are insignificant.

The volatile release rate along the riser is assumed to be proportional to the solid mixing rate. Particles are assumed to be moving upward axially while moving from core to annulus region radially. Particles are spherical, and particle agglomeration is neglected. $\mathrm{SO}_{2}$ and $\mathrm{HCl}$ emissions from combustion are insignificant. A partial slip condition and a symmetry boundary condition are assumed at the wall and the axis, respectively. Ash is separated as soon as it is formed

The impact of the water shift reaction is assumed to be insignificant. All gas-phase reactions are taken place within the reaction space, and the reactions in the surrounding fluid are neglected. The porosity and the flow resistance are considered to vary linearly with the burnout rate of the solid. The biomass bed and the char bed are composed of equally sized cylinders.

The mixture of hydrocarbon formed via pyrolysis is assumed as $\mathrm{CH}_{4}$. Other gas phase reactions apart from four major reactions are neglected. Initial velocity and the pressure are assumed to be zero and $101325 \mathrm{~Pa}$, respectively. No-slip boundary condition at the wall. balance is based only on the major components such as $\mathrm{C}, \mathrm{H}$,

Chartier et al. (2007)

Lombardi et al. (2013)

Shiehnejadhesar et al. (2015)

Gungor (2008)

Miltner et al. (2008)

Wickramasinghe et al. (2018)

It is assumed that particles travel at terminal velocity. The particle fluctuating velocity is negligible. Only two major gasphase reactions are considered.

The heat of devolatilization is negligible. Char consists of pure graphite. The volatile phase contains only $\mathrm{CH}_{4}, \mathrm{CO}, \mathrm{CO}_{2}, \mathrm{O}_{2}$, $\mathrm{H}_{2} \mathrm{O}, \mathrm{H}_{2}$, and $\mathrm{NH}_{3}$, and the volatile release from a particle is assumed to be proportional to the heat transferred to the particle.
Mueller et al. (2005)

\footnotetext{
(n)
}


Table 15.

Continued.

\begin{tabular}{|c|c|c|c|c|}
\hline \multirow{2}{*}{ Biomass source } & \multirow{2}{*}{ Kinetic Model } & \multicolumn{2}{|c|}{ Reactor model } & \multirow{2}{*}{ Reference } \\
\hline & & Reactor type and model description & Main simplifying assumptions & \\
\hline Rice husk & & $\begin{array}{l}\text { A CFD model was developed by Fluent for the combustion of rice } \\
\text { husk in a fluidized bed reactor. The turbulence effect was modeled } \\
\text { by using the standard k- } \varepsilon \text { model, and swirling flows were modeled } \\
\text { by using the RNG (renormalization group) k- } \varepsilon \text { model. } \\
\text { Instantaneous gas velocity and the random effects of turbulence on } \\
\text { the particle dispersion were modeled by the stochastic walk model } \\
\text { and discrete random walk (DRW) model, respectively. Coupling } \\
\text { between turbulence and reaction process was implemented by the } \\
\text { PDF modeling. }\end{array}$ & $\begin{array}{l}\text { Bubble diameter is assumed to be } 20 \mathrm{~mm} \text {, and the eruption of } \\
\text { bubbles is considered to eject the particles only in the y- } \\
\text { direction. The particle phase is sufficiently dilute. Turbulent } \\
\text { eddies obey a Gaussian probability distribution. The mean } \\
\text { diameter of particles is taken as } 1.6 \mathrm{~mm} \text { with a sphericity of } \\
0.19 \text {. }\end{array}$ & $\begin{array}{l}\text { Rozainee et al. } \\
(2010)\end{array}$ \\
\hline
\end{tabular}

and a solvent during the process. The latent heat is saved since water remains as liquid making the process more thermally efficient. Further, the hydrothermal conversion employs mild temperatures compared to most of the thermal processes. In addition, the emission of harmful gases is comparatively lesser since gaseous $\mathrm{SO}_{x}$ and $\mathrm{NO}_{x}$ easily solubilize in water (Gao et al., 2016).

\subsection{HTC process}

The thermal treatment of biomass with water at subcritical conditions in moderate temperatures between $100-374{ }^{\circ} \mathrm{C}$ and autogenous pressures usually in the range of 2-70 bar, which is high enough for water to remain in the liquid, is known as HTC or wet torrefaction (Hu et al., 2010; Gómez et al., 2020). Residence times of HTC can vary from a few minutes to several hours. Despite being first introduced by Friedrich Bergius in the early $19^{\text {th }}$ century, it has only gained its recent fame in the last decade owing to its large-scale applications and eco-friendliness (Ismail et al., 2019a). It transforms biomass usually with high moisture content into a solid product enriched in carbon called hydrochar, non-condensable gas mainly composed of $\mathrm{CO}_{\mathrm{x}}$ and liquid rich in organic compounds such as carboxylic acid (ex: acetic acid), aldehydes, alkenes, and aromatics (furanic, phenolic, etc.) (Lu et al., 2012; Pecchi et al., 2020). The basic product distribution of HTC is depicted in Figure 9. Similar to pyrolysis, the carbon content of biomass is increased while oxygen and hydrogen contents are decreased, thus resulting in a higher energy-dense hydrochar. The produced hydrochar has improved fuel properties such as high calorific value, high carbon content, high degree of homogeneity, low degradability, hydrophobicity, better self-binding properties, etc., and it is comparable to bituminous or lignite coal (Baratieri et al., 2015; Lentz et al., 2019). However, the distribution, composition, and structure of HTC products, including the properties of hydrochar (HHV, porosity, moisture content, etc.), vary depending on the processing conditions, reactor configuration, type of feedstock, morphology, etc. Thus again, optimization via modeling and simulation of complex underlying processes in HTC is salient commercially. A schematic representation of the HTC process is illustrated in Figure $\mathbf{1 0 .}$
Hydrochar is mainly used as a biofuel to harness energy via combustion or gasification. It also has several other value-added applications such as soil remediation and as adsorbents for water purification. Further, it can be used as carbon electrodes for super-capacitors when it is functionalized with nitrogen, sulfur, and phosphorous and also in catalysis. Moreover, HTC allows recovering valuable chemicals and nutrients from waste biomass. Some studies (Liu et al., 2017b; Lentz et al., 2019) claim hydrochar has more developed porosity than biochar, making it more suitable for soil remediation, enrichment, and carbon sequestration. Further, Gascó et al. (2018) reported that HTC could concentrate phosphorus and heavy metals in hydrochar. In addition, the HTC eliminates potential health risk substances such as pathogens that might be contained in wastes such as sewage sludge which are commonly treated biologically (Axelsson et al., 2012).

\subsection{HTC principle}

According to the available literature, the HTC process is largely exothermal, usually with an enthalpy change of around $1 \mathrm{MJ}$ per $1 \mathrm{~kg}$ of dry biomass feedstock (Pecchi et al., 2020). During the HTC process, biomass is degraded via a complex reaction pathway, and it undergoes four stages as depicted in Figure 11; i.e., hydrolysis, intermediate compounds degradation, the formation of aromatics, and polymerization (Gómez et al., 2020). However, several other mechanisms such as transformation reactions, Fischer-Tropsch reactions, and demethylation may also be present, and consequently, a vast number of intermediate products are formed, thus making a complex chemical network (Funke and Ziegler, 2010). Moreover, reaction kinetics are dependent on various other factors such as reaction conditions (temperature and heating rate), type of biomass (composition, density, and presence of inorganic compounds which can catalyze or inhibit reactions), and morphology (particle size, bulk density, and porosity), moisture content, reactor configuration, pressure, etc.

In subcritical conditions, water acts as an effective medium for acid-

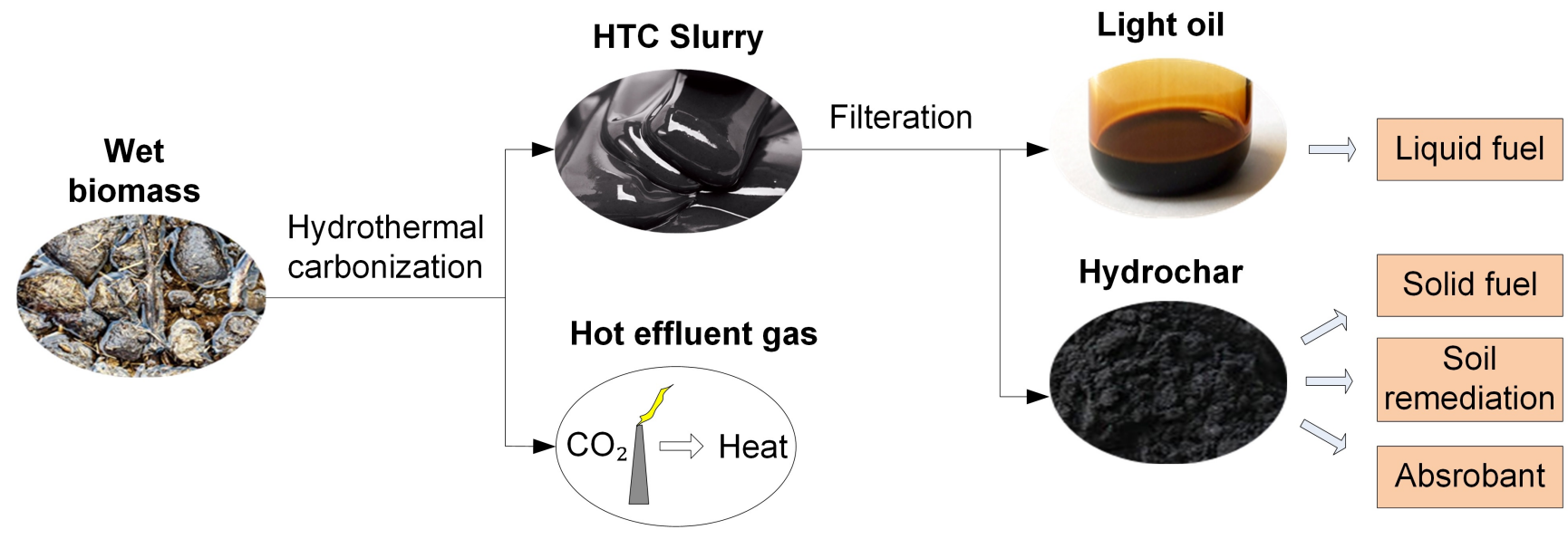

Fig. 9. Products and applications of hydrothermal carbonization. 


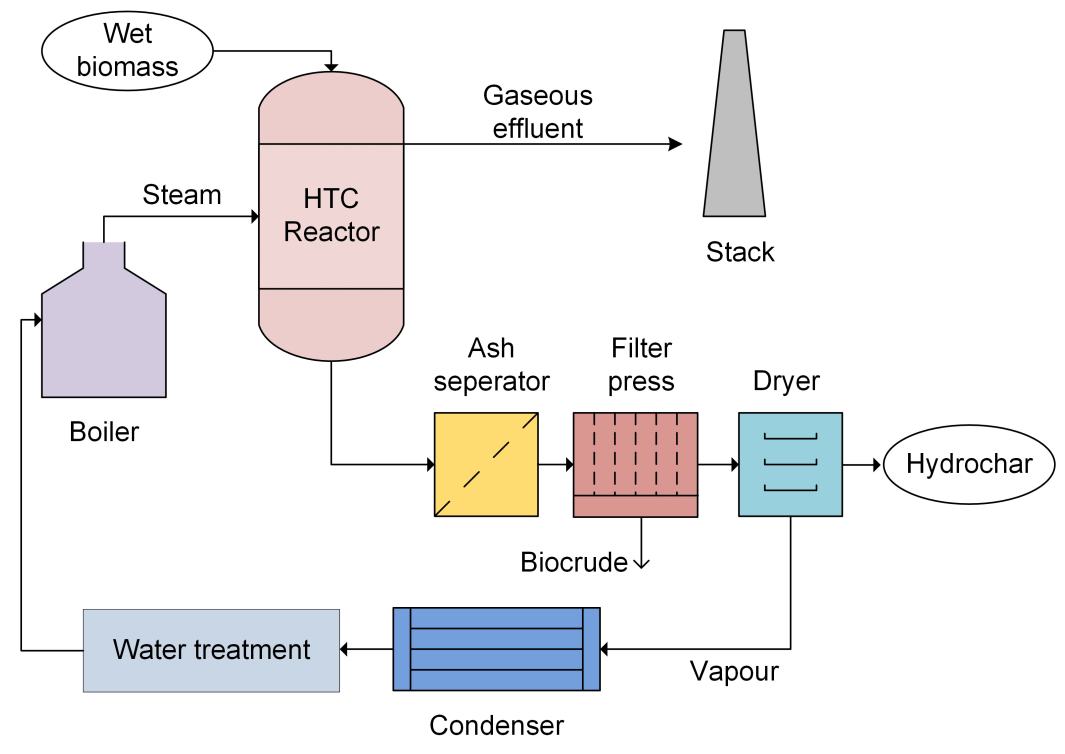

Fig. 10. A schematic illustration of a biomass hydrothermal carbonization process.

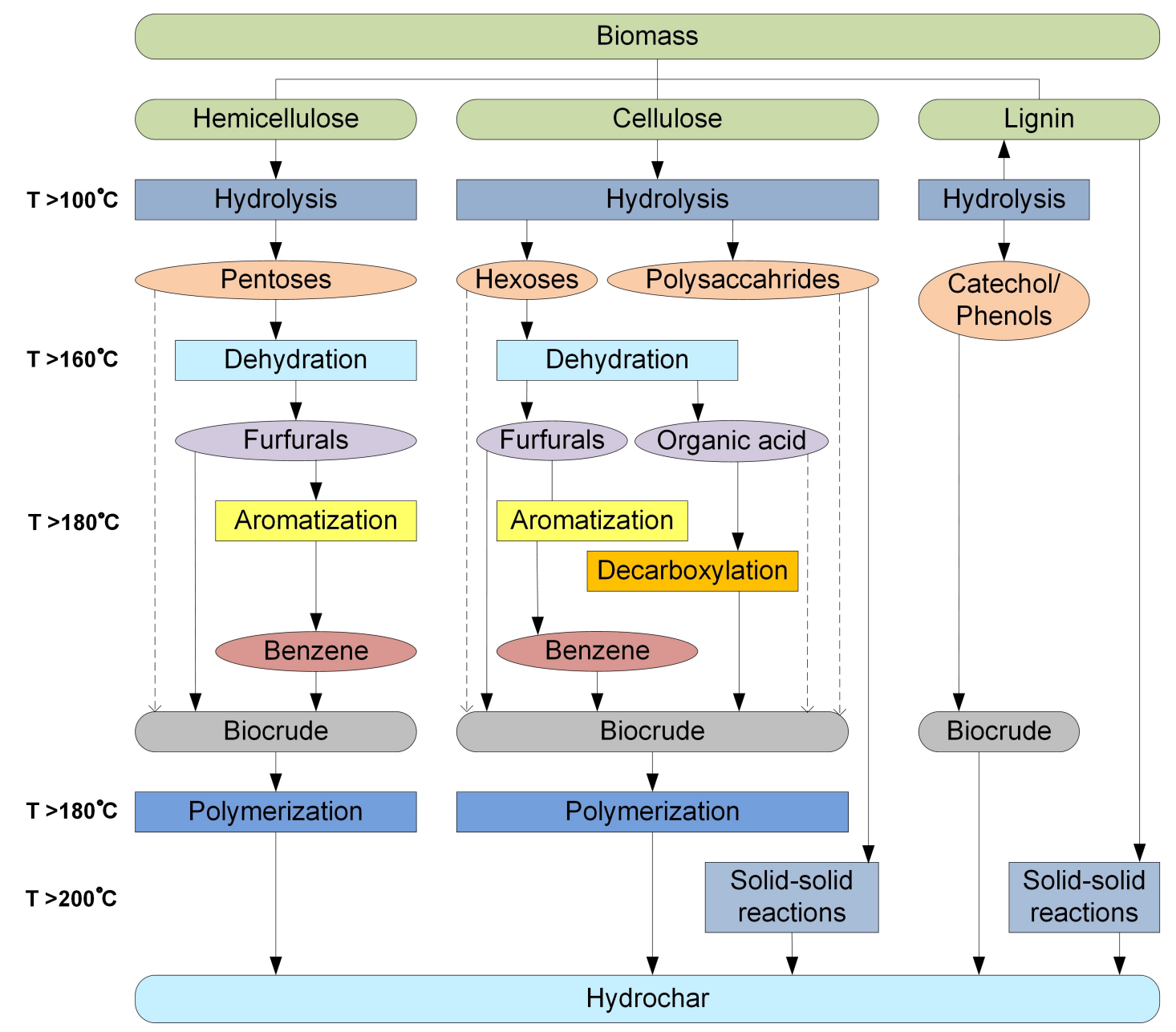

Fig. 11. Reaction stages and intermediate product formation of lignocellulosic biomass hydrothermal carbonization. 
base-catalyzed organic reactions such as hydrolysis and decarboxylations, which readily depolymerize the biopolymers present in biomass. In the first stage of HTC, biomass is hydrolyzed to form lighter chemical compounds such as glucose, xylose, pentose, hexose, phenol, catechol, glycerol, fatty acid, etc. Then dehydration and carboxylation reactions occur in the second stage, forming numerous intermediate products such as organic acids (for example; acetic acid, formic acid, lactic acid, etc.), ketones, phenols, carbon dioxide, methane, hydrogen, etc., while in the third stage, aromatics such as furfurals are formed further increasing the carbon content. Finally, in the fourth stage, hydrochar results through the condensation polymerization of aromatic networks (Gómez et al., 2020). Apart from this four-stage reaction mechanism, hydrochar can also be directly formed through an alternative route of solidsolid reactions, especially from lignin (Kruse et al., 2013).

\subsubsection{Effects of process parameters on HTC}

The main process parameters that affect HTC are temperature, retention time, biomass type, biomass to water ratio, pressure and catalysis. Similar to other thermal processes, the temperature is perceived to be the most influential parameter in HTC. Though increasing temperature improves conversion effectiveness, higher temperatures increase the gas yield while reducing the solid yield. Consequently, moderate temperatures favor the oil yield. Retention time being the second most influential parameter after temperature, it only impacts the hydrolysis reaction up to a certain time. Increasing the residence time at lower temperatures generally improves the hydrochar yield (Nizamuddin et al., 2017). Sermyagina et al. (2015) investigated the effects of temperature, retention time, and biomass to water ratio on HTC of coniferous wood chips. They reported that increasing the temperature from $180{ }^{\circ} \mathrm{C}$ to 250 ${ }^{\circ} \mathrm{C}$, resulted in a significant drop in the hydrochar yield while the heating value of hydrochar increased by about $40 \%$ at the highest temperature. Reducing the biomass to water ratio increased the yield due to the intensified hydrolysis reactions. Longer residence times caused a higher mass loss while improving the calorific value of hydrochar. Yet again, Khoo et al. (2020) studied the effects of hydrothermal temperature and retention time for microalgal biomass and confirmed the above results. They reported that increasing the temperature in the range of $180-240{ }^{\circ} \mathrm{C}$ reduced the hydrochar yield. However, the temperature effect on the hydrochar yield was more significant than the retention time.

Pressure is also a significant process parameter that influences the HTC process. Maintaining the pressure above the critical pressure can control the biomass decomposition and hydrolysis rate. The use of catalysts can enhance the yield by improving the hydrolysis level. Acid catalysts were reported to be more effective in enhancing hydrolysis. On the contrary, basic catalysts favor oil formation, but they reduce the hydrochar yield. Moreover, catalysts may also limit the formation of $\mathrm{NO}_{\mathbf{x}}$ (Nizamuddin et al., 2017). In addition, Heidari et al. (2018) studied the effects of process water recycling and particle size and reported an increase in solid yield by $12 \%$ and an increase in HHV of hydrochar by $2 \%$ after the first cycle of process water recycling. Increasing particle size increased the solid yield while reducing the HHV.

\subsection{Kinetic modeling}

The overall mass degradation rate of HTC is mainly decided based on both mass transfer and intrinsic reaction kinetics. Still, the understanding of the kinetics of HTC is limited due to the complex chemical reaction pathways and a vast number of intermediates present during the process. Further, most of the simplified kinetic models developed in previous studies are lumped component models, which may only be applied to similar types of feedstock in similar process conditions. This is mainly because reaction kinetics is affected by various parameters such as biomass composition, particle size, process conditions (biomass to water ratio, temperature, residence time, and pressure), and reactor configuration. In literature, several reaction schemes have been proposed, such as global first-order reaction, global $\mathrm{n}^{\text {th }}$ order reaction, pseudofirst-order reactions, pseudo $\mathrm{n}^{\text {th }}$ order reactions, single-step parallel reactions, and two-consecution parallel reactions (two-step parallel reactions).

Global first-order reaction schemes, which represent HTC of biomass by a single overall decomposition reaction that converts biomass into lump products, are the most simplified among the available kinetic models. Results of such models are usually accurate enough only for similar applications. HTC kinetics of sewage sludge and synthetic feces in the temperature range of 140-
$200{ }^{\circ} \mathrm{C}$ for $15-30$ min residence times via a global first-order reaction mechanism was studied by Danso-Boateng et al. (2013), and it was reported that the reaction temperature is more influential than the reaction time on the solid decomposition. Upon increasing temperature and residence time, the calorific value of hydrochar was enhanced. This first-order model claimed to have a reasonable overall accuracy though some experimental data did not fit perfectly with the model. Micali et al. (2019) employed a similar global first-order model for HTC of apple pomace at temperatures 260-305 ${ }^{\circ} \mathrm{C}$, whereas Gao et al. (2016) studied HTC kinetics of wheat straw and water hyacinth using a similar first-order global reaction scheme in the temperature range of $200-540{ }^{\circ} \mathrm{C}$ at different heating rates $\left(5-50{ }^{\circ} \mathrm{C} \mathrm{min}{ }^{-1}\right)$ and reported that the quality and energy yield of hydrochar (which significantly vary with the type of feedstock biomass) was reduced with increasing the temperature. Further, they identified that both hydrochar produced from wheat straw and water hyacinths were rich in oxygencontaining functional groups.

Reza et al. (2013) investigated the HTC kinetics of loblolly pine at 200$260^{\circ} \mathrm{C}$ and developed a simple model based on a pseudo-first-order reaction scheme for cellulose and hemicellulose with sufficient accuracy for the subjective temperature range. In this work, lignin was assumed to be inert in the temperature range of investigation, and aqueous extractives were assumed to react instantaneously. Further, this is a steady-state model which neglects the effect of the heating up process. Also, this study examined the effect of particle size and identified that the mass yield increases as the particle size is increased, thus implying that mass transfer is the rate-limiting effect. The significance of the heat-up phase, which was neglected in previous global first-order models, was discussed by ÁlvarezMurillo et al. (2016), and the corresponding temperature effect was included in the model by using an amplified Arrhenius equation such that temperature acts as a variable in determining both pre-exponential and exponential factors. Stobernack et al. (2020) similarly employed a kinetic model considering the heat-up phase temperature effects in developing a process model for HTC of OFMSW.

Pecchi et al. (2020) built a global $\mathrm{n}^{\text {th }}$ order kinetic model for digestate and sludge in the temperature range of $190-250{ }^{\circ} \mathrm{C}$, and it was claimed to have a significant accuracy. A similar kinetic model was employed by Tavakkol et al. (2021) in a 3D model for HTC of wet biomass in a rotary kiln reactor. Degradation rates of individual lignocellulose components during HTC of Australian saltbush in the temperature range of $200-260{ }^{\circ} \mathrm{C}$ and up to residence times of $60 \mathrm{~min}$ were investigated by Keiller et al (2019), and a kinetic model based on a pseudo $\mathrm{n}^{\text {th }}$ order reaction scheme was developed. In this study, one-fifth of lignin was assumed to remain inert in the temperature range of interest, whereas aqueous extractives were considered to degrade instantly under the applied process conditions. Hemicellulose was identified to be the most susceptible, while cellulose was the most resistive for hydrothermal degradation. Most importantly, the authors claim this model work can be served as universal standards for HTC kinetic modeling of lignocellulosic biomass.

On the other hand, Lucian et al. (2019) proposed a two consecutive parallel reaction model for HTC of olive trimming and grape marc at 180$250^{\circ} \mathrm{C}$ for residence times of $0-8 \mathrm{~h}$ and confirmed that hydrochar properties and product distribution were strongly affected by the temperature and the residence time. This study further revealed that temperature dependence is univocal, while residence time impact is complex. Also, the effect of the heat-up transient phase was studied, and carbonization was observed to begin in the heat-up phase. Most importantly, this lumped kinetic mode considers the secondary char formation via liquid-phase reactions. Overall, primary char formation was identified to be the fastest reaction, while gas formation reactions were the slowest. This model claimed to have better accuracy, with all model fitting errors being less than $10 \%$. Furthermore, a kinetic model based on a two-step parallel reaction scheme in which secondary char was formed through the conversion of intermediate solid product of the primary reaction, was employed by Baratieri et al. (2015). The study again confirmed that the first reaction step is significantly faster than the second reaction step, and hence, the secondary char formation is insignificant in low temperatures.

Gómez et al. (2020) elaborated a detailed reaction scheme taking into account all significant individual reactions occurring in different stages of HTC. However, owing to complexity, kinetic parameters were not determined for individual reactions, and experimentally determined 
fractional conversions were used instead for a continuous process model. This scheme can potentially be converted to a sophisticated HTC kinetic model by determining kinetics data for individual reactions so that it can be incorporated in a reactor model to achieve very high accuracies. But such a level of accuracy might be rarely required considering the computational capacity it may demand. The above kinetic models with the reaction mechanisms and the kinetic data are listed in Table 16.

\subsection{Reactor modeling}

There are several studies, as presented in Table 17, which have developed different reactor and process models via various approaches such as CFD and statistical techniques by using software tools and custom programs for HTC of waste biomass. Ismail et al. (2019b) developed a mathematical model to simulate unsteady state HTC of MSW in a pilot-scale batch reactor. It was developed as a customized program (named "COMMENT" code) using C\# language. The model can predict temperature, pressure, and water distribution profiles over time, and the model results were in good agreement with the experimental data under similar operating conditions. Further, this study revealed that the numerical predictions were highly sensitive to kinetics. This model can easily be scaled up to simulate commercial-level large reactors. On the other hand, Ismail et al. (2019a) developed a statistical model to predict the resource recovery (carbon and inorganic phosphorous) from HTC of poultry litter. This is based on the ANN technique combined with the Kriging interpolation approach for further improving the predictability. The model was validated by experimental data collected at temperatures $150-300{ }^{\circ} \mathrm{C}$ and residence times between $30-480 \mathrm{~min}$. This study further revealed that the temperature effect was more significant on resource recovery, whereas the effect of residence time was only significant at low temperatures. Furthermore, Baratieri et al. (2015) developed a simplified dynamic analytical model to simulate transient state HTC of grape marc in a batch reactor. The model is built based on the lump capacitance approach, and it can satisfactorily predict the thermal behavior of the reactor. This model can further be upgraded as a multi-phase model by introducing gas and solid phases and also by coupling thermal and kinetics routines into a single model.

A process model by "UniSim Design process simulator" was developed by Gómez et al. (2020) to simulate steady-state operation of HTC of various biomass such as sawdust, raps bran, oat husk and straw, pressed olive residue, and corn husk and cob. This model can be used for biomass with high cellulose contents. The accuracy of this model can be further improved by upgrading the kinetic model through incorporating the secondary reactions and also by modifying the conversion parameters of the reactions. This study highlighted that the continuous process had a better performance compared to the batch process in terms of efficiency and product yield. However, this model does not consider physical phenomena such as hydrodynamic of the reactor, heat and mass transfer resistances, and behavior of the reaction kinetics, which undoubtedly impacts the prediction accuracy. Lucian and Fiori (2017) developed a process model for continuous HTC of biomass (compost and grape marc) into pelletized hydrochar. The model was developed by a self-developed C\# program. This study also investigated the economics of the overall process. McGaughy and Toufiq Reza (2018) built a process model by Aspen Plus® V9 software to simulate continuous HTC of food waste. In this study, the highest solid yield was achieved at $200{ }^{\circ} \mathrm{C}$, and the solid yield varied between $68-75 \%$. Further, the produced hydrochar had moderate $\mathrm{HHV}\left(33.1 \mathrm{MJ} \mathrm{Kg}^{-1}\right)$ and low ash and sulfur contents. In addition, Stobernack et al. (2020) constructed a statistical regression model for continuous HTC of OFMSW in a continuous stirred tank reactor (CSTR). This general statistical model built based on empirical data can predict the product yield and distribution.

Mendecka et al. (2020) developed a 2D multiphase transient state CFD model by Ansys Fluent software to simulate the HTC of apple pomace in a batch reactor. The model can predict the temperature profile, product evolution in time, velocity flow fields, the spatial distribution of the mixture, etc. The model predictions were in good agreement with the available experimental data in the literature. However, a realistic validation of the model would be required to assure the prediction accuracy. The model can be further enhanced by direct coupling between the flow, heat transfer modeling, and kinetic routines. Sangare et al. (2021) built a 3D CFD model to simulate a batch stirred reactor for HTC of avocado stone. The model was developed by COMSOL Multiphysics 5.2 software. It can predict temperature profiles, biomass to water ratio effect on heat transfer, important hydrodynamics such as the effects of stirring speed, flow velocities, and solid distributions. This study revealed the existence of a stagnant zone just below the impeller, and the optimum mixing speed was identified to be $550 \mathrm{rpm}$. It further emphasized the thermal property differences of biomass and water under HTC conditions were negligible. In a similar approach, Tavakkol et al. (2021) developed a 3D CFD model by OpenFOAM to simulate a transient two-phase case for HTC of wet biomass in a batch rotary kiln reactor, and the model was based on the Eulerian-Lagrangian method in which the multicomponent gas phase and the discrete biomass particle were fully coupled. This model can accurately predict temperature profiles, product compositions, and complex physical processes involved in the drying, heating, and carbonization, such as the influence of reactor wall temperature, the effect of mass flow rate, influence of moisture content, effect of particle size, etc. and it was validated by a series of validation cases.

\section{Hydrothermal Liquefaction (HTL)}

\subsection{HTL Process}

HTL, also called hydrous pyrolysis, is a promising thermochemical conversion for biomass with high moisture content. This aqueous processing of biomass with substrate moisture or additive water usually operates at intermediate temperatures, i.e., $150-450{ }^{\circ} \mathrm{C}$ in the absence of oxygen under high pressures (>1 MPa) (Zhang, 2010; Magdeldin et al., 2017a). Many studies have introduced HTL as economically viable since it eliminates the requirement for pre-drying feedstock and produces bio-oil, also called bio-crude, as the major product (Zhang et al., 2012; Nazari et al., 2017). Nevertheless, HTL technology is still under the developing phase, and it is not often recognized as commercially viable (Chen et al. 2021).

HTL of biomass yields bio-oil, char, gases, and water-soluble products (WSP) (Nazari et al., 2017). Most importantly, clean higher quality bio-oil with higher LHV can be produced from HTL due to the diluted product concentration in the media, which prevents tar formation resulting from cross-linking and recombination reactions (Chan et al., 2015). Further, the HTL process can be made self-sufficient in energy by recycling a fraction of the produced bio-oil or char to fulfill the energy requirement of the HTL reactor. In addition, HTL is effective in pathogen elimination, especially for sludge and MSW treatment. However, when the solid concentration is very low, bio-oil produced from HTL may have low yields and high viscosities. Nevertheless, that can be avoided by employing co-conversion techniques (Nazari et al., 2017). Furthermore, the HTL-produced bio-oil has the potential to be enhanced to the level of a conventional hydrocarbon fuel through hydrotreating and hydrocracking by which a near-complete oxygen removal and molecular weight reduction can be achieved (Kumar et al., 2017).

\subsection{HTL principle}

Like HTC, subcritical or supercritical water acts as both a reactant and a solvent and thus takes part in biomass hydrolysis (Roberts et al., 2013). The properties of water, such as high ionic product and low dielectric constant, play critical roles both as a reactant and a solvent in HTL. Owing to the former attribute mentioned, i.e., higher ionic product in subcritical conditions, active hydronium $\left[\mathrm{H}_{3} \mathrm{O}\right]^{+}$and hydroxyl $[\mathrm{OH}]^{-}$ions contribute to cleavage of carbon-hetero bonds, thus degrading the biomass macromolecules. Further, oxygen present in biomass is removed, as $\mathrm{H}_{2} \mathrm{O}$ and $\mathrm{CO}_{2}$, via dehydration and decarboxylation, respectively. The former primarily increases the oil yield while the latter increases the $\mathrm{H} / \mathrm{C}$ ratio (Magdeldin et al., 2017a). The HTL-produced bio-oil has a significantly lesser oxygen content of $10-20 \mathrm{wt} \%$ compared to that of pyrolysis-produced bio-oil, which is about $40 \mathrm{wt} \%$. Moreover, the heating value of HTLproduced bio-oil is comparatively higher and is around $35 \mathrm{MJ} \mathrm{kg}^{-1}$, whereas the heating value of pyrolysis-produced bio-oil is about $16-19 \mathrm{MJ} \mathrm{kg}^{-1}$ (Zhu et al., 2014)

The HTL product yield and distribution are contingent upon the process conditions (temperature, pressure, and residence time), type of biomass, and solid concentration (Demirbaş, 2005). An increase in temperature tends to favor gases, while a decrease in temperature favors char production (Magdeldin et al., 2017a). The high pressures applied in HTL eliminate 
Table 16.

Hydrothermal carbonization kinetic models which were already employed or have potential in reactor modeling for waste biomass.

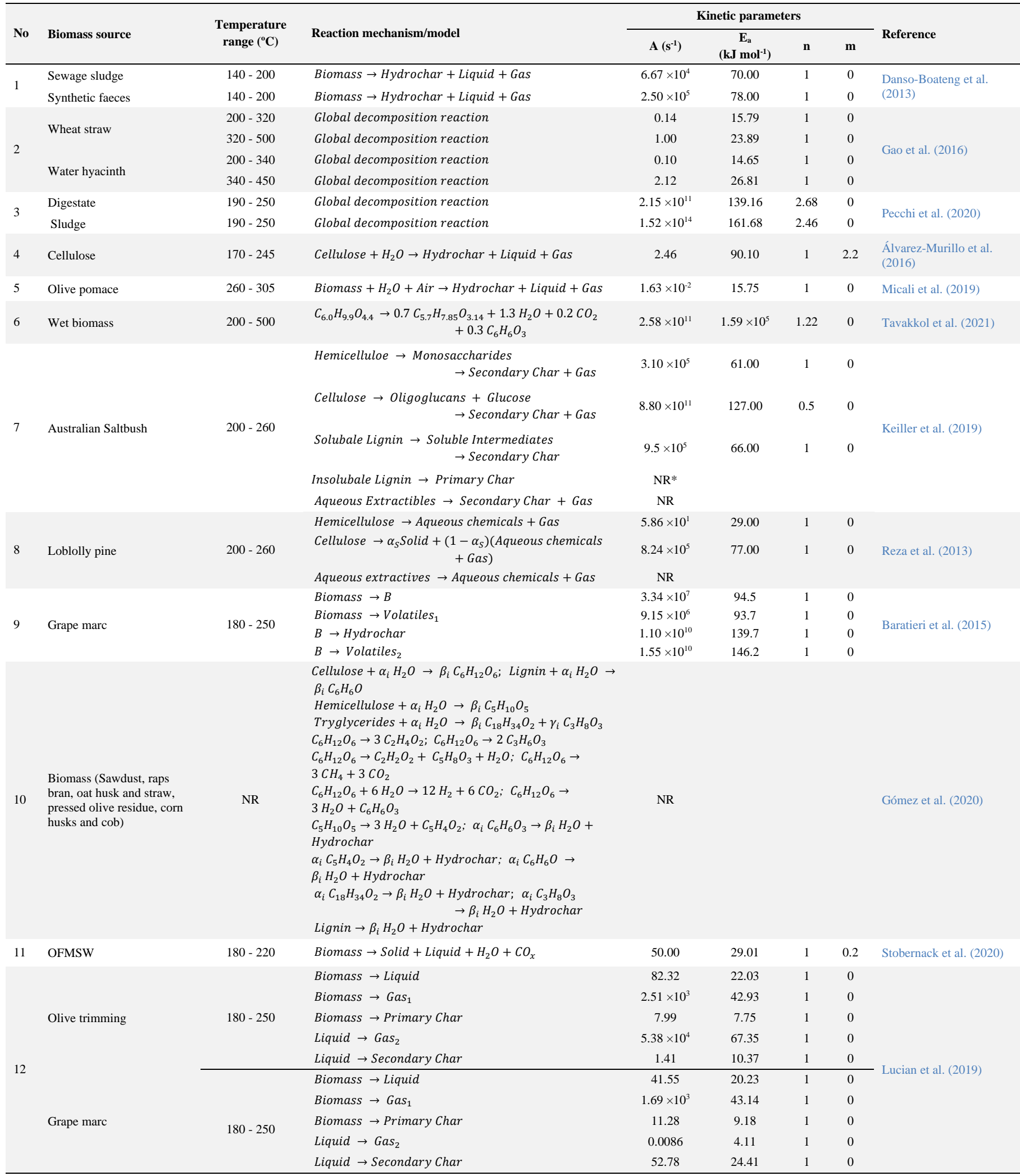

*NR: Not reporting

Please cite this article as: Perera S.M.H.D., Wickramasinghe C., Samarasiri B.K.T., Narayana M. Modeling of thermochemical conversion of waste biomass a comprehensive review. Biofuel Research Journal 32 (2021) 1481-1528. DOI: 10.18331/BRJ2021.8.4.3 
Table 17.

Hydrothermal carbonization reactor models developed for waste biomass.

\begin{tabular}{|c|c|c|c|c|}
\hline \multirow{2}{*}{ Feedstock } & \multirow{2}{*}{ Kinetic Model } & \multicolumn{2}{|c|}{ Reactor model } & \multirow{2}{*}{ Reference } \\
\hline & & Reactor type and model description & Main simplifying assumptions & \\
\hline
\end{tabular}

MSW Table 16; No $1 \quad \begin{aligned} & \text { A transient state numerical model was developed, using a } \\ & \text { customized code by C\# language for hydrothermal }\end{aligned}$

A 3D CFD model by OpenFOAM software was developed
for the wet carbonization of biomass in a rotary kiln reactor
(Batch reactor). The model was based on the Eulerian-
Lagrangian method. This model combines two OpenFOAM
standard solvers (coalChemistryFoam and MPPICFoam)
and four other customized sub-models to simulate the effect
of radiation, chemical kinetics by nth order Arrhenius, non-
spherical particles, and drying. Here the particle collision is
simulated by the MP-PIC model while the gas-phase
transport properties enthalpy \& heat capacities are
respectively determined from the temperature-dependent
Sutherland model (Parker and Sutherland, 1990) and
JANAF polynomials (Ku et al., 2014).

An advanced integrated hybrid artificial neural network -

Kriging statistical model was developed to correlate proces parameters to outputs for hydrothermal carbonization of poultry litter in a batch reactor. The model was developed by ANN then improved by the Kriging interpolation approach in which more data points from the limited number of collected experimental points were generated.

A 3D CFD model was developed for hydrothermal carbonization in a stirred autoclave reactor with an openloop controller system (batch reactor). This CFD model Avocado stone Table 16; No 4 developed by COMSOL Multiphysics 5.2 software uses the mixture model (turbulent or laminar) interface to simulate both steady-state and transient cases. Moreover, k-€ model turbulence model was included to model the turbulence flow.

A 2D multiphase transient state CFD model by ANSYS FLUENT® software was developed for HTC in a batch reactor. The flow simulation within the reactor was modeled by using the Mixture model. The concept of slip Olive pomace Table 16; No 5 velocities was used to allow relative velocities between liquid and solid phases, thus leading to a non-homogeneous mixture during the process. The numerical solution was based on the SIMPLE algorithm, and a second-order upwind scheme is used for discretization.

A process model was developed by Aspen Plus ${ }^{\circledR}$ V9 software for continuous HTC of food waste in a CSTR reactor. A Gibbs reactor in Aspen is used to simulate the chemical reactions.

Food waste Sawdust, raps bran, pressed olive residue, corn husks and cob using the UniSim Design process simulator. The developed process model uses the operational data of a German company commercial process, GRENOL GmbH, which on the concepts of stage-wise reactions and the liquid product recirculation.
The initial charge of the MSW is assumed to exist in the reactor, and the void space in the reactor is initially filled by air. The gas-phase consists of non-condensable gases from decomposition, air, and steam. Gas, solid and liquid phases are assumed to be in thermal equilibrium. The wall temperature is uniform. The heat capacities of the metal wall, MSW, solid product, water, steam, non-condensable gases, and air are assumed constant.

The gas phase is considered as Eulerian, whereas the biomass particles are treated as Lagrangian, and they form a moving bed. Gas-phase is assumed to be an ideal gas mixture Biomass particles with unspecified geometries and Biomass particles with unspecified geometries and
comparable thickness and effect of dense particle flows are considered. It is assumed that particles are thermally thin. Contact heat transfer between neighboring particles within the same computational cell is substituted by convection and radiation. Particle density is constant. Particle shrinkage is considered. It is assumed that drying occurs at the pressuredependent boiling temperature in a saturated atmosphere, and it considers the evaporation below the boiling temperature. Secondary reactions are neglected. The particle emissivity is taken as unity. The emission is a function of particle's surface temperature and surface area.
Ismail et al. (2019b)

The frozen rotor assumption is employed in the velocity field calculation for the steady-state case, and the results are used as initial values for the transient case. The experimental data obtained during the water heating under HTC conditions were used to estimate the average heat-transfer coefficient in the insulation to the environment. A diluted system consists of a dispersed phase of rigid spheres, and a continuous phase of Newtonian fluid is considered to study the dispersion behavior within the fluid. Approximation methods such as dispersed multiphase flow model approach and transport of diluted species are considered to yield sufficient accuracy. It is considered that the fluid is weakly compressible.

Three phases considered in this model are air, water, and solid, and the phases are considered as interpenetrating continua. It is assumed that water is compressible, and it remains liquid throughout the HTC process. Water density is a function of temperature ( $4^{\text {th }}$ order polynomial). The solid phase is considered a granular flow of constant density. Air is assumed to be a compressible ideal gas. The initial slurry (biomass and water) is homogeneous. Heat flux to the reactor is constant, and adiabatic conditions are assumed along the lateral surface of the reactor. The external environment consists of stationary air at $27{ }^{\circ} \mathrm{C}$, and the respective heat transfer coefficient is constant.

Sulfur content is neglected. The produced simple organic acids are liquid and are represented by formic and acetic acids. The produced gas is considered carbon dioxide. Solid hydrochar is assumed to be chemically inert. The yield of the continuous processing with compatible reaction times is assumed to be similar to that of the batch processing. The solubility of carbon dioxide at reactor conditions is insignificant. Food waste is homogenized.

This model is based on the hypothesis that the sub-processes occur in separated reaction stages (hydrolysis, intermediate product formation, aromatics formation, and hydrochar formation) as biomass passes through different reactors. The fractional conversion of each of the hydrolysis routes in the hydrolysis reactor is assumed to be equivalent to the mass ratio of the corresponding lignocellulose component in the biomass. Fractional conversion of all hydrochar forming reactions in the liquid product is assumed to be $90 \%$.

McGaughy and Toufiq Reza (2018) 
Table 17.

Continued.

\begin{tabular}{|c|c|c|c|c|}
\hline \multirow{2}{*}{ Feedstock } & \multirow{2}{*}{ Kinetic Model } & \multicolumn{2}{|c|}{ Reactor model } & \multirow{2}{*}{ Reference } \\
\hline & & Reactor type and model description & Main simplifying assumptions & \\
\hline $\begin{array}{l}\text { Compost and grape } \\
\text { marc }\end{array}$ & & $\begin{array}{l}\text { A process model for a continuous HTC operation with all } \\
\text { auxiliary equipment was developed by a self-developed } \\
\text { code by C\# language. }\end{array}$ & $\begin{array}{l}\text { The organic liquid mixture is represented by phenol itself. It } \\
\text { is assumed that all equipment is stationary and adiabatic. } \\
\text { Material losses are neglected. Solid, liquid, and gas yields are } \\
\text { assumed to independent of dry biomass to water ratio. }\end{array}$ & Lucian and Fiori (2017) \\
\hline OFMSW & Table 16; No 11 & $\begin{array}{l}\text { A statistical process model was developed for continuous } \\
\text { HTC of OFMSW in a CSTR reactor. }\end{array}$ & $\begin{array}{l}\text { The ambient temperature is taken as } 15^{\circ} \mathrm{C} \text {. All gaseous phase } \\
\text { volatile components are assumed to condensate during the } \\
\text { cooling phase. The gaseous product of the HTC process is } \\
\text { assumed to consist of } \mathrm{CO}_{2} \text { and } \mathrm{CO} \text { only. } 5 \% \text { of the transferred } \\
\text { heat is assumed to be lost. }\end{array}$ & Stobernack et al. (2020) \\
\hline Grape marc & Table 16; No 9 & $\begin{array}{l}\text { A simplified transient state thermal model developed by the } \\
\text { lumped capacitance approach through a resistance- } \\
\text { capacitance network for HTC of grape marc in a batch } \\
\text { reactor. }\end{array}$ & $\begin{array}{l}\text { The temperature difference inside each discrete component is } \\
\text { assumed to be negligible. The temperature inside the reactor } \\
\text { is uniform. The specific heat at constant pressure is assumed } \\
\text { to be equal to the specific heat at constant volume. }\end{array}$ & Baratieri et al. (2015) \\
\hline
\end{tabular}

dissipative heat loss via water evaporation and keep the biomass slurry in a single phase which does not require a substantial enthalpy input in maintaining the temperature compared to a two-phase system. Further, with increasing the pressure, the low molecular fraction in the bio-oil increases resulting in less viscous oil. In addition, when the pressure is higher, comparatively less retention time is required. Nevertheless, when the feed slurry is in the supercritical state, the pressure effect is comparatively less significant than the effects of the temperature and catalysts (Ong et al., 2019). The liquid yield of HTL is primarily composed of a hydrophobic crude phase with de-oxygenated hydrocarbons and water-soluble organics (Magdeldin et al., 2017a). The biooil yield from HTL can be significantly improved by the use of catalysts. Moreover, some studies (Karagöz et al., 2005; Mazaheri et al., 2010) have shown that the alkali catalysts yield higher oil yields than their counterparts.

\subsubsection{Effects of process parameters on $H T L$}

The yield and quality of the bio-oil produced from HTL vary considerably with the operating conditions. Similar to HTC, the main influential process parameters in HTL are temperature, retention time, biomass type, biomass to water ratio, heating rate, pressure, and catalysis. Commercial HTL reactors must be operated in optimum operating conditions to produce bio-oil with higher yield and quality. The optimum operating conditions generally vary with the type of biomass due to the compositional differences of biomass constituents such as hemicellulose, cellulose, lignin, protein, lipid, and carbohydrates (Xue et al., 2016). For instance, according to Feng et al. (2014), the bio-oil yields obtained from HTL of white pine bark, white spruce bark, and white birch bark at $300{ }^{\circ} \mathrm{C}$ for $15 \mathrm{~min}$ under $2 \mathrm{MPa}$ pressure were respectively $36 \%$, 58\%, and $67 \%$. Similar to other thermal processes, in HTL also, temperature is the most influential parameter. Under subcritical conditions, an increase in temperature results in a higher degradation rate leading to higher bio-oil yields. However, under supercritical conditions, increasing temperature increases the solid and gas yields while reducing the bio-oil yield due to the repolymerization of intermediate products at high temperatures. Shorter retention times result in higher bio-oil yields, but the time should be sufficiently long enough to complete reactions. Yet again, increasing the retention time encourages the repolymerization of intermediate products, thus leading to a lower bio-oil yield. Though the heating rate generally improves the bio-oil yield, the effect of the heating rate is comparatively less significant (Akhtar and Amin, 2011).

Water plays a critical role in hydrolysis, and hence biomass to water ratio is a very influential parameter in HTL. It also contributes to improving the biooil quality by stabilizing free radicals. As a result, reducing biomass to water ratio up to a certain limit improves the bio-oil yield. Once it reaches the limit, it causes a reduction in the yield (Yin et al., 2010; Liu et al., 2013b). Despite pressure not being significantly influential on the bio-oil yield, it plays a very important role in HTL. Water is kept in a single phase by pressure, and hence large enthalpy changes occurring due to phase change are eliminated. Most importantly, it governs the hydrolysis and biomass dissolution rate (Faeth et al., 2013). Catalysis can significantly increase the yield and quality of bio-oil. Alkali and acid catalysts are the most popular for HTL. Though strong acids such as hydrochloric, sulfuric, phosphoric, etc., are effective catalysts, their highly corrosive nature tarnish their ability to be used in industrial applications. Alkali salts such $\mathrm{NaOH}, \mathrm{KOH}, \mathrm{Na}_{2} \mathrm{CO}_{3}$, etc., are perceived to be effective alkali catalysts for HTL (Chen et al., 2015). In addition, particle size also mildly influences the bio-oil yield, and in fact, smaller particle sizes enhance the bio-oil yield (Xue et al., 2016).

\subsection{Kinetic modeling}

The actual reaction schemes involved in the HTL are highly complex due to a large number of chemical reactions and the resulting numerous intermediate products. As a result, it is practically very difficult to model individual reactions taking place during HTL, and hence the simplified lumped kinetic approach is frequently employed. However, there is no sufficient literature in the field of HTL kinetic modeling, and only very few studies have attempted the kinetic modeling of waste biomass. Given the fact that kinetics is strongly dependent on the type of biomass, there is a huge requirement for studying HTL kinetics of various waste biomass sources. Owing to this research gap, sophisticated reactor models are hindered from development.

Zhang et al. (2012) developed a kinetic model by comparing seven possible reaction schemes for HTL of high-diversity grassland perennials. In this model, biomass is considered to decompose into liquid (tar), char, and gases via three competitive parallel reactions, and then the produced tar undergoes a secondary cracking reaction to form secondary gases. This two-consecutive parallel reactions model was closely fitted with the experimental data. Reaction rate constants for all reactions in the model were represented via Arrhenius-type equations except for the reaction of biomass to char. Obeid et al. (2020) constructed a bulk kinetic model considering biomass components carbohydrate, lipid, protein, and lignin for the temperature range of $250-350{ }^{\circ} \mathrm{C}$ and the reaction times between 5 to 60 min. The study further identified that the bio-oil produced from lipids contained fatty acids, whereas phenol, furans, aldehydes, aromatics, and ketones were contained in the bio-oil produced from carbohydrates. The bio-oil derived from proteins contained amides, aromatics, amines, carboxylic acids, and short hydrocarbon chains, and the bio-oil produced from lignin was mainly composed of phenolic compounds. Moreover, a decreasing trend of bio-oil yield was observed with increasing the residence time for all biomass components. The above kinetic models with the reactions mechanisms and the kinetic data are listed in Table 18

\subsection{Reactor modeling}

For HTL of waste biomass, only a limited number of research has been conducted so far. One of the possible reasons for this can be the unavailability of more realistic kinetic models. Developing accurate reactor 
Table 18.

Hydrothermal liquefaction kinetic models which were already employed or have potential in reactor modeling for waste biomass.

\begin{tabular}{|c|c|c|c|c|c|c|c|c|}
\hline \multirow[b]{2}{*}{ No } & \multirow[b]{2}{*}{ Biomass source } & \multirow{2}{*}{$\begin{array}{c}\text { Temperature range } \\
\left({ }^{\circ} \mathrm{C}\right)\end{array}$} & \multirow[b]{2}{*}{ Reaction mechanism/model } & \multicolumn{4}{|c|}{ Kinetic parameters } & \multirow[b]{2}{*}{ Reference } \\
\hline & & & & $A\left(s^{-1}\right)$ & $\begin{array}{c}\mathbf{E}_{\mathrm{a}} \\
\left(\mathrm{kJ} \mathrm{mol}^{-1}\right)\end{array}$ & $\mathbf{n}$ & $\mathbf{m}$ & \\
\hline \multirow{4}{*}{1} & \multirow{4}{*}{ Prairie grass } & \multirow{4}{*}{$\approx 374$} & Biomass $+\mathrm{H}_{2} \mathrm{O} \rightarrow$ Liquid & $7.17 \times 10^{-2}$ & 14.00 & 1 & 0 & \multirow{4}{*}{ Zhang et al. (2012) } \\
\hline & & & Biomass $+\mathrm{H}_{2} \mathrm{O} \rightarrow$ Gases & $3.31 \times 10^{-1}$ & 32.42 & 1 & 0 & \\
\hline & & & Biomass $+\mathrm{H}_{2} \mathrm{O} \rightarrow$ Char $; k=0.0339-2.216 \times 10^{-4}(T-300)$ & & & & & \\
\hline & & & Liquid $\rightarrow$ Secondary gases & $2.67 \times 10^{-4}$ & 5.79 & 1 & 0 & \\
\hline \multirow{18}{*}{2} & \multirow{5}{*}{ Lipid } & \multirow{5}{*}{$250-350$} & Solid $\rightarrow$ Aqueous & 33.00 & 60.00 & 1 & \multirow{5}{*}{\multicolumn{2}{|c|}{ t }} \\
\hline & & & Aqueous $\rightarrow$ Crude & 2.14 & 28.80 & 1 & & \\
\hline & & & Crude $\rightarrow$ Aqueous & 12.89 & 60.00 & 1 & & \\
\hline & & & Crude $\rightarrow$ Solid & 3.23 & 3.30 & 1 & & \\
\hline & & & Crude $\rightarrow$ Gas & 0.14 & 0.17 & 1 & 1 & \\
\hline & \multirow{5}{*}{ Carbohydrate } & \multirow{5}{*}{$250-350$} & Solid $\rightarrow$ Aqueous & 3.81 & 22.73 & 1 & 1 & \multirow{5}{*}{ Obeid et al. (2020) } \\
\hline & & & Aqueous $\rightarrow$ Crude & 0.60 & 1.20 & 1 & 1 & \\
\hline & & & Crude $\rightarrow$ Aqueous & 3.00 & 9.16 & 1 & 1 & \\
\hline & & & Crude $\rightarrow$ Solid & 17.34 & 60.00 & 1 & 1 & \\
\hline & & & Aqueous $\rightarrow$ Gas & 0.61 & 1.06 & 1 & 1 & \\
\hline & \multirow{5}{*}{ Protein } & \multirow{5}{*}{$250-350$} & Solid $\rightarrow$ Aqueous & 12.24 & 59.79 & 1 & 1 & \\
\hline & & & Aqueous $\rightarrow$ Crude & 7.87 & 51.48 & 1 & 1 & \\
\hline & & & Crude $\rightarrow$ Aqueous & 0.85 & 4.03 & 1 & 1 & \\
\hline & & & Aqueous $\rightarrow$ Solid & 2.62 & 3.82 & 1 & 1 & \\
\hline & & & Aqueous $\rightarrow$ Gas & 0.36 & 0.38 & 1 & 1 & \\
\hline & \multirow{3}{*}{ Lignin } & \multirow{3}{*}{$250-350$} & Aqueous $\rightarrow$ Crude & 33.01 & 44.64 & 1 & 1 & \\
\hline & & & Crude $\rightarrow$ Aqueous & 54.06 & 59.84 & 1 & 1 & \\
\hline & & & Crude $\rightarrow$ Gas & 0.15 & 0.34 & 1 & 1 & \\
\hline
\end{tabular}

models for HTL is even more challenging due to the difficulty in computing specific thermodynamic interactions in organic-aqueous mixtures and predicting phase equilibria for the highly asymmetric multi-dimensional multicomponent system (Magdeldin et al., 2017a). Chan et al. (2018) constructed a regression model for HTL of palm kernel shell at the temperature range of 330$390{ }^{\circ} \mathrm{C}$, the pressure of $25-35 \mathrm{MPa}$, the reaction time of 60-120 min, and the biomass-to-water ratio between $0.20-0.50 \mathrm{wt} \%$. The developed quadratic model was accurately fitted with the experimental data with the coefficient of determination $\left(\mathrm{R}^{2}\right)$ and confidence level of 0.9109 and $95 \%$, respectively. The optimum bio-oil yield of $15.48 \mathrm{wt} \%$ was achieved at temperature $390{ }^{\circ} \mathrm{C}$ and pressure of $25 \mathrm{MPa}$ under the reaction time of $60 \mathrm{~min}$ for the biomass-to-water ratio of 0.20 . Further, the study investigated the mediation effect of supercritical $\mathrm{CO}_{2}$ on bio-oil yield and found the effect to be insignificant at a high temperature of about $390^{\circ} \mathrm{C}$ while it was considerable at $300^{\circ} \mathrm{C}$. However, more rigorous experiments are required to elaborate on the mediation effect of supercritical $\mathrm{CO}_{2}$. Similarly, Aierzhati et al. (2019) developed a regression model for HTL of food waste to predict the bio-oil yield with respect to feedstock composition, temperature, and retention time. The model predictions were accurately fitted with experimental data, with the standard errors of all parameters being less than 0.05 .

A steady-state Aspen Plus $®$ process model was developed by Magdeldin et al. (2017a) to simulate HTL of forest residue. Results for HTL yield obtained from a custom-built predictive linear programming model were used in this model. According to the model predictions, the resulting bio-oil had a calorific value (wet basis) of $10 \mathrm{MJ} \mathrm{kg}^{-1}$ against the feedstock calorific value (wet basis) of $27.6 \mathrm{MJ} \mathrm{kg}^{-1}$. This model needs to be validated to assure its accuracy. Similarly, Magdeldin et al. (2017b) developed a process model by Aspen Plus® to simulate HTL of forest residue for polygeneration of bio-oil, bio-char, and $\mathrm{H}_{2}$. The simulation was run at temperature $330{ }^{\circ} \mathrm{C}$ and pressure 210 bar. The maximum plant thermal efficiency achieved for the polygeneration based on lower heating values was $85.2 \%$. However, the model needs to be experimentally validated to assure its accuracy for the model to be used in other similar applications.
Tran et al. (2017) built a 3D CFD model by Ansys Fluent (ver. 18.0) to simulate fast HTL of wet biomass in a nozzle reactor. The model can predict temperature profile, the effect of mass flow rates on the RTD, and the effect of mass flow rates on the temperature profile. The model was validated for the RTD by the existing literature data and observed good compatibility between the model-predicted RTD and the literature data. Nevertheless, more rigorous experiments are required to ensure the model's validity for other important parameters such as product yield and temperature profiles. This model is not valid for high viscous fluid flows due to the assumption of a Newtonian fluid. Tran (2020) further developed this model for nonNewtonian fluid flow conditions. The power-law non-Newtonian model was employed to model the cold flow of biomass slurry and investigated the effects of the flow ratio of hot and cold flows, the viscosity of cold flow, and the total mass flow rate on the temperature profile and mixing. It was observed that the outlet temperature was strongly influenced by the flow ratio and the temperature profile was lower than the profile obtained for the Newtonian model. Further, the mixing zone shape was significantly different from that of the Newtonian model, and the mixing zone moved towards the outlet of the hot inlet tube. The viscosity of cold flow only had a minor impact on the temperature profile. Upon increasing the total mass flow rate, the mixing zone temperature increased, and the mixing zone shifted downwards. The basic assumptions and modeling techniques for the above models are presented in Table 19.

\section{Conclusions and prospects}

Thermochemical conversion processes are highly complex, and more detailed elaborations of chemistry (reaction mechanisms and kinetics) and hydrodynamics behind these processes are under the research level. Nevertheless, modeling and simulation is great tool for understanding these complex phenomena. There are many modeling studies conducted in the field of thermochemical conversion of waste biomass, and each of these models has unique features, capabilities, and limitations. The scale of applicability, degree of accuracy, and validity differ from model to model. 
Table 19.

Hydrothermal liquefaction reactor models developed for waste biomass.

\begin{tabular}{|c|c|c|c|}
\hline \multirow{2}{*}{ Biomass source } & \multicolumn{2}{|l|}{ Reactor model } & \multirow{2}{*}{ - Reference } \\
\hline & Reactor type and model description & Main simplifying assumptions & \\
\hline Forest residue & $\begin{array}{l}\text { Aspen Plus® model was developed for HTL of forest residue. HCOALGEN and } \\
\text { DCOALIGT. Non-conventional properties enthalpy and density were } \\
\text { determined by built in correlations HCOALGEN and DCOALIGT in Aspen. } \\
\text { RYIELD reactor block was used to simulated HTL reactor. A custom built } \\
\text { predictive Linear Programming model was used to predict product composition. }\end{array}$ & $\begin{array}{l}\text { Steady state operation. The reactor is perfectly insulated } \\
\text { and preheated to } 300{ }^{\circ} \mathrm{C} \text { during the start-up. Ash is } \\
\text { completely recovered with char. }\end{array}$ & Magdeldin et al. (2017a) \\
\hline Palm kernel shell & $\begin{array}{l}\text { A regression model was developed for HTL of palm kernel shell. An accurate } \\
\text { quadratic model was derived via analysis of variance (ANOVA) technique. }\end{array}$ & & Chan et al. (2018) \\
\hline Forest residue & $\begin{array}{l}\text { A process model was developed by Aspen Plus to simulate HTL of forest } \\
\text { residue for poly-generation. The reactor yield calculated via a predictive linear } \\
\text { programming model developed by the General Algebraic Modeling System- } \\
\text { GAMS software, was used as input for the built-in reactor model. }\end{array}$ & & Magdeldin et al. (2017b) \\
\hline Wet biomass & $\begin{array}{l}\text { A 3D CFD model by Ansys Fluent was developed for HTL of wet biomass in a } \\
\text { nozzle reactor. The 3D segregated double precision solver was used. } \\
\text { Simulations were extended from steady state which established the temperature } \\
\text { and flow fields to transient case in which steady state temperature and flow } \\
\text { fields were kept unchanged to establish the residence time distribution of the } \\
\text { mixing zone. }\end{array}$ & $\begin{array}{l}\text { The reactor is axisymmetric. } \\
\text { Newtonian fluids. }\end{array}$ & Tran et al. (2017) \\
\hline Food waste & $\begin{array}{l}\text { A regression model was developed for HTL of food waste. The model was } \\
\text { based on a second order polynomial with backward elimination and the } \\
\text { regression analysis was performed by using analysis of variance (ANOVA) and } \\
\text { residuals. }\end{array}$ & & Aierzhati et al. (2019) \\
\hline Wet biomass & $\begin{array}{l}\text { A CFD model by Ansys Fluent was developed for fast HTL of wet biomass in a } \\
\text { nozzle reactor under non-Newtonian fluid flow conditions. Simulations were } \\
\text { performed for both steady-state and transient state. The turbulence was modeled } \\
\text { by using a realizable k- } \varepsilon \text { turbulent model. }\end{array}$ & Non-Newtonian fluid flow conditions. & Tran (2020) \\
\hline
\end{tabular}

However, the unavailability of proper analysis of above mentioned has been an obstacle for further developments and commercial applications. This review study has investigated those discussed above and the potential ways of upgrading the existing models for waste biomass thermochemical conversation processes. The selection of a model for a particular application should be made considering simplifying assumptions which the model is based on, degree of accuracy, computational capacity, the flexibility of the model to allow different feedstock and reactor configurations, reliability (method of validation), and potential upgrades to enhance or broaden the prediction capabilities. The key challenges and prospects of reactor modeling of biomass thermochemical conversion are listed below:

i. Computational burden: more realistic and advanced models with less simplifying assumptions demand higher computational capacities, requiring fast solving efficient numerical schemes.

ii. Availability of detailed kinetic models: the accuracy, reliability, and applicability of a reactor model strongly depend on the kinetics, requiring more realistic kinetic models. Biomass decomposition reaction pathways are highly complex with numerous intermediates and are sensitive to various factors. Consequently, most of the reactor models have employed available lumped kinetic models.

iii. Complex hydrodynamics: biomass thermochemical conversion involves multiphase and complex fluid flows, and an accurate prediction of intermediate product formation is difficult

iv. Modeling of emerging trends of biomass thermochemical conversion: novel techniques such as chemical looping combustion, chemical looping pyrolysis-gasification, and catalytic processes are getting industrial attention.

v. Integration of predictive analytics with the conventional models: data analysis techniques such as machine learning, the response surface methodology, etc., are highly useful in improving the applicability of conventional models.

\section{References}

[1] Adeniyi, A.G., Ighalo, J.O., Amosa, M.K., 2019. Modelling and simulation of banana ( Musa spp.) waste pyrolysis for bio-oil production. Biofuels. 12(7), 1-5.
[2] Aierzhati, A., Stablein, M.J., Wu, N.E., Kuo, C.T., Si, B., Kang, X. Zhang, Y., 2019. Experimental and model enhancement of food waste hydrothermal liquefaction with combined effects of biochemical composition and reaction conditions. Bioresour. Technol. 284, 139147.

[3] Akhtar, J., Amin, N.A.S., 2011. A review on process conditions for optimum bio-oil yield in hydrothermal liquefaction of biomass. Renew. Sust. Energy Rev. 15(3), 1615-1624.

[4] Al-Qayim, K., Nimmo, W., Hughe, K.J., Pourkashanian, M., 2019 Effect of oxy-fuel combustion on ash deposition of pulverized wood pellets. Biofuel Res. J. 6(1), 927-936.

[5] Altafini, C.R., Wander, P.R., Barreto, R.M., 2003. Prediction of the working parameters of a wood waste gasifier through an equilibrium model. Energy Convers. Manage. 44(17), 2763-2777.

[6] Álvarez-Murillo, A., Sabio, E., Ledesma, B., Román, S., GonzálezGarcía, C.M., 2016. Generation of biofuel from hydrotherma carbonization of cellulose. Kinet. modell. Energy. 94, 600-608.

[7] Amutio, M., Lopez, G., Alvarez, J., Moreira, R., Duarte, G., Nunes, J., Olazar, M., Bilbao, J., 2013. Pyrolysis kinetics of forestry residues from the Portuguese Central Inland Region. Chem. Eng. Res. Des. 91(12), 2682-2690.

[8] Anca-Couce, A., 2016. Reaction mechanisms and multi-scale modelling of lignocellulosic biomass pyrolysis. Prog. Energy Combust. Sci. 53, 41-79

[9] Asthana, A., Ménard, Y., Sessiecq, P., Patisson, F., 2010. Modeling on-grate MSW incineration with experimental validation in a batch incinerator. Ind. Eng. Chem. Res. 49(16), 7597-7604.

[10] Axelsson, L., Franzén, M., Ostwald, M., Berndes, G., Lakshmi, G., Ravindranath, N.H., 2012. Jatropha cultivation in southern India: assessing farmers' experiences. Biofuels, Bioprod. Biorefin. 6(3), 246-256.

[11] Azzone, E., Morini, M., Pinelli, M., 2012. Development of an equilibrium model for the simulation of thermochemical gasification and application to agricultural residues. Renew. Energy. 46, 248-254

[12] Bach, Q.V., Skreiberg, Ø., 2016. Upgrading biomass fuels via wet torrefaction: a review and comparison with dry torrefaction. Renew. Sust. Energy Rev. 54, 665-677.

[13] Bach, Q.V., Skreiberg, Ø., Lee, C.J., 2017. Process modeling and 
optimization for torrefaction of forest residues. Energy. 138, 348-354.

[14] Balat, M., Balat, M., Kirtay, E., Balat, H., 2009. Main routes for the thermo-conversion of biomass into fuels and chemicals. part 1: pyrolysis systems. Energy Convers. Manage. 50(12), 3147-3157.

[15] Balu, E., Chung, J.N., 2012. System characteristics and performance evaluation of a trailer-scale downdraft gasifier with different feedstock. Bioresour. Technol. 108, 264-273.

[16] Baratieri, M., Basso, D., Patuzzi, F., Castello, D., Fiori, L., 2015. Kinetic and thermal modeling of hydrothermal carbonization applied to grape marc. Chem. Eng. Trans. 43(43), 505-510.

[17] Baruah, D., Baruah, D.C., 2014. Modeling of biomass gasification: a review. Renew. Sust. Energy Rev. 39, 806-815.

[18] Bates, R.B., Ghoniem, A.F., 2014. Modeling kinetics-transport interactions during biomass torrefaction: the effects of temperature, particle size, and moisture content. Fuel. 137, 216-229.

[19] Bech, N., Larsen, M.B., Jensen, P.A., Dam-Johansen, K., 2009. Modelling solid-convective flash pyrolysis of straw and wood in the Pyrolysis Centrifuge Reactor. Biomass Bioenergy. 33(6-7), 999-1011.

[20] Bhavanam, A., Sastry, R.C., 2013. Modelling of solid waste gasification process for synthesis gas production. J. Sci. Ind. Res. 72(9-10), 611-616.

[21] Bhoi, P.R., Ouedraogo, A.S., Soloiu, V., Quirino, R., 2020. Recent advances on catalysts for improving hydrocarbon compounds in bio-oil of biomass catalytic pyrolysis. Renew. Sust. Energy Rev. 121, 109676.

[22] Bridgwater, A.V., 2012. Review of fast pyrolysis of biomass and product upgrading. Biomass Bioenergy. 38, 68-94.

[23] Bryden, K.M., Ragland, K.W., Rutland, C.J., 2002. Modeling thermally thick pyrolysis of wood. Biomass Bioenergy. 22(1), 41-53.

[24] Bugge, M., Skreiberg, Ø., Haugen, N.E.L., Carlsson, P., Houshfar, E., Løvås, T., 2015. Numerical simulations of staged biomass grate fired combustion with an emphasis on NOx emissions. Energy Procedia. 75, $156-161$.

[25] Cao, Y., Bai, Y., Du, J., 2021. Air-steam gasification of biomass based on a multi-composition multi-step kinetic model: a clean strategy for hydrogen-enriched syngas production. Sci. Total Environ. 753, 141690.

[26] Cerciello, F., Apicella, B., Russo, C., Cortese, L., Senneca, O., 2021. Effects of pressure on lignocellulosic biomass fast pyrolysis in nitrogen and carbon dioxide. Fuel. 287, 119604

[27] Chan, Y.H., Quitain, A.T., Yusup, S., Uemura, Y., Sasaki, M., Kida, T., 2018. Optimization of hydrothermal liquefaction of palm kernel shell and consideration of supercritical carbon dioxide mediation effect. J. Supercrit. Fluids. 133, 640-646.

[28] Chan, Y.H., Yusup, S., Quitain, A.T., Tan, R.R., Sasaki, M., Lam, H.L., Uemura, Y., 2015. Effect of process parameters on hydrothermal liquefaction of oil palm biomass for bio-oil production and its life cycle assessment. Energy Convers. Manage. 104, 180-188.

[29] Chartier, J., Guernion, P.Y., Milo, I., 2007. CFD modelling of municipal solid waste incineration. Prog. Comput. Fluid Dyn. Int. J. 7(1), 19-24

[30] Chen, W.H., Lin, B.J., Huang, M.Y., Chang, J.S., 2015a. Thermochemical conversion of microalgal biomass into biofuels: a review. Bioresour. Technol. 184, 314-327.

[31] Chen, W.H., Peng, J., Bi, X.T., 2015b. A state-of-the-art review of biomass torrefaction, densi fi cation and applications. Renew. Sust. Energy Rev. 44, 847-866.

[32] Chen, X., Tian, Z.F., van Eyk, P.J., Lewis, D., Nathan, G.G.J., 2021. Numerical simulation of hydrothermal liquefaction of algae in a lab-scale coil reactor. Exp. Comput. Multiphase Flow. 1(1), 1-8.

[33] Chen, Y., Wu, Y., Ding, R., Zhang, P., Liu, J., Yang, M., Zhang, P., 2015c. Catalytic hydrothermal liquefaction of $D$. tertiolecta for the production of bio-oil over different acid/base catalysts. AIChE J. 61(4), 1118-1128.

[34] Chhiti, Y., Kemiha, M., 2013. Thermal conversion of biomass, pyrolysis and gasification: a review. Int. J. Eng. Sci. 2(3), 75-85.

[35] Chiou, B.S., Cao, T., Valenzuela-Medina, D., Bilbao-Sainz, C., AvenaBustillos, R.J., Milczarek, R.R., Du, W.X., Glenn, G.M., Orts, W.J., 2018. Torrefaction kinetics of almond and walnut shells. J. Therm. Anal. Calorim. 131(3), 3065-3075.

[36] Cordiner, S., Manni, A., Mulone, V., Rocco, V., 2017. Biomass fast pyrolysis process at laboratory scale: residence time and heating up evaluation in a shaftless screw reactor by means of a discrete element model approach, in: International Symposium on Advances in
Computational Heat Transfer. Begellhouse, Connecticut. pp. 10711083.

[37] Corella, J., Herguido, J., Gonzalez-Saiz., J., 1989. Steam gasification of biomass in fluidized bed-Effect of the type of feed stock, in: Ferrero, G.L., Maniatis, K., Buekens, A., Bridgwater, A.V. (Eds.), in: pyrolysis and gasification. London. Elsevier Applied Science., pp. 618-623.

[38] Corma, A., Huber, G.W., Sauvanaud, L., O'connor, P., 2007. Processing biomass-derived oxygenates in the oil refinery: catalytic cracking (FCC) reaction pathways and role of catalyst. J. Catal 247(2), 307-327

[39] da Silva, J.C., de Oliveira, R.C., da Silva Neto, A., Pimentel, V.C., dos Santos, A.D.A., 2015. Extraction, addition and characterization of hemicelluloses from corn cobs to development of paper properties. Procedia Mater. Sci. 8, 793-801.

[40] Dahlquist, E., Mirmoshtaghi, G., Larsson, E.K., Thorin, E., Yan, J., Engvall, K., Liliedahl, T., Dong, C., Hu, X., Lu, Q., 2013. Modelling and simulation of biomass conversion processes, in: $20138^{\text {th }}$ EUROSIM Congress on Modelling and Simulation. IEEE, pp. 506512.

[41] Damartzis, T., Zabaniotou, A., 2011. Thermochemical conversion of biomass to second generation biofuels through integrated process design-a review. Renew. Sust. Energy Rev. 15(1), 366-378.

[42] Danso-Boateng, E., Holdich, R.G., Shama, G., Wheatley, A.D., Sohail, M., Martin, S.J., 2013. Kinetics of faecal biomass hydrothermal carbonisation for hydrochar production. Appl. Energy. 111, 351-357.

[43] De Kam, M.J., Morey, R.V., Tiffany, D.G., 2009. Integrating biomass to produce heat and power at ethanol plants. Appl. Eng. Agric. 25(2), $227-244$

[44] Demirbas, A., 2005. Thermochemical conversion of biomass to liquid products in the aqueous medium. Energy Sources. 27(13), 1235-1243.

[45] Dhanavath, K.N., Shah, K., Bhargava, S.K., Bankupalli, S. Parthasarathy, R., 2018. Oxygen-steam gasification of karanja press seed cake: fixed bed experiments, ASPEN Plus process model development and benchmarking with saw dust, rice husk and sunflower husk. J. Environ. Chem. Eng. 6(2), 3061-3069.

[46] Dhar, S.A., Sakib, T.U., Hilary, L.N., 2020. Effects of pyrolysis temperature on production and physicochemical characterization of biochar derived from coconut fiber biomass through slow pyrolysis process. Biomass Convers. Biorefin. 1-17.

[47] Di Blasi, C., 1993. Analysis of convection and secondary reaction effects within porous solid fuels undergoing pyrolysis. Combust. Sci. Technol. 90(5-6), 315-340.

[48] Di Blasi, C., 2008. Modeling chemical and physical processes of wood and biomass pyrolysis. Prog. Energy Combust. Sci. 34(1), $47-$ 90.

[49] Dupont, C., Chen, L., Cances, J., Commandre, J.M., Cuoci, A., Pierucci, S., Ranzi, E., 2009. Biomass pyrolysis: kinetic modelling and experimental validation under high temperature and flash heating rate conditions. J. Anal. Appl. Pyrolysis. 85(1-2), 260-267.

[50] Efeovbokhan, V.E., Akinneye, D., Ayeni, A.O., Omoleye, J.A., Bolade, O., Oni, B.A., 2020. Experimental dataset investigating the effect of temperature in the presence or absence of catalysts on the pyrolysis of plantain and yam peels for bio-oil production. Data Brief $31,105804$.

[51] Elorf, A., Sarh, B., Bonnamy, S., Asbik, M., Rahib, Y., Chaoufi, J., 2019. Injection type effects on pulverized biomass (solid olive waste) combustion in a $50 \mathrm{~kW}$ combustor. Int. J. Renew. Energy Res. 9(2), 639-648

[52] Ergudenler, A., Ghaly, A.E., 1992. Determination of reaction kinetics of wheat straw using thermogravimetric analysis. Appl. Biochem. Biotechnol. 34(1), 75-91.

[53] Ergüdenler, A., Ghaly, A.E., Hamdullahpur, F., Al-Taweel, A.M., 1997. Mathematical modeling of a fluidized bed straw gasifier: part I-model development. Energy Sources. 19(10), 1065-1084.

[54] Eri, Q., Zhao, X., Ranganathan, P., Gu, S., 2017. Numerical simulations on the effect of potassium on the biomass fast pyrolysis in fluidized bed reactor. Fuel. 197, 290-297.

[55] Eseltine, D., Thanapal, S.S., Annamalai, K., Ranjan, D., 2013 
Torrefaction of woody biomass (Juniper and Mesquite) using inert and non-inert gases. Fuel. 113, 379-388.

[56] Faeth, J.L., Valdez, P.J., Savage, P.E., 2013. Fast hydrothermal liquefaction of Nannochloropsis sp. to produce biocrude. Energy Fuels. 27(3), 1391-1398.

[57] Fan, X., Yang, L., Jiang, J., 2020. Experimental study on industrial-scale CFB biomass gasification. Renewable Energy. 158, 32-36.

[58] Farzad, S., Mandegari, M.A., Görgens, J.F., 2016. A critical review on biomass gasification, co-gasification, and their environmental assessments. Biofuel Res. J. 3(4), 483-495.

[59] Fatehi, H., Weng, W., Li, Z., Bai, X.S., Aldén, M., 2021. Recent development in numerical simulations and experimental studies of biomass thermochemical conversion. Energy Fuels. 35(9), 6940-6963.

[60] Feng, S., Yuan, Z., Leitch, M., Xu, C.C., 2014. Hydrothermal liquefaction of barks into bio-crude-effects of species and ash content/composition. Fuel. 116, 214-220

[61] French, R., Czernik, S., 2010. Catalytic pyrolysis of biomass for biofuels production. Fuel Process. Technol. 91(1), 25-32

[62] Funke, A., Ziegler, F., 2010. Hydrothermal carbonization of biomass: a summary and discussion of chemical mechanisms for process engineering. Biofuels, Bioprod. Biorefin. 4(2), 160-177.

[63] Gabbar, H.A., Lisi, D., Aboughaly, M., Damideh, V., Hassen, I., 2020. Modeling of a plasma-based waste gasification system for solid waste generated onboard of typical cruiser vessels used as a feedstock. Designs. 4(3), 33.

[64] Gao, Y., Wang, X., Yang, H., Chen, H., 2012. Characterization of products from hydrothermal treatments of cellulose. Energy. 42(1), 457465.

[65] Gao, Y., Yu, B., Wu, K., Yuan, Q., Wang, X., Chen, H., 2016. Physicochemical, pyrolytic, and combustion characteristics of hydrochar obtained by hydrothermal carbonization of biomass. BioResources. 11(2), 4113-4133.

[66] Gascó, G., Paz-Ferreiro, J., Álvarez, M.L., Saa, A., Méndez, A., 2018. Biochars and hydrochars prepared by pyrolysis and hydrothermal carbonisation of pig manure. Waste Manage. 79, 395-403

[67] Ghabi, C., Benticha, H., Sassi, M., 2008. Two-dimensional computational modeling and simulation of wood particles pyrolysis in a fixed bed reactor. Combust. Sci. Technol. 180(5), 833-853.

[68] Ghassemi, H., Shahsavan-Markadeh, R., 2014. Effects of various operational parameters on biomass gasification process; a modified equilibrium model. Energy Convers. Manage. 79, 18-24.

[69] Gibilaro, L.G., Rowe, P.N., 1974. A model for a segregating gas fluidised bed. Chem. Eng. Sci. 29(6), 1403-1412.

[70] Gómez, J., Corsi, G., Pino-Cortés, E., Díaz-Robles, L.A., Campos, V., Cubillos, F., Pelz, S.K., Paczkowski, S., Carrasco, S., Silva, J., Lapuerta, M., Pazo, A., Monedero, E., 2020. Modeling and simulation of a continuous biomass hydrothermal carbonization process. Chem. Eng. Commun. 207(6), 751-768.

[71] Goodman, B.A., 2020. Utilization of waste straw and husks from rice production: a review. J. Bioresour. Bioprod. 5(3), 143-162.

[72] Goossens, W.R.A., 1971. Fluidization of binary mixtures in the laminar flow region. In Chem. Engng Progr. Symp. Ser. 67, 38-45.

[73] Gordillo, G., Annamalai, K., Carlin, N., 2009. Adiabatic fixed-bed gasification of coal, dairy biomass, and feedlot biomass using an airsteam mixture as an oxidizing agent. Renewable Energy. 34(12), 27892797.

[74] Govumoni, S.P., Koti, S., Kothagouni, S.Y., Venkateshwar, S., Linga, V.R., 2013. Evaluation of pretreatment methods for enzymatic saccharification of wheat straw for bioethanol production. Carbohydr. Polym. 91(2), 646-650.

[75] Goyal, H.B., Seal, D., Saxena, R.C., 2008. Bio-fuels from thermochemical conversion of renewable resources: a review. Renew. Sust. Energy Rev. 12(2), 504-517.

[76] Grønli, M.G., Melaaen, M.C., 2000. Mathematical model for wood pyrolysis comparison of experimental measurements with model predictions. Energy Fuels. 14(4), 791-800.

[77] Gunarathne, D.S., Udugama, I.A., Jayawardena, S., Gernaey, K.V., Mansouri, S.S., Narayana, M., 2019. Resource recovery from bio-based production processes in developing Asia. Sustainable Prod. Consumption. 17, 196-214
[78] Gungor, A., 2008. Two-dimensional biomass combustion modeling of CFB. Fuel. 87(8-9), 1453-1468.

[79] Gupta, A., Mahajani, S., 2020. Kinetic studies in pyrolysis of garden waste in the context of downdraft gasification: experiments and modeling. Energy. 208, 118427.

[80] Guran, S., 2020. Thermochemical conversion of biomass, in: Green Energy and Technology, pp. 159-194

[81] Harun, N.H.H.M., Samad, N.A.F.A., Saleh, S., 2017. Development of kinetics model for torrefaction of empty fruit bunch from palm oi waste. Energy Procedia. 105, 744-749.

[82] Heidari, M., Salaudeen, S., Dutta, A., Acharya, B., 2018. Effects of process water recycling and particle sizes on hydrothermal carbonization of biomass. Energy Fuels. 32(11), 11576-11586.

[83] Hernández, J.J., Ballesteros, R., Aranda, G., 2013. Characterisation of tars from biomass gasification: effect of the operating conditions. Energy. 50(1), 333-342.

[84] Hu, B., Wang, K., Wu, L., Yu, S.H., Antonietti, M., Titirici, M.M., 2010. Engineering carbon materials from the hydrothermal carbonization process of biomass. Adv. Mater. 22(7), 813-828.

[85] Incropera, F.P., Dewitt, D.P., 1990. Fundamentals of heat and mass transfer, Third edit. John Wiley \& Sons Inc.

[86] Ischia, G., Fiori, L., 2021. Hydrothermal carbonization of organic waste and biomass: a review on process, reactor, and plant modeling. Waste Biomass Valorization. 12(6), 2797-2824.

[87] Ismail, H.Y., Shirazian, S., Skoretska, I., Mynko, O., Ghanim, B. Leahy, J.J., Walker, G.M., Kwapinski, W., 2019. ANN-Kriging hybrid model for predicting carbon and inorganic phosphorus recovery in hydrothermal carbonization. Waste Manage. 85, 242-252.

[88] Ismail, T.M., Abd El-Salam, M., Monteiro, E., Rouboa, A., 2016. Eulerian-Eulerian CFD model on fluidized bed gasifier using coffee husks as fuel. Appl. Therm. Eng. 106, 1391-1402.

[89] Ismail, T.M., Yoshikawa, K., Sherif, H., El-Salam, M.A., 2019. Mathematical modeling of hydrothermal treatment of MSW to form a solid fuel in a commercial scale plant. Energy Procedia. 158, 1757 1764 .

[90] Jarungthammachote, S., Dutta, A., 2007. Thermodynamic equilibrium model and second law analysis of a downdraft waste gasifier. Energy. 32(9), 1660-1669.

[91] Kabir, M.J., Chowdhury, A.A., Rasul, M.G., 2015. Pyrolysis of municipal green waste: a modelling, simulation and experimenta analysis. Energies. 8(8), 7522-7541.

[92] Kaczor, Z., Buliński, Z., Werle, S., 2020. Modelling approaches to waste biomass pyrolysis: a review. Renewable Energy. 159, 427-443

[93] Kadem, S., Lachemet, A., Younsi, R., Kocaefe, D., 2011. 3dTransient modeling of heat and mass transfer during heat treatment of wood 弥. Int. Commun. Heat Mass Transfer. 38(6), 717-722.

[94] Kapoor, M., Panwar, D., Kaira, G.S., 2016. Bioprocesses for enzyme production using agro-industrial wastes, in: Agro-Industrial Wastes as Feedstock for Enzyme Production. Elsevier, pp. 61-93.

[95] Karagöz, S., Bhaskar, T., Muto, A., Sakata, Y., Oshiki, T., Kishimoto, T., 2005. Low-temperature catalytic hydrothermal treatment of wood biomass: analysis of liquid products. Chem. Eng. J. 108(1-2), 127 137.

[96] Kartal, F., Özveren, U., 2020. A deep learning approach for prediction of syngas lower heating value from CFB gasifier in Aspen plus ${ }^{\circledR}$. Energy. 209, 118457.

[97] Keche, A.J., Gaddale, A.P.R., Tated, R.G., 2015. Simulation of biomass gasification in downdraft gasifier for different biomass fuels using ASPEN PLUS. Clean Technol. Environ. Policy. 17(2), 465473.

[98] Keiller, B.G., Muhlack, R., Burton, R.A., van Eyk, P.J., 2019. Biochemical compositional analysis and kinetic modeling of hydrothermal carbonization of Australian Saltbush. Energy Fuels. $33(12), 12469-12479$

[99] Kersten, S.R., Wang, X., Prins, W., van Swaaij, W.P., 2005. Biomass pyrolysis in a fluidized bed reactor. part 1: literature review and mode simulations. Ind. Eng. Chem. Res. 44(23), 8773-8785

[100]Khoo, C.G., Lam, M.K., Mohamed, A.R., Lee, K.T., 2020. Hydrochar production from high-ash low-lipid microalgal biomass via hydrothermal carbonization: effects of operational parameters and 
products characterization. Environ. Res. 188, 109828.

[101]Koroneos, C., Lykidou, S., 2011. Equilibrium modeling for a dwndraft biomass gasifier for cotton stalks biomass in comparison with experimental data. J. Chem. Eng. Mater. Sci. 2(4), 61-68.

[102] Kruse, A., Funke, A., Titirici, M.M., 2013. Hydrothermal conversion of biomass to fuels and energetic materials. Curr. Opin. Chem. Biol. 17(3), 515-521.

[103]Ku, X., Li, T., Løvås, T., 2014. Eulerian-lagrangian simulation of biomass gasification behavior in a high-temperature entrained-flow reactor. Energy Fuels. 28(8), 5184-5196.

[104]Kumar, M., Oyedun, A.O., Kumar, A., 2017. Hydrothermal liquefaction of biomass for the production of diluents for bitumen transport. Biofuels, Bioprod. Biorefin. 11(5), 811-829.

[105]Kuo, P.C., Wu, W., Chen, W.H., 2014. Gasification performances of raw and torrefied biomass in a downdraft fixed bed gasifier using thermodynamic analysis. Fuel. 117, 1231-1241.

[106]Lanzetta, M., Di Blasi, C., 1998. Pyrolysis kinetics of wheat and corn straw. J. Anal. Appl. Pyrolysis. 44(2), 181-192.

[107]Lentz, Z., Kolar, P., Classen, J.J., 2019. Valorization of swine manure into hydrochars. Processes. 7(9), 560.

[108]Li, T., Wang, L., Ku, X., Güell, B.M., Løvås, T., Shaddix, C.R., 2015. Experimental and modeling study of the effect of torrefaction on the rapid devolatilization of biomass. Energy Fuels. 29(7), 4328-4338.

[109]Liu, H.M., Li, M.F., Sun, R.C., 2013a. Hydrothermal liquefaction of cornstalk: 7-lump distribution and characterization of products. Bioresour. Technol. 128, 58-64.

[110]Liu, H., Chen, B., Wang, C., 2020. Pyrolysis kinetics study of biomass waste using Shuffled Complex Evolution algorithm. Fuel Process. Technol. 208, 106509 .

[111]Liu, H., Elkamel, A., Lohi, A., Biglari, M., 2013b. Computational fluid dynamics modeling of biomass gasification in circulating fluidized-bed reactor using the eulerian-eulerian approach. Ind. Eng. Chem. Res. $52(51), 18162-18174$.

[112]Liu, Q., Chmely, S.C., Abdoulmoumine, N., 2017a. Biomass treatment strategies for thermochemical conversion. Energy Fuels. 31(4), 35253536.

[113]Liu, Y., Yao, S., Wang, Y., Lu, H., Brar, S.K., Yang, S., 2017b. Bio- and hydrochars from rice straw and pig manure: inter-comparison. Bioresour. Technol. 235, 332-337.

[114]Lombardi, F., Lategano, E., Cordiner, S., Torretta, V., 2013. Waste incineration in rotary kilns: a new simulation combustion tool to support design and technical change. Waste Manage. Res. J. Sust. Circ. Econ. 31(7), 739-750

[115]Lu, X., Jordan, B., Berge, N.D., 2012. Thermal conversion of municipal solid waste via hydrothermal carbonization: comparison of carbonization products to products from current waste management techniques. Waste Manage. 32(7), 1353-1365.

[116]Lucian, M., Fiori, L., 2017. Hydrothermal carbonization of waste biomass: process design, modeling, energy efficiency and cost analysis. Energies. 10(2), 211.

[117]Lucian, M., Volpe, M., Fiori, L., 2019. Hydrothermal carbonization kinetics of lignocellulosic agro-wastes: experimental data and modeling. Energies. 12(3), 516.

[118]Luz, F.C., Cordiner, S., Manni, A., Mulone, V., Rocco, V., 2018 a. Biomass fast pyrolysis in screw reactors: prediction of spent coffee grounds bio-oil production through a monodimensional model. Energy Convers. Manage. 168, 98-106.

[119]Luz, F.C., Cordiner, S., Manni, A., Mulone, V., Rocco, V., 2018b. Biomass fast pyrolysis in a shaftless screw reactor: a 1-D numerical model. Energy. 157, 792-805.

[120]Magdeldin, M., Kohl, T., Järvinen, M., 2017a. Techno-economic assessment of integrated hydrothermal liquefaction and combined heat and power production from lignocellulose residues. J. Sust. Dev. Energy, Water Environ. Syst. 6(1), 89-113.

[121]Magdeldin, M., Kohl, T., Järvinen, M., 2017b. Techno-economic assessment of the by-products contribution from non-catalytic hydrothermal liquefaction of lignocellulose residues. Energy. 137, 679695.

[122]Magnanelli, E., Tranås, O.L., Carlsson, P., Mosby, J., Becidan, M., 2020. Dynamic modeling of municipal solid waste incineration. Energy. 209,
118426.

[123]Mandø, M., Rosendahl, L., Yin, C., Sørensen, H., 2010. Pulverized straw combustion in a low-NOx multifuel burner: modeling the transition from coal to straw. Fuel. 89(10), 3051-3062.

[124]Mansaray, K.G., Al-Taweel, A.M., Ghaly, A.E., Hamdullahpur, F. Ugursal, V.I., 2000a. Mathematical modeling of a fluidized bed rice husk gasifier: part I-model development. Energy Sources. 22(1), 8398.

[125]Mansaray, K.G., Al-Taweel, A.M., Ghaly, A.E., Hamdullahpur, F. Ugursal, V.I., 2000b. Mathematical modeling of a fluidized bed rice husk gasifier: part II-model sensitivity. Energy Sources. 22(2), 167 . 185.

[126]Mansaray, K.G., Al-Taweel, A.M., Ghaly, A.E., Hamdullahpur, F. Ugursal, V.I., 2000c. Mathematical modeling of a fluidized bed rice husk gasifier: part IIII-model verification. Energy Sources. 22(3), 281 296.

[127]Martín-Lara, M.A., Blázquez, G., Zamora, M.C., Calero, M., 2017. Kinetic modelling of torrefaction of olive tree pruning. Appl. Therm. Eng. 113, 1410-1418.

[128]Matamba, T., Tahmasebi, A., Khoshk Rish, S., Yu, J., 2020 Promotion effects of pressure on polycyclic aromatic hydrocarbons and $\mathrm{H}_{2}$ formation during flash pyrolysis of palm kernel shell. Energy Fuels. 34(3), 3346-3356

[129]Matta, J., Bronson, B., Gogolek, P.E., Mazerolle, D., Thibault, J. Mehrani, P., 2017. Comparison of multi-component kinetic relations on bubbling fluidized-bed woody biomass fast pyrolysis reactor model performance. Fuel. 210, 625-638.

[130]Mazaheri, H., Lee, K.T., Bhatia, S., Mohamed, A.R., 2010 Subcritical water liquefaction of oil palm fruit press fiber for the production of bio-oil: effect of catalysts. Bioresour. Technol. 101(2), $745-751$

[131]McGaughy, K., Toufiq Reza, M., 2018. Hydrothermal carbonization of food waste: simplified process simulation model based on experimental results. Biomass Convers. Biorefin. 8(2), 283-292.

[132]Mendecka, B., Di Ilio, G., Lombardi, L., 2020. Thermo-fluid dynamic and kinetic modeling of hydrothermal carbonization of olive pomace in a batch reactor. Energies. 13(16), 4142.

[133]Micali, F., Mendecka, B., Lombardi, L., Milanese, M., Ferrara, G. De Risi, A., 2019. Experimental investigation on high-temperature hydrothermal carbonization of olive pomace in batch reactor, in: AIP Conference Proceedings. 2191(1), p. 020112.

[134]Miller, R.S., Bellan, J., 1997. A generalized biomass pyrolysis mode based on superimposed cellulose, hemicelluloseand liqnin kinetics. Combust. Sci. Technol. 126(1-6), 97-137.

[135]Miller, R.S., Bellan, J., 1998. Numerical simulation of vortex pyrolysis reactors for condensable tar production from biomass Energy Fuels. 12(1), 25-40.

[136]Miltner, M., Makaruk, A., Harasek, M., Friedl, A., 2008 Computational fluid dynamic simulation of a solid biomass combustor: modelling approaches. Clean Technol. Environ. Policy. 10(2), 165-174.

[137]Mueller, C., Brink, A., Hupa, M., 2005. Numerical simulation of the combustion behavior of different biomasses in a bubbling fluidized bed boiler, in: $18^{\text {th }}$ International Conference on Fluidized Bed Combustion ASMEDC. 41839, pp. 771-781.

[138]Naqvi, S.R., Tariq, R., Hameed, Z., Ali, I., Naqvi, M., Chen, W.H., Ceylan, S., Rashid, H., Ahmad, J., Taqvi, S.A., Shahbaz, M., 2019. Pyrolysis of high ash sewage sludge: kinetics and thermodynamic analysis using Coats-Redfern method. Renewable Energy. 131, 854 860.

[139]Nazari, L., Yuan, Z., Ray, M.B., Xu, C.C., 2017. Co-conversion of waste activated sludge and sawdust through hydrothermal liquefaction: optimization of reaction parameters using response surface methodology. Appl. Energy. 203, 1-10.

[140]Neves, D., Thunman, H., Matos, A., Tarelho, L., Gómez-Barea, A. 2011. Characterization and prediction of biomass pyrolysis products Prog. Energy Combust. Sci. 37(5), 611-630.

[141]Nguyen, Q., Nguyen, D.D., Vothi, H., He, C., Goodarzi, M., Bach, Q.V., 2020. Isothermal torrefaction kinetics for sewage sludge pretreatment. Fuel. 277, 118103 
[142]Nikolopoulos, N., Isemin, R., Atsonios, K., Kourkoumpas, D., Kuzmin, S., Mikhalev, A., Nikolopoulos, A., Agraniotis, M., Grammelis, P., Kakaras, E., 2013. Modeling of Wheat Straw Torrefaction as a Preliminary Tool for Process Design. Waste Biomass Valorization. 4(3), 409-420.

[143]Nizamuddin, S., Baloch, H.A., Griffin, G.J., Mubarak, N.M., Bhutto, A.W., Abro, R., Mazari, S.A., Ali, B.S., 2017. An overview of effect of process parameters on hydrothermal carbonization of biomass. Renew. Sust. Energy Rev. 73, 1289-1299.

[144]Obeid, R., Lewis, D.M., Smith, N., Hall, T., van Eyk, P., 2020. Reaction kinetics and characterisation of species in renewable crude from hydrothermal liquefaction of monomers to represent organic fractions of biomass feedstocks. Chem. Eng. J. 389, 124397.

[145]Ong, B.H., Walmsley, T.G., Atkins, M.J., Varbanov, P.S., Walmsley, M.R., 2019. A heat-and mass-integrated design of hydrothermal liquefaction process co-located with a Kraft pulp mill. Energy. 189, 116235

[146] Ong, H.C., Chen, W.H., Farooq, A., Gan, Y.Y., Lee, K.T., Ashokkumar, V., 2019. Catalytic thermochemical conversion of biomass for biofuel production: a comprehensive review. Renew. Sust. Energy Rev. 113, 109266

[147]Ong, H.C., Chen, W.H., Singh, Y., Gan, Y.Y., Chen, C.Y., Show, P.L., 2020. A state-of-the-art review on thermochemical conversion of biomass for biofuel production: a TG-FTIR approach. Energy Convers. Manage. 209,112634 .

[148] Osman, A.I., Young, T.J., Farrell, C., Harrison, J., Al-Muhtaseb, A.A.H., Rooney, D.W., 2020. Physicochemical characterization and kinetic modeling concerning combustion of waste berry pomace. ACS Sustainable Chem. Eng. 8(47), 17573-17586.

[149]Othaman, M.F., Sabudin, S., Mohideen Batcha, M.F., 2016. A short review on biomass thermo-chemical conversion: recent advances. Int. J. Eng. Technol. 8(6), 2494-2499.

[150]Özsin, G., Pütün, A.E., 2017. Kinetics and evolved gas analysis for pyrolysis of food processing wastes using TGA/MS/FT-IR. Waste Manage. 64, 315-326.

[151]Panwar, N.L., Kothari, R., Tyagi, V.V., 2012. Thermo chemical conversion of biomass-Eco friendly energy routes. Renew. Sust. Energy Rev. 16(4), 1801-1816.

[152]Parker, G., Sutherland, A.J., 1990. Fluvial armor. J. Hydraul. Res. 28(5), 529-544.

[153]Patuzzi, F., Gasparella, A., Baratieri, M., 2014. Thermochemical and fluid dynamic model of a bench-scale torrefaction reactor. Waste Biomass Valorization. 5(2), 165-173.

[154]Pecchi, M., Patuzzi, F., Benedetti, V., Di Maggio, R., Baratieri, M., 2020. Kinetic analysis of hydrothermal carbonization using high-pressure differential scanning calorimetry applied to biomass. Appl. Energy. 265, 114810.

[155]Pecha, M.B., Arbelaez, J.I.M., Garcia-Perez, M., Chejne, F., Ciesielski, P.N., 2019. Progress in understanding the four dominant intra-particle phenomena of lignocellulose pyrolysis: chemical reactions, heat transfer, mass transfer, and phase change. Green Chem. 21(11), 2868-2898.

[156]Peng, J.H., Bi, X.T., Sokhansanj, S., Lim, C.J., 2013. Torrefaction and densification of different species of softwood residues. Fuel. 111, 411421

[157]Perera, S.M., Wickramasinghe, C., Narayana, M., 2020. Process parameter optimization of urban biowaste carbonization, in: 2020 Moratuwa Engineering Research Conference (MERCon) IEEE, pp. 130135.

[158]Peters, B., 2011. Validation of a numerical approach to model pyrolysis of biomass and assessment of kinetic data. Fuel. 90(6), 2301-2314.

[159]Peters, B., Bruch, C., 2001. A flexible and stable numerical method for simulating the thermal decomposition of wood particles. Chemosphere. 42(5-7), 481-490

[160]Porpatham, E., Ramesh, A., Nagalingam, B., 2012. Effect of compression ratio on the performance and combustion of a biogas fuelled spark ignition engine. Fuel. 95, 247-256.

[161]Prasertcharoensuk, P., Hernandez, D.A., Bull, S.J., Phan, A.N., 2018. Optimisation of a throat downdraft gasifier for hydrogen production. Biomass Bioenergy. 116, 216-226.

[162]Prins, M.J., Ptasinski, K.J., Janssen, F.J., 2006. Torrefaction of wood: part
1. weight loss kinetics. J. Anal. Appl. Pyrolysis. 77(1), 28-34

[163]Qin, L., Wu, Y., Hou, Z., Jiang, E., 2020. Influence of biomass components, temperature and pressure on the pyrolysis behavior and biochar properties of pine nut shells. Bioresour. Technol. 313, 123682.

[164]Ramzan, N., Ashraf, A., Naveed, S., Malik, A., 2011. Simulation of hybrid biomass gasification using Aspen plus: a comparative performance analysis for food, municipal solid and poultry waste. Biomass Bioenergy. 35(9), 3962-3969.

[165]Ranzi, E., Cuoci, A., Faravelli, T., Frassoldati, A., Migliavacca, G., Pierucci, S., Sommariva, S., 2008. Chemical kinetics of biomass pyrolysis. Energy Fuels. 22(6), 4292-4300.

[166]Ravi, M.R., Jhalani, A., Sinha, S., Ray, A., 2004. Development of a semi-empirical model for pyrolysis of an annular sawdust bed. J. Anal. Appl. Pyrolysis. 71(1), 353-374.

[167]Reza, M.T., Yan, W., Uddin, M.H., Lynam, J.G., Hoekman, S.K., Coronella, C.J., Vásquez, V.R., 2013. Reaction kinetics of hydrothermal carbonization of loblolly pine. Bioresour. Technol. 139 $161-169$

[168]Roberts, G.W., Fortier, M.O.P., Sturm, B.S., Stagg-Williams, S.M., 2013. Promising pathway for algal biofuels through wastewater cultivation and hydrothermal conversion. Energy Fuels. 27(2), 857 867.

[169]Román, S., Libra, J., Berge, N., Sabio, E., Ro, K., Li, L., Ledesma, B., Álvarez, A., Bae, S., 2018. Hydrothermal carbonization: modeling, final properties design and applications: a review. Energies. 11(1), 216

[170]Rozainee, M., Ngo, S.P., Salema, A.A., Tan, K.G., 2010 Computational fluid dynamics modeling of rice husk combustion in a fluidised bed combustor. Powder Technol. 203(2), 331-347.

[171]Safarian, S., Ebrahimi Saryazdi, S.M., Unnthorsson, R., Richter, C., 2020. Artificial neural network integrated with thermodynamic equilibrium modeling of downdraft biomass gasification-power production plant. Energy. 213, 118800.

[172]Safarian, S., Unnbórsson, R., Richter, C., 2019. A review of biomass gasification modelling. Renew. Sust. Energy Rev. 110, 378-391.

[173]Safin, R.G., Barcik, Š., Tuntsev, D.V., Safin, R.R., Hismatov, R.G., 2016. A mathematical model of thermal decomposition of wood in conditions of fluidized bed. Acta Fac. Xylologiae. 58(2), 141-148.

[174]Salman, C.A., Omer, C.B., 2020. Process modelling and simulation of waste gasification-based flexible polygeneration facilities for power, heat and biofuels production. Energies. 13(16), 4264.

[175]Sangare, D., Bostyn, S., Moscosa-Santillan, M., Gökalp, I., 2021. Hydrodynamics, heat transfer and kinetics reaction of CFD modeling of a batch stirred reactor under hydrothermal carbonization conditions. Energy. 219, 119635.

[176]Sanlisoy, A., Carpinlioglu, M.O., 2017. A review on plasma gasification for solid waste disposal. Int. J. Hydrogen Energy. 42(2), 1361-1365.

[177]Saravanakumar, A., Haridasan, T.M., Reed, T.B., 2010. Flaming pyrolysis model of the fixed bed cross draft long-stick wood gasifier Fuel Process. Technol. 91(6), 669-675.

[178]Sarkar, A., Mondal, B., Chowdhury, R., 2014. Mathematical modeling of a semibatch pyrolyser for sesame oil cake. Ind. Eng. Chem. Res. 53(51), 19671-19680.

[179]Sarkar, J.K., Wang, Q., 2020. Different pyrolysis process conditions of South Asian waste coconut shell and characterization of gas, biochar, and bio-oil. Energies. 13(8), 1970.

[180]Sermyagina, E., Saari, J., Kaikko, J., Vakkilainen, E., 2015 Hydrothermal carbonization of coniferous biomass: effect of process parameters on mass and energy yields. J. Anal. Appl. Pyrolysis. 113 551-556.

[181]Shang, L., Ahrenfeldt, J., Holm, J.K., Bach, L.S., Stelte, W. Henriksen, U.B., 2014. Kinetic model for torrefaction of wood chips in a pilot-scale continuous reactor. J. Anal. Appl. Pyrolysis. 108, 109116.

[182]Shang, L., Ahrenfeldt, J., Holm, J.K., Barsberg, S., Zhang, R., Luo, Y.H., Egsgaard, H., Henriksen, U.B., 2013. Intrinsic kinetics and devolatilization of wheat straw during torrefaction. J. Anal. Appl. Pyrolysis. 100, 145-152. 
[183] Shankar Tumuluru, J., Sokhansanj, S., Hess, J.R., Wright, C.T., Boardman, R.D., 2011. A review on biomass torrefaction process and product properties for energy applications. Ind. Biotechnol. 7(5), 384401.

[184]Sharma, A., Pareek, V., Zhang, D., 2015. Biomass pyrolysis-a review of modelling, process parameters and catalytic studies. Renew. Sust. Energy Rev. 50, 1081-1096.

[185] Shiehnejadhesar, A., Scharler, R., Mehrabian, R., Obernberger, I., 2015. Development and validation of CFD models for gas phase reactions in biomass grate furnaces considering gas streak formation above the packed bed. Fuel Process. Technol. 139, 142-158.

[186]Shih, T.H., Liou, W.W., Shabbir, A., Yang, Z., Zhu, J., 1995. A new k-€ eddy viscosity model for high reynolds number turbulent flows. Comput. Fluids. 24(3), 227-238.

[187]Siegel, R., J.R. Howell, 1992. Thermal Radiation Heat Transfer, Third edit. Hemisphere Publishing Corporation.

[188] Silva, V.B., Rouboa, A., 2013. Using a two-stage equilibrium model to simulate oxygen air enriched gasification of pine biomass residues. Fuel Process. Technol. 109, 111-117.

[189]Simone, M., Nicolella, C., Tognotti, L., 2013. Numerical and experimental investigation of downdraft gasification of woody residues. Bioresour. Technol. 133, 92-101.

[190]Somerville, M., Deev, A., 2020. The effect of heating rate, particle size and gas flow on the yield of charcoal during the pyrolysis of radiata pine wood. Renewable Energy. 151, 419-425.

[191]Soria-Verdugo, A., Rubio-Rubio, M., Goos, E., Riedel, U., 2020. On the characteristic heating and pyrolysis time of thermally small biomass particles in a bubbling fluidized bed reactor. Renewable Energy. 160, 312-322.

[192]Stobernack, N., Mayer, F., Malek, C., Bhandari, R., 2020. Evaluation of the energetic and environmental potential of the hydrothermal carbonization of biowaste: modeling of the entire process chain. Bioresour. Technol. 318, 124038.

[193] Sukiran, M.A., Abnisa, F., Syafiie, S., Wan Daud, W.M.A.W., Nasrin, A.B., Abdul Aziz, A.A., Loh, S.K., 2020. Experimental and modelling study of the torrefaction of empty fruit bunches as a potential fuel for palm oil mill boilers. Biomass Bioenergy. 136, 105530.

[194]Sun, S., Tian, H., Zhao, Y., Sun, R., Zhou, H., 2010. Experimental and numerical study of biomass flash pyrolysis in an entrained flow reactor. Bioresour. Technol. 101(10), 3678-3684.

[195]Sun, Y., Liu, L., Wang, Q., Yang, X., Tu, X., 2016. Pyrolysis products from industrial waste biomass based on a neural network model. J. Anal. Appl. Pyrolysis. 120, 94-102.

[196]Sutton, D., Kelleher, B., Ross, J.R., 2001. Review of literature on catalysts for biomass gasification. Fuel Process. Technol. 73(3), 155-173.

[197]Świechowski, K., Liszewski, M., Bąbelewski, P., Koziel, J.A., Białowiec, A., 2019. Oxytree pruned biomass torrefaction: mathematical models of the influence of temperature and residence time on fuel properties improvement. Materials. 12(14), 2228

[198]Talero, G., Rincón, S., Gómez, A., 2019a. Biomass torrefaction in a standard retort: a study on oil palm solid residues. Fuel. 244, 366-378

[199]Talero, G., Rincón, S., Gómez, A., 2019b. Torrefaction of oil palm residual biomass: thermogravimetric characterization. Fuel. 242, 496506.

[200]Tavakkol, S., Zirwes, T., Denev, J.A., Jamshidi, F., Weber, N., Bockhorn, H., Trimis, D., 2021. An Eulerian-Lagrangian method for wet biomass carbonization in rotary kiln reactors. Renew. Sust. Energy Rev. 139, 110582.

[201]Tran, K.Q., 2020. Non-newtonian analysis of a counter-flow mixing reactor for fast hydrothermal liquefaction, in: Computer Aided Chemical Engineering. Elsevier Masson SAS. 48, pp. 1069-1074.

[202]Tran, K.Q., Håkansson, L., Trinh, T.T., 2017. CFD pre-study of Nozzle reactor for fast hydrothermal liquefaction. Energy Procedia. 142, 861866.

[203]Trendewicz, A., Braun, R., Dutta, A., Ziegler, J., 2014. One dimensional steady-state circulating fluidized-bed reactor model for biomass fast pyrolysis. Fuel. 133, 253-262.

[204]Tungalag, A., Lee, B., Yadav, M., Akande, O., 2020. Yield prediction of MSW gasification including minor species through ASPEN plus simulation. Energy. 198, 117296.
[205]Tuntsev, D. V., Safin, R.R., Hismatov, R.G., Halitov, R.A., Petrov, V.I., 2015. The mathematical model of fast pyrolysis of wood waste, in: 2015 International Conference on Mechanical Engineering, Automation and Control Systems (MEACS) IEEE, pp. 1-4.

[206]Turner, I., Rousset, P., Rémond, R., Perré, P., 2010. International journal of heat and mass transfer an experimental and theoretical investigation of the thermal treatment of wood (Fagus sylvatica L.) in the range $200-260^{\circ} \mathrm{C}$. Int. J. Heat Mass Transf. 53(4), 715-725.

[207]Tursi, A., 2019. A review on biomass: importance, chemistry, classification, and conversion. Biofuel Res. J. 6(2), 962-979.

[208]Van Der Stelt, M.J.C., 2010. Chemistry and reaction kinetics of biowaste torrefaction. Tech. Univ. Eindhoven.

[209] Vassilev, S.V., Baxter, D., Andersen, L.K., Vassileva, C.G., 2010. An overview of the chemical composition of biomass. Fuel. 89(5), 913 933.

[210]Wang, H., Wang, L., Zhang, J., Jing, Y., Cao, Y., 2020a. Effects of pyrolysis temperature and reaction time on the performance of swinemanure-derived bio-binder. Transp. Res. Part D Transp. Environ. 89, 102608.

[211]Wang, S., Shen, Y., 2020. CFD-DEM study of biomass gasification in a fluidized bed reactor: effects of key operating parameters. Renewable Energy. 159, 1146-1164

[212]Wang, T., Meng, D., Zhu, J., Chen, X., 2020b. Effects of pelletizing conditions on the structure of rice straw-pellet pyrolysis char. Fuel. 264,116909

[213]Wang, Y., Yan, L., 2008a. CFD modeling of a fluidized bed sewage sludge gasifier for syngas. Asia-Pacific J. Chem. Eng. 3(2), 161-170

[214]Wang, Y., Yan, L., 2008b. CFD studies on biomass thermochemical conversion. Int. J. Mol. Sci. 9(6), 1108-1130.

[215]Wickramasinghe, D.G.C., Narayana, M., Amarasinghe, A.D.U.S. 2018. Numerical simulation of suspension biomass combustor with two chambers, in: 2018 Moratuwa Engineering Research Conference (MERCon) IEEE, pp. 226-230.

[216]Wijekoon, P., Wickramasinghe, C., Athapattu, B.C.L., Narayana, M. de Alwis, A., Vithanage, M., 2021. Biomass valorization and phytoremediation as integrated technology for municipal solid waste management for developing economic context. Biomass Convers. Biorefin. 11(2), 363-382

[217]Winterberg, M., Tsotsas, E., 2000. Modelling of heat transport in beds packed with spherical particles for various bed geometries and/or thermal boundary conditions. Int. J. Therm. Sci. 39(5), 556-570.

[218]Xia, C., Cai, L., Zhang, H., Zuo, L., Shi, S.Q., Lam, S.S., 2021. A review on the modeling and validation of biomass pyrolysis with a focus on product yield and composition. Biofuel Res. J. 8(1), 1296 1315 .

[219]Xiao, R., Yang, W., Cong, X., Dong, K., Xu, J., Wang, D., Yang, X. 2020. Thermogravimetric analysis and reaction kinetics of lignocellulosic biomass pyrolysis. Energy. 201, 117537.

[220]Xiong, Q., Kong, S.C., Passalacqua, A., 2013. Development of a generalized numerical framework for simulating biomass fas pyrolysis in fluidized-bed reactors. Chem. Eng. Sci. 99, 305-313.

[221]Xiong, Q., Yang, Y., Xu, F., Pan, Y., Zhang, J., Hong, K., Lorenzini, G., Wang, S., 2017. Overview of computational fluid dynamics simulation of reactor-scale biomass pyrolysis. ACS Sustainable Chem. Eng. 5(4), 2783-2798.

[222]Xu, L., Jiang, Y., Wang, L., 2017. Thermal decomposition of rape straw: pyrolysis modeling and kinetic study via particle swarm optimization. Energy Convers. Manage. 146, 124-133.

[223]Xue, Y., Chen, H., Zhao, W., Yang, C., Ma, P., Han, S., 2016. A review on the operating conditions of producing bio-oil from hydrothermal liquefaction of biomass. Int. J. Energy Res. 40(7), 865877.

[224]Yang, H., Zhou, Y., Liu, J., 2009. Land and water requirements of biofuel and implications for food supply and the environment in China. Energy Policy. 37(5), 1876-1885.

[225]Yin, S., Dolan, R., Harris, M., Tan, Z., 2010. Subcritical hydrothermal liquefaction of cattle manure to bio-oil: effects of conversion parameters on bio-oil yield and characterization of bio-oil. Bioresour. Technol. 101(10), 3657-3664.

[226]Yu, J., Guo, Q., Gong, Y., Ding, L., Wang, J., Yu, G., 2021. A review 
of the effects of alkali and alkaline earth metal species on biomass gasification. Fuel Process. Technol. 214, 106723.

[227]Zadeh, Z.E., Abdulkhani, A., Saha, B., 2021. A comparative production and characterisation of fast pyrolysis bio-oil from Populus and Spruce woods. Energy. 214, 118930.

[228]Zainal, Z.A., Ali, R., Lean, C.H., Seetharamu, K.N., 2001. Prediction of performance of a downdraft gasifier using equilibrium modeling for different biomass materials. Energy Convers. Manage. 42(12), 14991515 .

[229]Zhang, B., Chen, J., He, Z., Chen, H., Kandasamy, S., 2019. Hydrothermal liquefaction of fresh lemon-peel: parameter optimisation and product chemistry. Renewable Energy. 143, 512-519.

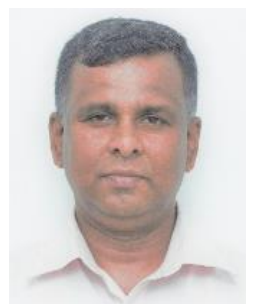

Dr. Mahinsasa Narayana is a Professor at the University of Moratuwa (Sri Lanka). He received his $\mathrm{Ph} . \mathrm{D}$. from the Northumbria University Newcastle (UK). His research interests include modeling and simulation and biomass thermochemical conversion. $\mathrm{He}$ has previously published over 90 peer-reviewed publications, and his research profile on Google Scholar can be found at the following link:

https://scholar.google.com/citations?user=DMb_w1cAAAAJ\&hl=en

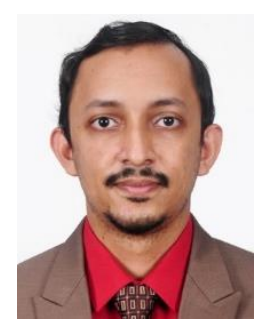

B.K.T. Samarasiri is currently following his second Master's degree in Environmental Engineering at Lakehead University, Canada. He has a Master's degree (by research) and B.Sc. Eng. (Hons) degree in Chemical and Process Engineering from the University of Moratuwa, Sri Lanka. He also has industrial experience in working as a Chemical Engineer particularly, in petrochemical manufacturing processes, municipal solid waste management, and industrial wastewater treatment. He has published several peerreviewed research articles related to environmental engineering. His research interests are biorefinery processes, catalytic reactions, wastewater treatment, techno-economic and life cycle analysis, and bioenergy. His Google Scholar profile can be found at the following link:

https://scholar.google.com/citations?user=oh5O5JoAAAAJ\&hl=en
[230]Zhang, B., Huang, H.J., Ramaswamy, S., 2012. A kinetics study on hydrothermal liquefaction of high-diversity grassland perennials. Energy Sources Part A. 34(18), 1676-1687.

[231]Zhang, L., Xu, C.C., Champagne, P., 2010. Overview of recent advances in thermo-chemical conversion of biomass. Energy Convers. Manage. 51(5), 969-982

[232]Zhang, Y., 2010. Hydrothermal liquefaction to convert biomass into crude oil, in: Biofuels from Agricultural Wastes and Byproducts. Wiley-Blackwell, Oxford, UK. 42(37), pp. 201-232.

[233]Zhu, Y., Biddy, M.J., Jones, S.B., Elliott, D.C., Schmidt, A.J., 2014. Techno-economic analysis of liquid fuel production from woody biomass via hydrothermal liquefaction (HTL) and upgrading. Appl. Energy. 129, 384-394

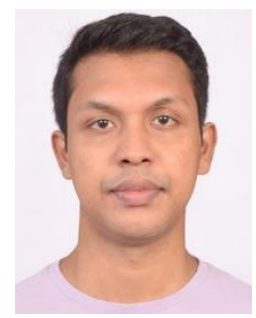

Sinhara M.H.D. Perera is a Ph.D. researcher at Chemical Engineering Department at Mississippi State University, USA. He has a Master's degree in Sustainable Process Engineering from the University of Moratuwa, Sri Lanka, and a Bachelor's degree in Chemical Engineering from the same university. He is specialized in modeling and simulation and has published peer-reviewed research papers in the same area. Further, he has industrial experience of over five years as a chemical engineer. His research interests are modeling \& simulation, sustainable energy, and biomass. His research profile is available at https://orcid.org/0000-0002-0202-4626

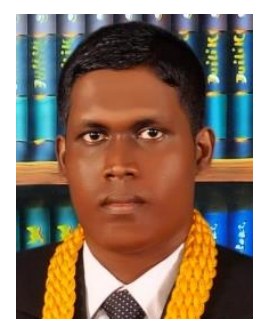

Chathuranga Wickramasinghe has a Master's degree and a Bachelor's degree in Chemical and Process Engineering from the University of Moratuwa, Sri Lanka. His work focuses specifically on process modeling and biomass thermochemical conversion. He has previously published several peer-reviewed publications, and his research profile on Google Scholar can be found at the following link:

https://scholar.google.co.uk/citations?user=YcGYXGMAAAAJ\&hl=en 